\title{
AVALIAÇÃO AGRONÔMICA DA DISPONIBILIZAÇÃO DE NITROGÊNIO À CULTURA DE FEIJÃO SOB SISTEMA DE SEMEADURA DIRETA
}

\author{
ERALDO AUGUSTO DE CARVALHO
}

Tese apresentada à Escola Superior de Agricultura "Luiz de Queiroz", Universidade de São Paulo, para obtenção do título de Doutor em Agronomia, Área de Concentração: Fitotecnia.

P I R A C I C A B A

Estado de São Paulo - Brasil

Dezembro - 2002 


\title{
AVALIAÇÃO AGRONÔMICA DA DISPONIBILIZAÇÃO DE NITROGÊNIO À CULTURA DE FEIJÃO SOB SISTEMA DE SEMEADURA DIRETA
}

\section{ERALDO AUGUSTO DE CARVALHO}

Engenheiro Agrônomo

Orientador: Prof. Dr. DURVAL DOURADO NETO

\author{
Tese apresentada à Escola Superior de \\ Agricultura "Luiz de Queiroz", \\ Universidade de São Paulo, para obtenção \\ do título de Doutor em Agronomia Área de \\ Concentração: Fitotecnia.
}

P I R A C I C A B A

Estado de São Paulo - Brasil

Dezembro - 2002 


\section{Dados Internacionais de Catalogação na Publicação (CIP) DIVISÃO DE BIBLIOTECA E DOCUMENTAÇÃO - ESALQ/USP}

Carvalho, Eraldo Augusto de

Avaliação agronômica da disponibilização de nitrogênio àcultura de feijão sob sistema de semeadura direta / Eraldo Augusto de Carvalho. - Piracic aba, 2002.

$63 \mathrm{p.}$

Tese (doutorado) - Escola Superior de Agricultura Luiz de Queiroz, 2002. Bibliografia.

1. Adubação nitrogena da 2. Feijão 3. Fixação de nitrogênio 4. Inoculação 5. Semea-dura direta 6. Semente 7. Sistema de produção I. Titulo

CDD 635.652

"Permitida a cópia total ou parcial deste documento, desde que citada a fonte - $O$ autor" 
À minha esposa ZILDETE, pelo apoio;

Aos meus filhos CÉSAR AUGUSTO, TATIANE e ERALDO AUGUSTO, pela compreensão;

Ao meu pai SEBASTIÃO DE CARVALHO (In Memoriam) e à minha mãe MARIA AUGUSTA DE CARVALHO, por terem ensinado à criança o caminho onde deve andar;

O Autor Dedica. 


\section{AGRADECIMENTOS}

Ao professor Dr. Durval Dourado Neto, pelo exemplo de vida, companheirismo e inestimável auxílio prestado na elaboração do presente trabalho;

Ao Professor Dr. José Dias Costa, pela amizade e incentivo;

Ao Professor Dr. Tomaz Caetano Ripoli, pelo apoio e amizade;

Ao Professor Dr. Antônio Luiz Fancelli por ter sido o arquiteto na montagem deste trabalho;

Aos Professores Dr. Steven R. Temple e Dra. Leisa Huyck, Universidade da Califórnia, Davis (EUA), pelo incentivo, amizade e grande auxílio prestado no desenvolvimento deste trabalho;

Aos professores Scarlet Hubber, Dr. Ford R. Denison, Dr. J. H. Richards, Dr. Paul Gepts, Dr. Chris Van Kessel, University of California, Davis (EUA), pelas preciosas informações prestadas;

Ao Dr. Douglas Calazans e Miguel Leuzzi pelo apoio;

Aos amigos do curso de pós-graduação Flávio Murilo Pereira da Costa, Marcos Palhares, Márcio Augusto Soares, Roseli Fátima Caseiro, Luiz Carlos Timm, André Souza Lacerda, Wulf Schmidt pela carinho e amizade;

Aos funcionários Maria Aparecida Teixeira Soledade, Ilze Helena Cândida de Gaspari das Neves, Sílvia Borghesi, Maria Ivete Monteiro de Almeida pelo ajuda;

À Escola Superior de Agronomia de Paraguaçu Paulista e à Fundação Gammon de Ensino, pela cooperação;

À Escola Superior de Agricultura "Luiz de Queiroz", Universidade de São Paulo, pela oportunidade oferecida;

À CAPES, Ministério da Educação e Cultura, pela bolsa de estudos concedida. 


\section{SUMÁRIO}

Página

LISTA DE FIGURAS .......................................................................................

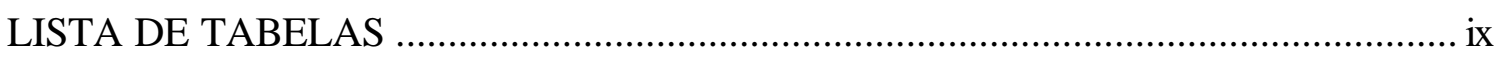

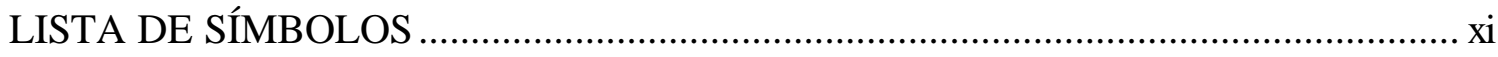

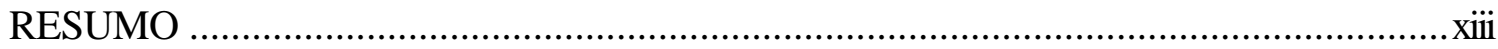

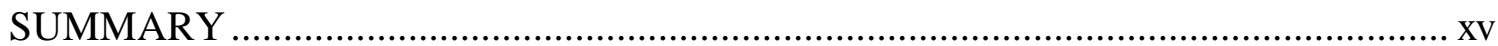

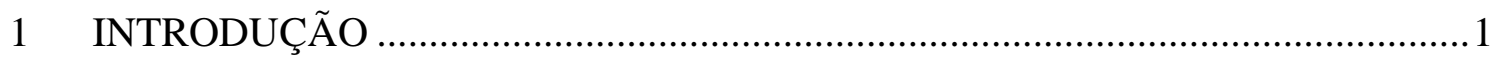

2 REVISÃO DE LITERATURA ............................................................... 6

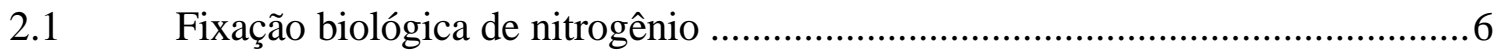

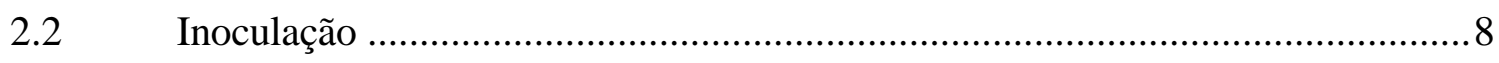

2.3 Nitrogênio mineral e inoculação .................................................................13

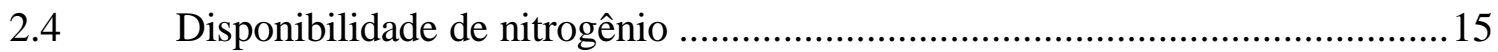

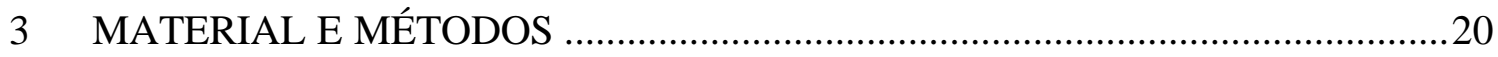

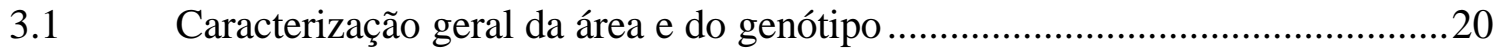

3.2 Delineamento experimental e descrição dos tratamentos ...............................21

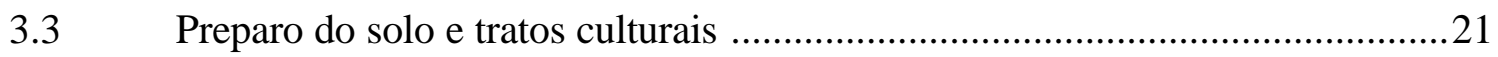

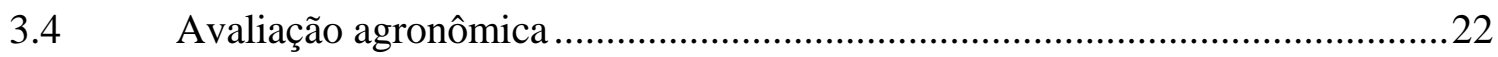

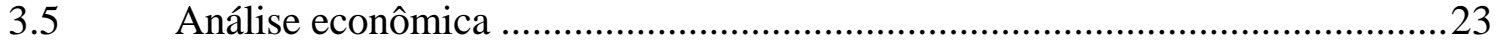

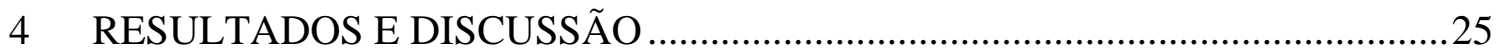

4.1 Avaliação agronômica no florescimento ....................................................25

4.1.1 Massa de matéria seca de parte aérea ..........................................................25

4.1.2 Teor de nitrogênio na planta.....................................................................29

4.1.3 Números de nódulos por planta...........................................................29

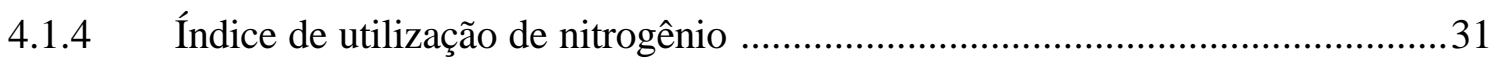


4.2 Avaliação Agronômica na colheita .......................................................... 32

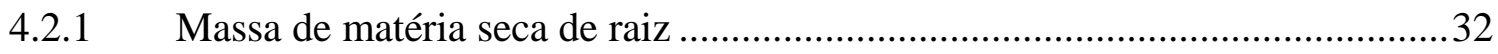

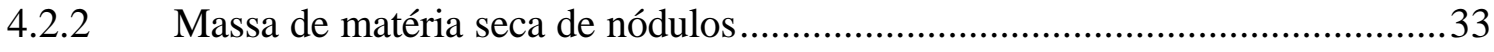

4.2.3 Número de vagens por planta e número de grãos por vagem .........................35

4.2.4 Massa de 100 sementes e rendimentos de grãos ...........................................36

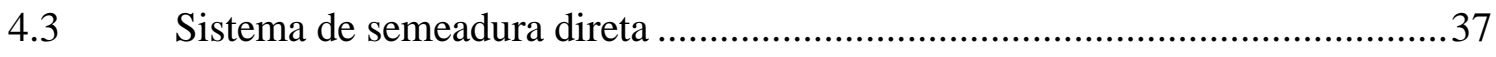

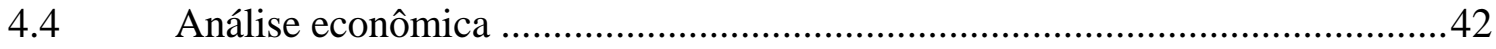

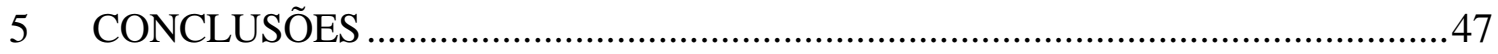

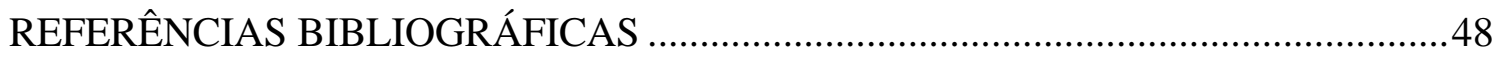




\section{LISTA DE FIGURAS}

Página

1 Adaptado de Van Kessel \& Hartley (2000). Modelo conceitual referente aos principais fatores que exercem influência no controle na fixação de $\mathrm{N}_{2}$ em leguminosas nos diferentes sistemas de produção. 18

2 Massa de matéria da parte aérea (MSpa, g. $\mathrm{pl}^{-1}$ ) nos tratamentos sem adubação nitrogenada em cobertura (excluindo a testemunha). 26

3 Massa de matéria seca da parte aérea (MSpa, g. $\mathrm{pl}^{-1}$ ) nos tratamentos em que as sementes não foram inoculadas com RL, Co e Mo na semeadura.

4 Massa de matéria seca da parte aérea (MSpa, g.pl ${ }^{-1}$ ) nos tratamentos que apresentaram média superior.

5 Massa de matéria seca da parte aérea (MSpa, g. $\mathrm{pl}^{-1}$ ) no tratamentos $\mathrm{T}_{3}$, $\mathrm{T}_{5}$ e $\mathrm{T}_{7}$ que tiveram em comum adubação nitrogenada..................................... 28

6 Número médio de nódulos por planta em todos os tratamentos. .......................... 30

7 Índice de utilização de nitrogênio (IUN, \%) nos diferentes tratamentos. ............ 31

8 Massa de matéria seca de raiz $\left(\mathrm{MSr}, \mathrm{g} \cdot \mathrm{pI}^{-1}\right)$ nos diferentes tratamentos. ............. 33

9 Massa de matéria seca de nódulos (MSn, mg.pl ${ }^{-1}$ ) nos diferentes

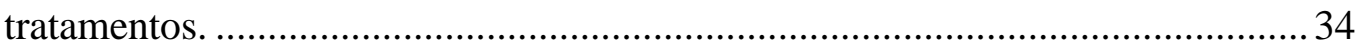

10 Número médio de vagens por planta $(\mathrm{Nv})$ e número médio de grãos por

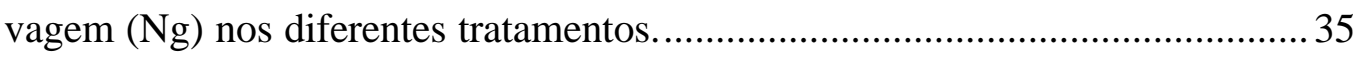

11 Rendimento de grãos $\left(\mathrm{Rg}, \mathrm{kg} \cdot \mathrm{ha}^{-1}\right)$ nos diferentes tratamentos.......................... 37

12 Rendimento de grãos $\left(\mathrm{Rg}, \mathrm{kg} \mathrm{ha}^{-1}\right)$ em função da adubação nitrogenada nos tratamentos $\mathrm{T}_{1}, \mathrm{~T}_{8}$ e $\mathrm{T}_{9}$

13 Rendimento médio de grãos $\left(\mathrm{Rg}, \mathrm{kg}_{\mathrm{h}} \mathrm{ha}^{-1}\right)$ nos tratamentos $\mathrm{T}_{4}, \mathrm{~T}_{5}, \mathrm{~T}_{6}, \mathrm{~T}_{7}$ e $\mathrm{T}_{9}$. 
14 Variação temporal de preço do saco de feijão (Brandalizze Consulting, 2000 - Informação pessoal)....................................................................... 44 


\section{LISTA DE TABELAS}

Página

1 Propriedades químicas do solo onde foi instalado o experimento.

20

2 Descrição dos tratamentos especificando o produto comercial (Rhizobium leguminosarum bv. Phaseoly - RL, nitrato de amônio - NA na semeadura - S - e em cobertura - C), e a dose.

3 Histórico da área (rotação de culturas sob sistema de semeadura direta). 23

4 Massa de matéria seca da parte aérea (MSpa, g.pl ${ }^{-1}$ ) do feijoeiro (cv. Pérola), teor de nitrogênio ( $\mathrm{Tn}, \mathrm{g} . \mathrm{kg}^{-1}$ ) na planta e número de nódulos (Nn) por planta no florescimento (estádio fenológico $\mathrm{R}_{6}$ ) referentes aos nove tratamentos. Piracicaba, SP. 1999.

5 Massa de matéria seca de raízes (MSr) e de nódulos (MSn), número médio de vagens por planta $(\mathrm{Nv})$ e de grãos por vagem $(\mathrm{Ng})$, massa de 100 grãos $\left(\mathrm{M}_{100}\right)$ e rendimento de grãos $(\mathrm{Rg})$ do feijoeiro, cv. Pérola, inoculado com Rhizobium leguminosrum bv. Phaseoly, Co e Mo nos diferentes tratamentos.

6 Comparação entre os rendimentos (valores absolutos - Rg - e relativos $\mathrm{Rr}$ ) referentes à cultura de feijão no tratamento $\mathrm{T}_{1}$ com os tratamentos $\mathrm{T}_{2}, \mathrm{~T}_{4}$ e $\mathrm{T}_{6}$ e os tratamentos $\mathrm{T}_{3}, \mathrm{~T}_{5}$ e $\mathrm{T}_{7}$. Piracicaba, SP. 1999

7 Comparação entre os rendimentos (valores absolutos - Rg - e relativos $\mathrm{Rr}$ ) referentes à cultura de feijão no tratamento $\mathrm{T}_{8}$ com os tratamentos $\mathrm{T}_{2}, \mathrm{~T}_{4}$ e $\mathrm{T}_{6}$ e os tratamentos $\mathrm{T}_{3}, \mathrm{~T}_{5}$ e $\mathrm{T}_{7}$. Piracicaba, SP. 1999. 39

8 Comparação entre os rendimentos (valores absolutos - $\mathrm{Rg}$ - e relativos $\mathrm{Rr}$ ) referentes à cultura de feijão no tratamento $\mathrm{T}_{9}$ com os 
tratamentos $\mathrm{T}_{2}, \mathrm{~T}_{4}$ e $\mathrm{T}_{6}$ e os tratamentos $\mathrm{T}_{3}, \mathrm{~T}_{5}$ e $\mathrm{T}_{7}$. Piracicaba, SP. 1999.

9 Coeficientes técnicos $\left(\mathrm{U}\right.$, unidade.ha $\left.{ }^{-1}\right)$ de produção de feijão referentes aos diferentes tratamentos ( $\mathrm{T}_{1}$ a $\left.\mathrm{T}_{9}\right)$. Piracicaba, SP. Dezembro de 1999. 42

10 Custos unitário (CU, US\$.unidade ${ }^{-1}$ ) e total $\left(U S \$ . h a^{-1}\right.$ ) de produção de feijão referentes aos diferentes tratamentos $\left(\mathrm{T}_{1}\right.$ a $\left.\mathrm{T}_{9}\right)$. Piracicaba, SP. Dezembro de 1999. 43

11 Rendimento de grãos ( $\left.\mathrm{Rg}, \mathrm{kg} . \mathrm{ha}^{-1}\right)$, preço $\left(\mathrm{Pr}, \mathrm{US} \$ . \mathrm{kg}^{-1}\right)$, receita bruta $\left(\mathrm{RB}, \mathrm{US} \$ . \mathrm{ha}^{-1}\right)$, custo total $\left(\mathrm{CT}, \mathrm{US} \$ . \mathrm{ha}^{-1}\right)$, receita líquida (RL, US\$.ha ${ }^{-1}$ ), índice de lucratividade (IL, \%), da cultura de feijão conduzidos em todos os tratamentos. Piracicaba, SP. Dezembro de 1999. 


\section{LISTA DE SÍMBOLOS}

AS Agricultura sustentável

Ca Cálcio

CESSR Contribuição especial à seguridade social rural

Co Cobalto

CO Custo operacional de produção

CT Custo total de produção

CTC Capacidade de troca catiônica

ESALQ Escola Superior de Agricultura "Luiz de Queiroz"

FBN Fixação biológica de nitrogênio

IL Índice de lucratividade

IUN Índice de utilização de nitrogênio

K Potássio

Mg Magnésio

MO Matéria orgânica

Mo Molibdênio

MSn Massa de matéria seca de nódulos

MSpa Massa de matéria seca de parte aérea 
MSr Massa de matéria seca de raiz

N Nitrogênio

$\mathrm{N}_{2} \quad$ Gás nitrogênio

NA Nitrato de amônio

P Fósforo

Pl Planta

Rg Rendimento de grãos

RB Receita bruta

RL Receita líquida

RL Rhizobium leguminosarum bv. phaseoly

S Enxofre

SB Soma de bases

SSD Sistema de semeadura direta

$\mathrm{T}_{\mathrm{i}} \quad$ Tratamento i (i = 1 a 9 )

USP Universidade de São Paulo 


\section{AVALIAÇÃO AGRONÔMICA DA DISPONIBILIZAÇÃO DE NITROGÊNIO À CULTURA DE FEIJÃO SOB SISTEMA DE SEMEADURA DIRETA}

Autor: ERALDO AUGUSTO DE CARVALHO

Orientador: Prof. Dr. DURVAL DOURADO NETO

\section{RESUMO}

A combinação de nove tratamentos (T) foi utilizada com o objetivo de fazer uma avaliação agronômica da disponibilização de nitrogênio (N) na produção de feijão, quando inoculado com Rhizobium leguminosarum bv. Phaseoly (RL), cobalto (Co) e molibdênio (Mo), conduzidos sob sistema de semeadura direta (SSD). $\mathrm{T}_{1}$ disponibilizou $\mathrm{N}$ através do solo, $\mathrm{T}_{2}$ através da inoculação das sementes com RL (400 g por $50 \mathrm{~kg}$ de sementes) imediatamente antes da semeadura, $T_{3}$ através da inoculação das sementes com RL e adubação nitrogenada em cobertura $\left(60 \mathrm{~kg} \cdot \mathrm{ha}^{-1}\right)\left(\mathrm{ANC}_{60}\right)$, utilizando como fonte de $\mathrm{N}$ o nitrato de amônio (NA) contendo $33 \%$ de $\mathrm{N}, \mathrm{T}_{4}$ através inoculação das sementes com Co e Mo (116 g.ha ${ }^{-1}$ ), produto formulado contendo 1,5\% de Co e 10,0\% de Mo, $\mathrm{T}_{5}$ através da inoculação das sementes com Co e Mo e $\mathrm{ANC}_{60}, \mathrm{~T}_{6}$ através da inoculação das sementes com Co, Mo e RL, T7 através da inoculação das sementes com Co, Mo e $\mathrm{RL}$ e $\mathrm{ANC}_{60}, \mathrm{~T}_{8}$ através de $\mathrm{ANC}_{60}, \mathrm{~T}_{9}$ através da adubação mineral na semeadura com NA $\left(20 \mathrm{~kg} \cdot \mathrm{ha}^{-1}\right)$ e $\mathrm{ANC}_{60}$. A área escolhida localiza-se no município de

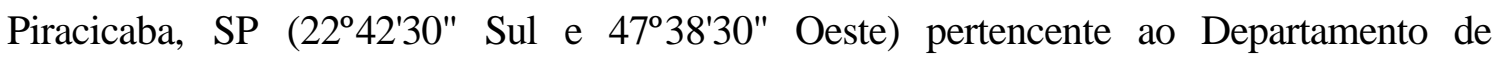
Produção Vegetal da Escola Superior de Agricultura "Luiz de Queiroz", Universidade de São Paulo, onde o SSD vem sendo usado desde 1993, sendo que as culturas implantadas 
nessa área nunca foram inoculadas com bactérias fixadoras de N. O solo foi amostrado na camada de 0,0-0,2 m anualmente, de 1994 a 1999, mostrando evolução dos atributos químicos do solo. Os parâmetros utilizados na análise foram: número de nódulos, massa de matéria seca de raízes, nódulos, e parte aérea, número de vagens por planta, número de grãos por vagem, massa de 100 grãos, teor de nitrogênio na planta, índice de utilização de nitrogênio (IUN), coeficientes técnicos e custo de produção total, índice de lucratividade (IL) e rendimento de grãos $(\mathrm{Rg})$. Os resultados evidenciaram que o $\mathrm{T}_{7}$ é uma alternativa para disponibilizar $\mathrm{N}$ à cultura, dentro do SSD, obtendo o maior $\mathrm{Rg}$. $\mathrm{O}$ SSD foi eficiente na manutenção do teor de matéria orgânica no solo, mas não foi eficiente para suprir totalmente a demanda da planta por $\mathrm{N}$, evidenciando a necessidade da adoção de métodos alternativos para incrementar sua disponibilidade no SSD. 


\section{AGRONOMIC EVALUATION OF NITROGEN AVAILABILITY TO COMMON BEAN CROP CARRIED OUT UNDER NO TILLAGE SYSTEM \\ Author: ERALDO AUGUSTO DE CARVALHO \\ Adviser: Prof. Dr. DURVAL DOURADO NETO}

\section{SUMMARY}

To evaluate the nitrogen $(\mathrm{N})$ availability to common bean grain yield under no tillage system (SSD) after inoculation with Rhizobium leguminosarum bv. phaseoly (RL), cobalt (Co) and molybdenum (Mo), nine treatments $(\mathrm{T})$ were used. $\mathrm{T}_{1}$ supplied $\mathrm{N}$ from the soil, $\mathrm{T}_{2}$ supplied $\mathrm{N}$ through the inoculation of the seed prior to sowing with $\mathrm{RL}$ (400 g per $50 \mathrm{~kg}$ of seeds), $\mathrm{T}_{3}$ supplied $\mathrm{N}$ through the inoculation of the seed prior to sowing with RL and additional $\mathrm{N}$ was also added using a top dressing with $60 \mathrm{~kg} \cdot \mathrm{ha}^{-1}$ of ammonium nitrate (NA) with $33 \%$ of $\mathrm{N}\left(\mathrm{ANC}_{60}\right), \mathrm{T}_{4}$ supplied $\mathrm{N}$ through inoculation of the seed prior to sowing with Co and Mo (116 g.ha $\left.{ }^{-1}\right)$ using a formulated product containing Co (1.5\%) and Mo (10.0\%), $\mathrm{T}_{5}$ supplied $\mathrm{N}$ through inoculation of the seed prior to sowing with $\mathrm{Co}$ and $\mathrm{Mo}$ and $\mathrm{ANC}_{60}, \mathrm{~T}_{6}$ supplied $\mathrm{N}$ through inoculation of the seed prior to sowing with Co and Mo and RL, $\mathrm{F}$ supplied $\mathrm{N}$ through inoculation of the seed prior to sowing with $\mathrm{Co}$ and $\mathrm{Mo}$ and $\mathrm{RL}$ and $\mathrm{ANC}_{60}, \mathrm{~T}_{8}$ supplied $\mathrm{N}$ through using a top dressing, $\mathrm{T}_{9}$ supplied $\mathrm{N}$ using $\mathrm{NA}$ in the sowing $\left(20 \mathrm{~kg} \cdot \mathrm{ha}^{-1}\right)$ and $\mathrm{ANC}_{60}$. The field experiment was carried out at Crop Science Department, Esalq, University of São Paulo,

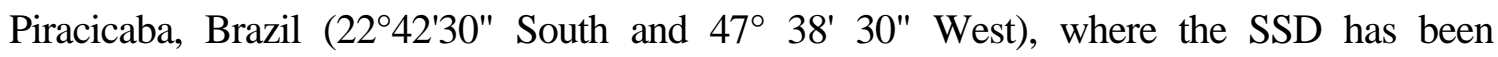


practiced since 1993, and the crop had never been inoculated with $\mathrm{N}$ fixing bacteria. The soil was sampled annually at 0.0 to $0.2 \mathrm{~m}$ depth, from 1993 to 1999 , showing evolution in the soil chemical attributes. The following agronomic parameters related to common bean crop were used for statistical analysis: the number of nodules, roots and nodules dry biomass, shoot dry biomass, number of pods per plant and grains per pod, and 100 grains mass, the plant nitrogen content, the nitrogen utilization index (IUN), the technical crop production coefficients, the total production cost, the profitability index (IL) and grain yield ( $\mathrm{Rg}$ ). The results showed that $\mathrm{T}_{7}$ was an alternative to make nitrogen available to common bean crop inside SSD, reaching the best productivity. No tillage system was efficient in the maintenance of the soil organic matter, but it was not efficient enough to supply the total demand of the plant for nitrogen, showing the need of alternative methods adoption to increment its availability to the system. 


\section{INTRODUÇÃO}

As plantas da família Fabaceae, comumente denominadas leguminosas, são importante fonte protéica ao Homem e aos animais, ocupando área equivalente a $11 \%$ das terras cultiváveis do mundo (FAO, 1992). As leguminosas constituem a base da dieta humana no terceiro mundo. A cultura de feijão (Phaseolus vulgaris L.), no Brasil, é a quarta em extensão de área semeada e a sexta em valor de produção (Teixeira \& Rocha, 1988). A produção brasileira de feijão está estacionada em torno de 2,2 milhões de toneladas (Vieira, 1989), com um rendimento médio de 467 kg.ha ${ }^{-1}$, aproximadamente com $20 \%$ do total mundial (FAO, 1992).

A cultura de feijão tem sido implantada em novas áreas, dentre as quais destacase a região Noroeste de São Paulo, Sul de Mato Grosso, Goiás, Minas Gerais, Tocantins e Mato Grosso do Sul, utilizando-se irrigação e insumos modernos (Ferreira et al., 2000). Apesar disso, nos últimos anos houve uma redução na oferta de feijão no mercado, provavelmente decorrente da baixa produtividade da cultura. Um dos fatores mais limitante à produtividade do feijoeiro é a baixa disponibilidade de nutrientes no solo, sobretudo fósforo e nitrogênio (Polidoro et al., 1998).

No Brasil, o feijão é freqüentemente cultivado em terras ácidas e de baixa fertilidade, condições que agem negativamente sobre mineralização da matéria orgânica e a produtividade (Diaz-Romeu et al., 1970; Malavolta, 1972). Apesar disso, o Brasil, no momento é o maior produtor mundial de feijão do gênero Phaseolus com área de 5,0 milhões de hectares correspondendo a 3,0 milhões de toneladas (Fancelli \& Dourado Neto, 1999).

A planta de feijão apresenta boa resposta à adubação nitrogenada. Porém, embora sendo uma leguminosa, é conhecida como deficitária na fixação biológica de N. Embora a adubação nitrogenada seja recomendada para essa cultura, alguns autores citam que ela 
não é economicamente viável em razão de seus custos (Silva et al, 1976; CIAT, 1978; Vargas et al, 1991) e do baixo rendimento.

O sistema convencional (SC) e o sistema de semeadura direta (SSD) são no momento os sistemas de produção mais utilizados pelos agricultores brasileiros na cultura de feijão. Caracterizado pelo uso de adubação mineral nitrogenada e pelo preparo do solo com arados e grades de diferentes tipos e dimensões, o SC pode resultar na desagregação e degradação do solo em condições tropicais e subtropicais, e poluição de águas subterrâneas pela infiltração do nitrato $\left(\mathrm{NO}_{3}{ }^{-}\right)$. Nesse sistema, são ainda observados problemas de (a) espelhamento e compactação do solo, (b) desgaste de implementos, e (c) grande dispêndio de combustível. Assim, o SC passa ter conotação de não ecológico, poluente, não sustentável e não protetor do solo. O SSD envolve o não revolvimento do solo, a manutenção dos resíduos culturais na superfície do solo e a rotação de culturas. O SSD é uma prática cultural que pode ser utilizada com sucesso na cultura de feijão.

Desde 1970, o SSD vem sendo utilizado no Brasil com significativa contribuição no controle da erosão (Mondardo, 1978; Derpersch et al., 1994; Blevins et al, 1997) e aumento do teor de matéria orgânica do solo (Sidiras \& Pavan, 1994; Thomas, 1990; Sá, 1997; e Kinsella, 1997). A introdução do SSD no Brasil, no início da década de 1970, foi um grande avanço em direção à sustentabilidade do sistema agrícola, promovendo a melhoria da qualidade do solo e aumentando o potencial produtivo. Estima-se que $32 \%$ da área cultivada com grãos no Brasil (cerca de 13,5 milhões de ha) é manejada no SSD, sendo que 70,5\% está localizada na região Sul do país. Alguns problemas inerentes à sua plena utilização têm sido levantados, tais como: (a) qualificação dos agricultores, (b) custo elevado de máquinas, e (c) falta de estudos relativos à dinâmica de nutrientes no SSD, principalmente o nitrogênio.

A inoculação das sementes com Rhizobium, cobalto (Co) e molibdênio (Mo), como fonte de nitrogênio à cultura de feijão no SSD, constitui-se em um importante fator a ser utilizado na redução dos custos de produção e conseqüente incremento na receita (Ferreira et al, 2000). As leguminosas quando eficientemente noduladas, apresentam teores de molibdênio nos nódulos que chegam a ser dez vezes superiores às 
encontradas nas folhas. Em condições de deficiência de molibdênio, esse tende a se acumular apenas nos nódulos, em detrimento das outras partes da plantas (Vidor \& Peres, 1988). Em alguns solos, o conteúdo total e solúvel de molibdênio é baixo e somente a calagem não é capaz de suprir as exigências das plantas (Bataglia et al, 1975). Como a quantidade de molibdênio requerida pela planta é pequena, a sua aplicação via semente, através da inoculação, pode se constituir na forma mais prática e econômica de adubação (Vidor \& Perez, 1988). Essa deficiência de Mo no solo afeta o sistema de fixação biológica de nitrogênio (FBN - processo caracterizado pela conversão do nitrogênio gasoso - $\mathrm{N}_{2}$ - em nitrogênio amoniacal disponível à planta). Os primeiros sintomas na planta lembram a deficiência de nitrogênio, caracterizada pelo amarelecimento generalizado da planta (Vidor \& Peres, 1988).

No Brasil, a prática de inoculação do feijoeiro dentro do SSD é ainda recente, carecendo de informações técnicas no sentido de caracterizar a sua aplicabilidade e economicidade.

A agricultura sustentável (AS), ou gerenciamento harmônico da produção agrícola, emergiu nas últimas duas décadas constituindo-se no novo desafio da agricultura nesses últimos anos. Isso trouxe a promessa de aumentar a lucratividade e os benefícios ao ambiente. Avanços na agricultura sustentável requer incremento na utilização da FBN como maior fonte de nitrogênio para as plantas.

O grupo NifTAL, no Havaí, constatou respostas variadas nas leguminosas em função do local e da espécie, quando tentaram estabelecer modelos matemáticos que permitissem predizer a resposta de uma leguminosa à inoculação em função dos rizóbios existentes no solo. A inoculação resultou em significativo aumento da produtividade do feijoeiro em apenas $50 \%$ das vezes, principalmente em solos com baixa população de rizóbios específicos (inferior a 100 rizóbios por g de solo) (Thies et al, 1991).

Em trabalho subseqüente, os mesmos autores (Thies et al, 1991) observaram que, na ausência de rizóbios naturalizados nos solos, a magnitude de resposta à inoculação foi diretamente proporcional à disponibilidade de $\mathrm{N}$ no solo.

A relação solo-planta-atmosfera é importante fator a ser considerado na sustentabilidade agroecológica, por ser a base da produção de alimentos para 
humanidade, principalmente quando os prognósticos apontam para uma duplicação da população mundial e uma demanda triplicada de produção de alimentos nos próximos cinqüenta anos. Um dos requisitos para o sucesso da AS é o conhecimento da variabilidade do solo para o manejo eficiente de aplicação de fertilizantes.

Não é realístico considerar AS em uma visão abrangente na ausência do aproveitamento do nitrogênio atmosférico $\left(\mathrm{N}_{2}\right)$ através da fixação biológica ( $\left.\mathrm{FBN}\right)$, como uma das alternativas para o suprimento de nitrogênio para as plantas nos diferentes sistemas de produção. Inúmeras são as vantagens de suprir as planta com nitrogênio oriundos da fixação biológica $(\mathrm{FBN})$. Destaca-se entre outras vantagens: (a) o baixo custo, que a torna acessível aos produtores; (b) a inexistência de problemas ambientais normalmente causados pelo uso de insumos agrícolas; e (c) a abundância de nitrogênio gasoso na atmosfera (fonte praticamente inesgotável).

Além disso, o uso de micronutrientes, tais como Co e Mo, a adoção de práticas administrativas consistentes e sistemas de produção não poluentes e econômicos são também igualmente importantes. Pesquisa é necessária para aperfeiçoar a agricultura sustentável. Estudos têm revelado aumento da produtividade da cultura de feijão através da FBN, obtendo-se rendimentos de até $1600 \mathrm{~kg} . h a^{-1}$ (Döbereiner \& Duque, 1980).

Ênfase na FBN tem sido dada (Brockwell \& Bottomley, 1995; Brockwell et al, 1995; e Streeter \& Smith, 1998) com diferentes abordagens: estirpes e competitividade (Triplett \& Sadowsky, 1992; e Maier \& Triplett, 1996), fixação de $\mathrm{N}_{2}$ em diferentes práticas culturais (Peoples \& Herridge, 1990; Peoples \& Craswell, 1992; e Peoples et al., 1995ab), indicando que a FBN e a dinâmica de $\mathrm{N}$ nas leguminosas é a chave da agricultura sustentável no mundo. Isso indica que, dentre outras, quatro são as formas de fornecer nitrogênio às plantas de feijão dentro do SSD: (a) naturalmente pelo solo, (b) inoculação da semente com Rhizobium, (c) inoculação da semente com cobalto (Co) e molibdênio (Mo), e (d) adubação nitrogenada com fertilizante mineral sintetizado industrialmente.

O desenvolvimento de métodos e sistemas que minimize o uso do nitrogênio mineral e maximize a produção de alimentos deve ser priorizado. 
A adoção da prática da inoculação por parte dos agricultores vai depender dos retornos líquidos econômicos. Porém, quando houver redução nos custos de produção e aumento no rendimento, a receita líquida será maximizada e o risco da exploração será minimizado.

O presente trabalho teve por objetivo avaliar a disponibilização de nitrogênio à cultura de feijão, sob sistema de semeadura direta, em função (a) da inoculação da semente com cobalto, molibdênio e Rhizobium leguminosarum bv. Phaseoly e (b) da adubação nitrogenada (semeadura e cobertura) através de uma análise agronômica (componentes de produtividade e análise econômica). 


\section{REVISÃO DE LITERATURA}

\subsection{Fixação biológica de nitrogênio}

Umas das alternativas para o suprimento de $\mathrm{N}$ para a planta de feijão é a FBN (Freire \& Kolling, 1986), processo caracterizado pela conversão do nitrogênio gasoso $\left(\mathrm{N}_{2}\right)$ em nitrogênio amoniacal $\left(\mathrm{NH}_{3}\right)$ disponível para a planta.

As vantagens da FBN são várias, dentre elas, destacam-se: (a) o baixo custo, que a torna acessível aos produtores, (b) a inexistência dos problemas ambientais normalmente causados pelo uso de insumos agrícolas (Bock \& Herbert, 1991); e (c) a abundância de nitrogênio gasoso na atmosfera e uma fonte praticamente inesgotável. $\mathrm{Na}$ natureza, a FBN e realizada por determinados grupos de microorganismos procarióticos. Dentre esses organismos fixadores de nitrogênio, destaca-se um grupo de particular importância, constituído pelas bactérias dos solo da família Rhizobiaceae, pertencente aos gêneros Bradyrhizobium, Azorhizobium e Rhizobium, denominados genericamente de rizóbios (Jordan, 1984). Os rizóbios caracterizam-se pela capacidade de interação simbiótica com o sistema radicular de leguminosas, por meio de formação de estruturas denominadas nódulos radiculares (Jordan, 1984). Assim que a simbiose é estabelecida, a

planta fornece fotoassimilados a bactéria, recebendo em troca produtos nitrogenados provenientes da fixação de $\mathrm{N}_{2}$ tais como; aminoácidos e ureídeos (Schubert, 1986).

O processo de domesticação e seleção de cultivares de feijão em relação a determinadas características desejáveis do ponto de vista comercial, pode ter sido acompanhado de um processo indireto de seleção negativa em relação a capacidade de nodulação, alterando o equilíbrio simbiótico estabelecido pela seleção natural no processo evolutivo do sistema rizóbio-feijão (Mytton, 1984). 
Assim, características de nodulação e eficiência simbiótica na fixação do №de ter sido negligenciados no período de domesticação do Phaseolus e no processo de melhoramento, dando-se maior atenção apenas as características agronômicas do material de interesse, puramente comercial. A capacidade de nodulação e a capacidade fixar nitrogênio atmosférico em leguminosas são eventos, distintos e complexos, com respostas muito variáveis no caso do feijão. Geralmente, as estirpes nativas ou selecionadas de rizóbio são ineficientes e incapazes de suprir as necessidades de nitrogênio, durante todo o ciclo de crescimento da planta (Graham \& Halliday, 1976; Graham \& Rosas, 1977; Westermann \& Kolar, 1978; Rennie \& Kemp, 1983; Redden et al, 1990; Vargas et al, 1991). A eficiência da FBN é influenciada não só pela variedade do feijão e pela estirpe de rizóbio, como também pela interação entre os simbiontes (Pacovski et al, 1984; Hungria \& Ruschel, 1992). Esses resultados evidenciam a importância de se considerar tanto a estirpe de rizóbio quanto a variedade de feijão, nos programas visando a otimização da FBN, no sistema rizóbio-leguminosa.

Outro aspecto relacionado com a eficiência do processo de FBN, no sistema rizóbio-feijão, e a disponibilidade de carbohidratos para os nódulos, tanto em quantidade como em qualidade. $\mathrm{Na}$ época de formação das vagens, a planta diminui o fluxo de carbohidratos para os nódulos, limitando a FBN (Lawn et al., 1974). Variedades com maior capacidade de manter a constância do fluxo de carbohidratos para os nódulos tem se mostrado mais eficientes nesse processo de fixação (Graham \& Halliday, 1976; Adams et al, 1978). Assim, alterações na eficiência fotossintética da planta podem afetar indiretamente o processo de FBN. Estudos realizados no Centro Internacional de Agricultura Tropical (CIAT, 1975, 1976, 1978), demonstraram que as variedades de Phaseolus vulgaris de maturação tardia apresentavam tendência a maior acúmulo de nitrogênio fixado simbioticamente.

Graham \& Rosas (1977) demonstraram que FBN no sistema rizóbio-feijoeiro, em plantas de hábito de crescimento indeterminado, é mais eficiente nos cultivares de porte trepador do que nos não trepadores. Devido, em parte ao efeito de ciclo de crescimento mais longo no feijoeiro de porte trepador. Sistemas simbióticos envolvendo rizóbio e variedades de feijão de maturação precoce são, geralmente ineficientes quanto a 
capacidade de fixar nitrogênio (Graham, 1981). Esse fato pode ser explicado com base no período necessário ao desenvolvimento radicular, no início do crescimento da planta, e a senescência dos nódulos na fase de enchimento dos grãos (Ruschel et al,, 1982; Rennie \& Kemp, 1983). Sob condições de dias longos do Canadá, Rennie \& Kemp (1983) observaram que o sistema simbiótico de rizóbio e variedades de feijão de maturação tardia foram eficiente na FBN. Entretanto, em sistema simbiótico envolvendo variedades de feijão de maturação precoce, os mesmos autores verificaram que algumas variedades foram ineficientes no processo de fixação biológica do nitrogênio. Morrison \& Baird (1987), utilizando-se plantas não trepadoras, de habito de crescimento determinado e indeterminado, verificaram que o tempo necessário para o estabelecimento dos nódulos não variou para os dois tipos de planta. A duração da simbiose parece estar relacionada com o ciclo de crescimento dos feijoeiro, como nos genótipos de habito de crescimento indeterminado. Os programas de melhoramento, tem como meta principal a obtenção de estirpes de Rhizobium de elevada eficiência, entretanto poucos trabalhos têm sido direcionados para melhoramento da planta hospedeira em resposta a nodulação. Além disso, a seleção do feijoeiro e seu cultivo em terras férteis pode ter tido uma seleção negativa, em relação a capacidade de nodulação e fixação de Nㅡ em genótipos domesticados de feijão (Kaplan, 1965; Gentry, 1969; Pereira \& Bliss, 1987; Gepts et al., 1988; Pereira, 1990).

\subsection{Inoculação}

O nitrogênio é o nutriente requerido em maior quantidade pela cultura de feijão comum. Sabe-se que, para atingir produtividade de 1,5 t.ha $^{-1}$ de grãos são necessários $101 \mathrm{~kg} \mathrm{~N} . \mathrm{ha}^{-1}$ dos quais $33 \%$ são exportados da lavoura pelo grãos e vagens (Malavolta \& Lima Filho, 1997). As três fontes de fornecimento dessas doses elevadas de N são: (a) o solo, principalmente pela decomposição da matéria orgânica; (b) os fertilizantes nitrogenados; e (c) o processo de fixação biológica do nitrogênio atmosférico $\left(\mathrm{N}_{2}\right)$.

$\mathrm{O}$ reservatório de $\mathrm{N}$ presente na matéria orgânica do solo é limitado, podendo ser esgotado rapidamente por sucessivos cultivos. Além disso, as condições de temperatura e umidade predominantes no território brasileiro acelera os processos de decomposição 
da matéria orgânica e perdas de $\mathrm{N}$, resultando em solos com teores pobres desse nutriente, entre 0,05 e $0,30 \%$ de N. A preservação da matéria orgânica com uma relação $\mathrm{C} / \mathrm{N}$ adequada é importante para a manutenção dos organismos do solo, sem os quais a sustentabilidade dos sistemas agrícolas são inviáveis. Os fertilizantes nitrogenados representam a forma assimilada com maior rapidez pelas plantas, mas a um custo elevado. $\mathrm{O}$ processo industrial que transforma o $\mathrm{N}_{2}$ em amônia $\left(\mathrm{NH}_{3}\right)$ requer hidrogênio derivado de gás de petróleo, catalisador de ferro, altas temperaturas $\left(300\right.$ a $\left.600^{\circ} \mathrm{C}\right)$ e altas pressões (200 a 800 atm). O gasto de fontes energéticas não renováveis é calculado em seis barris de petróleo por tonelada de $\mathrm{NH}_{3}$ sintetizada e o principal agravante na utilização dos fertilizantes nitrogenados reside na baixa eficiência de sua utilização pela plantas, raramente ultrapassando $50 \%$.

Isso significa que a metade dos fertilizantes nitrogenados aplicados na agricultura são perdidos por lixiviação (lavagem no perfil do solo), pela denitrificação (transformação do $\mathrm{NO}_{3}{ }^{-}$em $\mathrm{N}_{2}$ e $\mathrm{NO}_{2}{ }^{2-}$ ) e pela volatilização do $\mathrm{NH}_{3}$. A terceira fonte de $\mathrm{N}$ para a cultura de feijão e a FBN (Endo, 1986) realizado por algumas bactérias especificas (Bradyrhizobium, Azorhizobium e Rhizobium) denominadas genericamente de rizóbios (Jordan, 1984), que habitam livremente no solo. O $\mathrm{N}_{2}$ constitui $80 \%$ dos gases atmosféricos, que também se difundem pelo espaços porosos dos solo, nenhum animal ou planta consegue quebrar a tripla ligação entre os dois átomos de $\mathrm{N}_{2}$, que é uma das mais fortes que se tem notícia na natureza. $\mathrm{O}$ feijoeiro teve origem na América onde os povos andinos já utilizavam dessa leguminosa na alimentação. Theophrastus (370-285 a.C.) citado por Fred et al. (1932), escreveu "o feijão é o melhor revigorador dos solos, não é opressivo, aduba o solo, porque a planta cresce e apodrece facilmente".

$\mathrm{O}$ aumento do $\mathrm{pH}$ dos solo favorece: (a) a fixação simbiótica do $\mathrm{N}_{2}$, por influenciar o crescimento das raízes, (b) a absorção da água e de nutrientes, (c) a atividade da bactéria responsável pela fixação do $\mathrm{N}$, apesar dessa fixação não ter sido suficiente para a maioria das variedades manterem sua produção (Fancelli \& Dourado Neto, 1999). Saito et al. (1982) relataram que a inoculação das sementes com estirpes selecionadas de rizóbios, em condições de campo, não havia garantido, até então, o 
desenvolvimento de simbioses eficientes, tendo em vista a sobrevivência e competição pelo sítios de nodulação na planta, entre estirpes nativas e introduzidas.

Brockwell et al. (1982) sugeriram que algumas das causas das respostas negativas à inoculação, em condições de campo, tem sido: (a) a baixa qualidade dos inoculantes, decorrente da queda na taxa de sobrevivência da bactéria no veículo utilizado; (b) o uso de estirpes de baixa competitividade com estirpes de rizóbio nativas; e (c) a baixa adaptação das estirpes introduzidas as condições ambientais do local de introdução. Piha \& Munns (1987), comparando o efeito da inoculação, em casa de vegetação, de estirpes nativas e selecionadas em feijão, verificaram que nenhuma das variáveis de produção e de fixação de nitrogênio avaliadas foi afetada negativamente pelas estirpes nativas. Isso significa, que o baixo desempenho dos feijões cultivados no campo não pode ser atribuído ao efeito da competição com o rizóbio nativo pelo sítios de nodulação na planta. O processo de nodulação é controlado geneticamente pela leguminosa e pelo rizóbio hospedeiro (Nutman, 1969).

A simbiose rizóbio-hospedeiro depende da compatibilidade genética de ambos, sendo que a planta hospedeira desempenha papel preponderante nos estágios iniciais da nodulação (Nutman, 1969; Nutman, 1981; Pereira \& Bliss, 1987). A nodulação pode ser considerada uma doença (bacteriose) benéfica (Sequira, 1984).

Staples \& Toenniessen (1981) consideraram que o número de nódulos por planta fornece a medida da maior ou menor susceptibilidade do hospedeiro a infecção por bactérias do gênero Rhizobium; entretanto, o número de nódulos por planta é um componente hereditário em determinadas leguminosas, incluindo a soja (Glycine Max) (Weber,1966). Thies et al. (1991) concluíram que a resposta de leguminosas a inoculação foi fortemente afetada pelo número de rizóbios já estabelecido no solo, pela disponibilidade de $\mathrm{N}$ no solo, e pela demanda $\mathrm{N}$ pela colheita (coeficiente de correlação igual a 0,92 ) e que o número de rizóbios já estabelecidos no solo podem explicar $59 \%$ da variação observada em tentativas de resposta a inoculação.

Estudos anteriores, mostraram um declínio na resposta de inoculação, para a cultura da soja, quando o número de rizóbios no solo era superior a 10 rizóbios por g de solo (Weaver \& Frederick, 1974). 
Singleton \& Tavares (1986) também observaram declínio na inoculação quando o número de rizóbios foi superior a 20 indivíduos por g de solo para amendoim (Arachis hypogaea), cowpea (Vigna unguiculata), feijão (Phaseolus vulgaris), soja (Glycine max), e feijão de lima (Phaseolus lunatus). Os rizóbios podem sobreviver saprofiticamente prolongados períodos no solo. Uma vez que os rizóbios já se estabeleceram no solo, parece improvável que a planta se beneficiaria da inoculação pela forte competitividade existente entre eles.

Brockwell \& Bottomley (1995) concluíram que a prática da inoculação será benéfica para os agricultores, quando houver incremento no rendimento de grãos, no conteúdo de proteína e na quantidade de nitrogênio no solo (Stevenson \& Van Kessel, 1997).

A fixação de $\mathrm{N}_{2}$ em leguminosas tem focalizado a seleção de estirpes de rizóbios de alta capacidade de infecção das raízes, porém, variação significante em efetividade entre as estirpes selecionadas foi observada (Hobbs \& Mahon, 1982; Rennie \& Rennie, 1988; Graham \& Temple, 1984; Bremer et al, 1990; Bliss, 1993; Carter et al., 1995; Rosas et al, 1998). Além disso, variabilidade genotípica que afeta componentes de produtividade como, massa e número de nódulos, ou atividade da nitrogenase foi observada dentre as espécies de leguminosas (Wani et al, 1995). Assim sendo, quando existe a presença de uma numerosa população indígena no solo, a seleção de rizóbios pode esconder qual é o mais efetivo, entre uma gama extensiva de genótipos (Bliss \& Miller, 1988; Herridge \& Rose, 1994). Quando os níveis iniciais de N no solo são baixos, a planta terá um demorado período de "demanda" por $\mathrm{N}$ podendo reduzir o rendimento, nodulação e fixação de $\mathrm{N}_{2}$ (Eaglesham et al, 1983).

Outro fato importante está relacionado com a resposta ao Co e ao Mo, tendo como conseqüência o incremento na produtividade (Gurley \& Giddens, 1969; Lips et al., 1973). A calagem tem sido considerada uma prática suficiente para o suprimento do molibdênio para as culturas, por torná-lo disponível para as plantas, em conseqüência da elevação do pH do solo, que promove liberação de íons de Mo adsorvidos na superfície dos óxidos de ferro e alumínio (Stout et al, 1951; Hodgson, 1963; Leeper, 1970). Em alguns solos os conteúdos total e solúvel de Mo são baixos e, assim somente a calagem 
não é capaz de suprir as exigências das plantas (Bataglia et al, 1975). No caso de culturas fixadoras de nitrogênio, como o feijão, que possuem demanda adicional de Mo para o complexo da nitrogenase, tem-se observado a necessidade de doses elevadas de calcário para a otimização da produtividade.

Mengel (1994) concluiu que a atividade nitrogenase e um processo flexível que ajusta a demanda da planta por $\mathrm{N}$, e parte dessa resposta, tem sido associada a maior liberação de Mo do solo e, portanto ao melhor suprimento de nitrogênio as plantas (Sedberry Júnior et al, 1973, Lantmann et al, 1985; Burmester et al, 1988; Adams et al., 1990).

Parker \& Harris (1977) observaram que uma variedade não nodulante de soja respondia ao $\mathrm{N}$ mineral na presença ou na ausência de $\mathrm{Mo}$, com incrementos na produção e m teor de $\mathrm{N}$ nas folhas. Por outro lado, uma variedade de soja não nodulante somente respondia ao $\mathrm{N}$ mineral na ausência de Mo. Se a quantidade de Mo no solo é suficiente par atender o metabolismo normal da planta a o mecanismo de fixação de $\mathrm{N}$, as plantas de soja não respondem a adubação mineral com nitrogênio. Mas, uma ligeira deficiência de Mo no solo afeta o sistema FBN, e os primeiros sintomas na planta lembram a deficiência de nitrogênio, caracterizado pelo amarelecimento generalizado da planta (Vidor \& Peres, 1988). Nesta situação os sintomas podem ser corrigidos tanto com o fornecimento de nitrogênio como de Mo (De Mooy et al, 1973; Parker \& Harris, 1977).

O teor de Mo na semente é fator determinante na resposta à produção, principalmente em solos deficiente desse nutriente. Assim, adequado conteúdo de Mo na semente pode garantir níveis elevados de produtividade no feijão, mesmo em solos deficientes nesse nutriente.

Pesquisa tem mostrado que o decréscimo na atividade da nitrogenase sob condições de seca ocorre em dois estágios. No primeiro estágio, ocorre diminuição da permeabilidade do nódulo, limitando o suprimento de oxigênio ao bacteróide restringindo a respiração e resultando em simultâneo decréscimo na atividade da nitrogenase (Sprent, 1976; Durant et al, 1987; Walsh, 1995). O segundo estágio ocorre quando a atividade nodular já está drasticamente reduzida e a atividade da nitrogenase 
pode ser constrangida pelo conteúdo da leghemoglobina (Hungria \& Vargas, 1999; Serraj et al., 1999).

A não disponibilidade de água acarreta interrupção no transporte dos compostos nitrogenados dos nódulos para a planta, acarretando um acúmulo de amônia $\left(\mathrm{NH}_{3}\right)$ e produtos finais nos nódulos, levando ao colapso total da fixação do $\mathrm{N}_{2}$.

\subsection{Nitrogênio mineral e inoculação}

$\mathrm{O}$ feijoeiro exige quantidades relativamente altas de $\mathrm{N}$ e $\mathrm{K}$, e quantidades relativamente baixas de P, Ca, Mg, e S (Malavolta \& Lima Filho, 1997; Malavolta et al., 1989).

Grande parte dos nutrientes absorvidos, não é exportada pelo grãos, proporcionando a devolução dos restos culturais de aproximadamente 67, 5, 78, 51, 15, $9 \mathrm{~kg}^{-h^{-1}}$ respectivamente de $\mathrm{N}, \mathrm{P}, \mathrm{K}, \mathrm{Ca}, \mathrm{Mg}$ e $\mathrm{S}$, equivalente a mais de $50 \%$ do montante absorvido. Para uma faixa de produtividade de 0,9 a 2,5 t.ha ${ }^{-1}$ o conteúdo de macronutrientes em kg.ha-1 da parte colhida, é de 102, 9, 94 e 15 respectivamente para $\mathrm{N}, \mathrm{P}, \mathrm{K}$, e S (planta inteira), enquanto que nos grãos a quantidade exportada é de 41, 4, 9 e $10 \mathrm{~kg} \cdot \mathrm{ha}^{-1}$, respectivamente, para $\mathrm{N}, \mathrm{P}, \mathrm{K}, \mathrm{e} \mathrm{S}$.

O P é constituinte dos aminoácidos e das proteínas, e a sua deficiência pode ser o principal fator que contribui com a baixa produtividade do feijoeiro, pois limita crescimento da planta e a FBN (Graham, 1981). Tsai et al. (1993), observaram que a nodulação e a fixação biológica de nitrogênio para a planta de feijão não foram afetadas pelo aumento quantitativo de $\mathrm{P}, \mathrm{K}$ e $\mathrm{S}$ no solo. Quando a planta recebeu um balanço apropriado de nutrientes não houve nenhuma inibição, mas sim um efeito sinergístico da adubação nitrogenada sobre a nodulação do feijoeiro.

Quando o nível inicial de $\mathrm{N}$ disponível no solo é baixo, o período de alta demanda por $\mathrm{N}$ pela planta é retardado, podendo reduzir a produção, a nodulação e a fixação de $\mathrm{N}_{2}$ (Eaglesham et. al., 1993).

Em todo mundo, estudos buscando elucidar a melhor época para realizar a adubação nitrogenada para a cultura de feijão têm sido realizado. Entretanto, a 
quantidade de $\mathrm{N}$ disponível no solo no momento da semeadura, não tem sido considerada.

Chen et al. (1992) e Starling et al. (1998) observaram decréscimo no rendimento de grãos na cultura da soja quando o nível de $\mathrm{N}$ disponível no solo era de $51 \mathrm{~kg}^{-h^{-1}}$ na profundidade de $0,00-0,40 \mathrm{~m}$ e aproximadamente $20 \mathrm{~kg}^{-h a^{-1}}$ na profundidade de 0,00 $0,15 \mathrm{~m}$.

A maioria dos estudos sobre aplicação de $\mathrm{N}$ mineral e a nodulação tem sido negativa ou não conclusiva (Parker \& Harris, 1977; Semu \& Hume, 1979; Beverly \& Jarrell, 1984; Hardarson et al., 1984; Sorwli \& Mytton, 1986; Jensen, 1987; Herridge \& Brockwell, 1988; Imsande, 1992; Ying et al, 1992; Yinbo et al, 1997; Starling et al, 1998).

Singleton et al (1999) comparando o rendimento de grãos em uma série de experiências com leguminosas fertilizadas e não fertilizadas, concluíram que raramente a produção teria aumento pela aplicação N mineral. Rennie \& Kemp (1983) testando diferentes variedades de feijão, observaram uma significativa redução na quantidade de $\mathrm{N}_{2}$ fixado mediante aplicação de $40 \mathrm{~kg} \cdot \mathrm{ha}^{-1}$ de nitrogênio. Isso foi observado em algumas variedades mas não em outras. Assim, as leguminosas diferem entre si na resposta a aplicação de nitrogênio. George \& Singleton (1992) usando ${ }^{15} \mathrm{~N}$, notaram que o feijão comum era mais eficiente no acúmulo de nitrogênio do que a soja. Nesse estudo o feijão continuou fixar $\mathrm{N}$ mineral, apesar da disponibilidade de $\mathrm{N}$ mineral para o feijão estar em níveis bem mais baixos do que a soja. Claramente, o feijão comum foi mais eficiente em busca do $\mathrm{N}$ disponível no solo do que a soja, teve biomassa de raiz mais extensa (61\%) e maior quantia de $\mathrm{N}$ acumulada por unidade de biomassa da raiz do que a soja. Diferenças genéticas em produção de biomassa de raiz, e a capacidade de acumular $\mathrm{N}$ disponível no solo, torna pouco provável um significativo aumento na produção pela adição de $\mathrm{N}$ mineral para o feijão. Em vários solos a quantidade de $\mathrm{N}$ disponível no momento da smeadura e suficiente para atender a demanda da planta pelo N. Essa demanda pela planta hospedeira por nitrogênio passa a ser visível quando apresentar pobre nodulação ou quando os rizóbios presentes no solo forem ineficazes para infeccionar as raízes e estabelecer eficiente simbiose. Alguns estudos relatam que 
as leguminosas não são eficientes na assimilação de nitrato durante a fase de desenvolvimento de vegetativo e a fixação do Nㅡ é sua principal fonte de $\mathrm{N}$ (Imsande \& Edwards, 1988; Imsande, 1989). Entretanto, tem sido colocado que o tempo para aplicação de $\mathrm{N}$ mineral e mais sério do que o normalmente se assume. Durante o enchimento das vagens a translocação do $\mathrm{N}$ foliar para a semente pode auto destruir o aparato fotossintético da planta (Sinclair \& De Wit, 1976) acelerando a senescência e reduzindo a taxa fotossintética líquida.

Freqüentemente, no momento em que a planta completou o enchimento das vagens, o $\mathrm{N}$ disponível no solo esgotou-se, e o $\mathrm{N}$ adicional acumulado pelas leguminosas é oriundo da FBN (Jensen, 1987; Zapata et al., 1987; Van Kessel, 1994; Unkovich, 1997). Como a semente é carente em $\mathrm{N}$, adicionar $\mathrm{N}$ mineral pode não mostrar o efeito prejudicial sobre a fixação biológica do $\mathrm{N}_{2}$ nesse estágio fenológico.

\subsection{Disponibilidade de nitrogênio}

Limitando o revolvimento do solo e a manutenção da cobertura vegetal pode aumentar a viabilidade do solo (Lafond et., 1992) e estimular a demanda de $\mathrm{N}$ pela planta e a FBN. A manutenção de resíduos culturais proporcionou a cultura da soja um aumento na porcentagem de FBN de $75 \%$ quando conduzida sob sistema convencional de semeadura para 85\% quando foi conduzida sob SSD sobre os resíduos vegetais (Wheatley et al., 1995). Similarmente, a nodulação da soja aumentou substancialmente quando o solo e os resíduos vegetais não foram revolvidos e a quantidade total de $\mathrm{N}$ fixado passou de 180 para $232 \mathrm{~kg} \cdot \mathrm{ha}^{-1}$ (Hughes \& Herridge, 1989). Após quatro anos, sob condições ambientais semi-árido, a cultura da ervilha aumentou para $31 \%$ a FBN e a lentilha para 10\% (Matus et al., 1997). Cultivo de leguminosas só aumentará o N no solo quando a quantia de $\mathrm{N}$ removida na colheita for menor que a quantia $\mathrm{N}$ que ficará no solo através dos resíduos vegetais. Entre 45 e 75\% do N nas leguminosas está na biomassa acima do solo e removido pelo grão na colheita (Beck et al, 1991; Peoples \& Craswell, 1992; Ravuri \& Hume, 1993). O uso de alguns sistemas de produção podem afetar a sustentabilidade agrícola, o sistema convencional, com práticas tradicionais como preparo do solo usando grades, reduz a matéria orgânica no solo e aumenta erosão, 
especialmente nos trópicos. Como alternativa, o não revolvimento dos resíduos e do solo, e plantar diretamente em cima dos resíduos vegetais, protege o solo contra erosão pela ação da água. Além disso, melhora a estrutura do solo, a capacidade de retenção de água, e aumenta o teor de matéria orgânica no solo (Blevins et al, 1977; Kemper \& Derpersch, 1981; Sidiras et al., 1982, citados por Pavan et al., 1985). Vários estudos também indicam que o não revolvimento do solo e os resíduos vegetais aumentam a quantidade de biomassa e a população de microorganismos no solo (Powlson \& Jenkinson, 1981; Alvarez et al., 1995, citados por Ferreira et al., 1999).

Além disso, o declínio da matéria orgânica no solo ocorre após sucessivos cultivos especialmente no trópicos (Boddey et al., 1997; Vlek et al., 1997), isto implica em baixa fertilidade, desestruturação do solo, incapacidade de reter água e baixa atividade biológica. Deve-se ainda considerar que a preservação da matéria orgânica com uma relação $\mathrm{C} / \mathrm{N}$ adequada é importante para manutenção dos organismos do solo, sem os quais a sustentabilidade dos sistemas agrícolas são inviáveis. Nos sistemas agrícolas cerca $80 \%$ do $\mathrm{N}_{2}$ vem da simbiose envolvendo leguminosas com espécies de Rhizobium sp., Bradyrhizobium sp., Sinorhizobium sp., Azorhizobium sp., Mesorhizobium sp.; Allorhizobium sp. (Vance, 1998). A velocidade de decomposição da matéria orgânica, pode aumentar em até quatro vezes das regiões temperadas para os trópicos, apenas em função das características climáticas, mais especificamente pelas diferenças térmicas hídricas e de fotoperíodo. Alterações significativas dos processos naturais também ocorrem em função das atividades humanas, principalmente pela agricultura, a qual modifica substancialmente os ecossistemas naturais. Destaca-se que os solos brasileiros de modo geral possuem fertilidade natural baixa, sendo normalmente ácidos e pobres em fósforo e nitrogênio. Nas ultimas década, com o advento da modernização, principalmente nos estados da região Sul e em São Paulo (respondem pela metade da produção e receita agrícola brasileira), ocorreu um grande incremento no uso dos fertilizantes minerais (notadamente os nitrogenados), da mecanização e dos agrotóxicos. Entretanto, essas regiões tradicionais, apesar do uso intensivo desses insumos agrícolas, em função de métodos inadequados de manejo do solo e de cultivo, 
vêm apresentando sérios problemas de degradação ambiental e gradativa queda de produtividade.

Concomitantemente à expansão da base tecnológica (químico e mecânica) de elevado custo e demanda energética, houve quase um abandono no uso dos adubos orgânicos, adubação verde, rotação de culturas e demais práticas de cobertura e proteção do solo, bem como do manejo mais adequado dos resíduos vegetais.

Nas condições tropicais, a intensa movimentação do solo destrói a matéria orgânica, a estrutura e os agregados do solo muito rapidamente, tornando as áreas agricultáveis cada vez mais vulneráveis aos fenômenos climáticos, hídricos, e térmicos, acarretando a erosão. Faz-se necessário a formulação de sistemas de produção mais estáveis, que melhor conservem os recursos naturais, que tenham custos mais baixos, e sejam mais eficientes sob a ótica produtiva.

Dentre as diferentes formas de suprimento de matéria orgânica ao solo, uma das mais efetivas é aquela realizada através dos cultivos de deferentes vegetais, ou pelo aporte de resíduos como cobertura morta e pela rotação de cultura, que irão adicionar ao longo do tempo, consideráveis quantidades de carbono orgânico. Essa prática melhora as condições físicas do solo tais como; (a) estrutura, (b) capacidade de retenção de água, (c) consistência, (d) densidade, (e) infiltração, (f ) porosidade, e (g) aeração. Essa melhoria depende basicamente da decomposição de resíduos vegetais (processo esse essencialmente biológico) que disponibilizarão nitrogênio no solo através da mineralização da matéria orgânica e fixação biológica de nitrogênio.

A agricultura depende fixação biológica do № (Becker et al., 1995; Roger, 1995; Vlek et al., 1995; Mccown, 1996; Smil, 1997) e da inoculação de sementes para obtenção do $\mathrm{N}_{2}$ atmosférico como fonte de nitrogênio para as plantas. Nos últimos anos tem-se notado um recuo na utilização desse recurso, e a variável aceitação por parte dos agricultores na utilização desta tecnologia tem sido reportada (Hall \& Clark, 1995).

Singleton et al. (1992), concluíram que existe evidente vantagens na inoculação, no entanto respostas a inoculação tem sido variáveis devido principalmente a variabilidade dos estudos, as vezes conduzidos em pequenas parcelas e em diferentes condições ambientais e edáficas. As leguminosas respondem fortemente a inoculação 
quando são introduzidas em áreas novas, ou onde os rizóbios nativos residentes são ineficientes na infecção das raízes. Quando grão-de-bico (Cicer arietinum) e lentilha (Lens culinaris) foram introduzidos na América do Norte, responderam fortemente a inoculação (Van Kessel \& Hartley, 2000). Nos anos subseqüentes, quando a população residente aumentou em quantidade e competitividade, a fixação de $\mathrm{N}_{2}$ permaneceu, mas as respostas a inoculação diminuiu. $\mathrm{Na}$ Figura 1 são mostrados as variáveis que interferem no processo de fixação biológica do nitrogênio. Entre estas variáveis está o sistema de produção adotado que pode contribuir com a melhoria das qualidades físicas, químicas e biológicas do solo, aumentando a disponibilidade de nitrogênio no sistema.

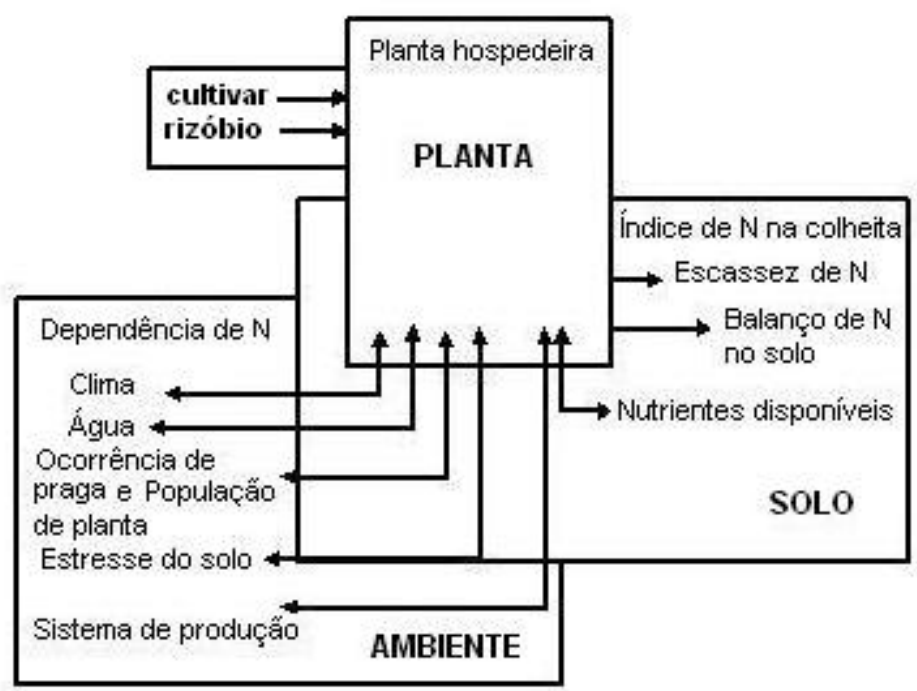

Figura 1 - Adaptado de Van Kessel \& Hartley (2000). Modelo conceitual referente aos principais fatores que exercem influência no controle na fixação de $\mathrm{N}_{2} \mathrm{em}$ leguminosas nos diferentes sistemas de produção.

Para obtenção de altos rendimentos na produção de feijão, tem sido indicada a utilização de técnicas agrícolas modernas, tais como: (a) irrigação, (b) fertilizantes, (c) semeadura em nível, (d) sementes certificadas ou de boa qualidade. Isso promove uma retirada crescente de micronutrientes do solo, sem que se estabeleça uma reposição adequada. Associado a esse fato, a má correção da acidez, e o inadequado manejo, 
provavelmente, estão alterando a disponibilidade de micronutrientes essenciais a nutrição do feijão. O molibdênio, o cobalto, o zinco, o cobre, o manganês, e o boro são os elementos mais deficientes, e afeta drasticamente as espécies cultivadas, principalmente nos solos de cerrado. Não há indicações de que haja toxidez ao Rhizobium, quando a inoculação com Co e Mo é feita imediatamente antes da semeadura do feijão. Amane et al (1994) concluíram que o Mo pode substituir a adubação nitrogenada em cobertura, no entanto a aplicação de Mo foi realizada via foliar aos 25 dias após a emergência, o que de certa forma deixa de fornecer Mo a planta nos estágios iniciais de desenvolvimento. Berger et al. (1996) observaram aumento no rendimento (2207 kg.ha $\left.{ }^{-1}\right)$ da variedade cultivada Ouro e Ouro Negro, com a aplicação de 90 kg.ha ${ }^{-1}$ de Mo via foliar aos 25 dias após a emergência permitindo um aumento de $53 \%$ em relação a testemunha em Viçosa, MG. Porém, quando conduziram o mesmo experimento em Coimbra - Mg o rendimento máximo de grãos (1682 kg.ha $\left.{ }^{-1}\right)$ foi alcançado com a aplicação de $78 \mathrm{~kg} \cdot \mathrm{ha}^{-1}$ de Mo, correspondendo a um acréscimo de $63 \%$ em relação à testemunha. Quando o solo contém suficiente quantidade de $\mathrm{N}$ para suprir a demanda da planta, a quantidade de $\mathrm{N}_{2}$ fixada será pequena, evidenciando que a nitrogenase é um processo flexível que ajusta a demanda da planta por N (Mengel, 1994) e a quantidade de $\mathrm{N}_{2}$ fixada torna-se muito mais dependente da demanda de $\mathrm{N}$ pela planta do que intrínseca capacidade do rizóbio em fixar $\mathrm{N}_{2}$. 


\section{MATERIAL E MÉTODOS}

\subsection{Caracterização geral da área e do genótipo}

O preparo do solo foi constituído de dessecação das plantas daninhas utilizandose do herbicida glifosate $\left(3,0 \mathrm{~L} \cdot \mathrm{ha}^{-1}\right.$ do produto comercial). Em seguida foi realizada a abertura dos sulcos manualmente, com espaçamento de $0,5 \mathrm{~m}$ entre linhas. A semeadura foi realizada manualmente em 24 de agosto de 1999, utilizando-se a variedade cultivada Pérola (grupo Carioca), obtendo-se um estande final de 12 plantas por metro linear.

$\mathrm{O}$ experimento foi instalado em área pertencente à Escola Superior de Agricultura "Luiz de Queiroz" - Universidade de São Paulo - Campus de Piracicaba ESALQ, localizada no município de Piracicaba - SP (latitude $22^{\circ} 42^{\prime} 30^{\prime \prime} \mathrm{S}$ e longitude $47^{\circ} 38^{\prime} 30^{\prime} \mathrm{W}$ ), com altitude de $546 \mathrm{~m}$. As médias anuais de precipitação pluvial, temperatura e umidade relativa do ar são $1370 \mathrm{~mm}, 23,5^{\circ} \mathrm{C}$ e $70-80 \%$, respectivamente.

O solo é classificado como tipo Latossolo Vermelho-Escuro, textura argilosa, cujo resultado da análise química para fins de fertilidade, de amostras obtidas na camada de 0,0 a 0,2 m, está relacionado na Tabela 1 .

Tabela 1. Propriedades químicas do solo onde foi instalado o experimento.

\begin{tabular}{ccccccccccc}
\hline Ano & $\begin{array}{c}\mathrm{pH} \mathrm{em} \\
\mathrm{CaCl}_{2}\end{array}$ & $\begin{array}{c}\mathrm{MO} \\
\mathrm{g} \cdot \mathrm{dm}^{-3}\end{array}$ & $\begin{array}{c}\mathrm{P}(\mathrm{resina}) \\
\mathrm{mg} \cdot \mathrm{dm}^{-3}\end{array}$ & $\mathrm{~K}$ & $\mathrm{Ca}$ & $\mathrm{Mg}$ & $\mathrm{H}+\mathrm{Al}$ & $\mathrm{SB}^{1}$ & $\mathrm{~T}^{2}$ & $\mathrm{~V}$ \\
\hline 1994 & 4,8 & 20,0 & 25,0 & 3,6 & 36,0 & 15,0 & 47,0 & 54,6 & 101,6 & 53,7 \\
1995 & 5,5 & 33,0 & 44,0 & 5,1 & 33,7 & 12,2 & 31,0 & 51,0 & 82,0 & 61,1 \\
1996 & 5,2 & 19,0 & 30,0 & 2,7 & 46,0 & 16,0 & 28,0 & 64,7 & 92,7 & 69,7 \\
1997 & 5,0 & 20,0 & 29,0 & 3,6 & 51,0 & 23,0 & 28,00 & 77,6 & 105,6 & 73,4 \\
1998 & 5,2 & 18,0 & 34,0 & 5,7 & 41,0 & 14,0 & 31,0 & 60,7 & 91,7 & 66,1 \\
1999 & 5,8 & 22,0 & 21,0 & 5,4 & 54,0 & 29,0 & 35,3 & 88,4 & 123,7 & 71,5 \\
\hline
\end{tabular}

${ }^{1}$ Soma de bases. ${ }^{2}$ Capacidade de troca catiônica

Departamento de Solos e Nutrição de Plantas, Esalq, Universidade de São Paulo 


\subsection{Delineamento experimental e descrição dos tratamentos}

O delineamento experimental foi em blocos ao acaso com nove tratamentos, com quatro repetições. Cada parcela foi constituída por seis linhas de $5 \mathrm{~m}$ de comprimento por $3 \mathrm{~m}$ de largura. A descrição dos tratamentos utilizados (formas de fornecimento de nitrogênio às plantas) está na Tabela 2.

Tabela 2. Descrição dos tratamentos especificando o produto comercial (Rhizobium leguminosarum bv. Phaseoly - RL, nitrato de amônio - NA - na semeadura - S e em cobertura - C), e a dose.

\begin{tabular}{|c|c|c|c|c|}
\hline \multirow{2}{*}{ Tratamento } & \multicolumn{2}{|c|}{ Produto via } & \multicolumn{2}{|c|}{ Dose } \\
\hline & semente & solo & $\mathrm{g} / 50 \mathrm{~kg}$ de semente & kg.ha ${ }^{-1}$ de N \\
\hline$\overline{T_{1}}$ & \multicolumn{2}{|c|}{ Testemunha } & & 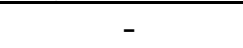 \\
\hline $\mathrm{T}_{2}$ & RL & & 400 & - \\
\hline $\mathrm{T}_{3}$ & RL & NA & 400 & $60(\mathrm{C})$ \\
\hline $\mathrm{T}_{4}$ & Co-Mo & & 116,7 & - \\
\hline $\mathrm{T}_{5}$ & Co-Mo & NA & 116,7 & $60(\mathrm{C})$ \\
\hline $\mathrm{T}_{6}$ & $\mathrm{RL}+\mathrm{Co}-\mathrm{Mo}$ & & $400+116,7$ & - \\
\hline $\mathrm{T}_{7}$ & $\mathrm{RL}+\mathrm{Co}-\mathrm{Mo}$ & NA & $400+116,7$ & $60(\mathrm{C})$ \\
\hline $\mathrm{T}_{8}$ & - & NA & - & $60(\mathrm{C})$ \\
\hline $\mathrm{T}_{9}$ & - & NA & - & $20(\mathrm{~S})+60(\mathrm{C})$ \\
\hline
\end{tabular}

\subsection{Preparo do solo e tratos culturais}

Todos os tratamentos foram adubados na semeadura com $80 \mathrm{~kg} \mathrm{ha}^{-1}$ de $\mathrm{P}_{2} \mathrm{O}_{5}$ (superfosfato simples) e $50 \mathrm{~kg} \mathrm{ha}^{-1}$ de $\mathrm{K}_{2} \mathrm{O}$ (cloreto de potássio) como adubação de manutenção, e a adubação nitrogenada em cobertura foi realizada 25 dias após a emergência das plantas (estádio fenológico $\mathrm{V}_{4}$ ).

A inoculação das sementes foi realizada imediatamente antes da semeadura na dose indicada na Tabela 2. As estirpes foram fornecidas pelo Embrapa Arroz e Feijão e foi utilizada uma concentração mínima de $10^{8}$ células viáveis de RL por $\mathrm{g}$ de turfa.

Durante o desenvolvimento da cultura foram realizadas duas aplicações do herbicida fosmesan $\left(0,25 \mathrm{~L}_{\text {.ha }}{ }^{-1}\right)$, em pós-emergência, visando o controle principalmente do picão preto (Bidens pilosa), bem como os tratos fitossanitários visando ao controle de pragas (Empoasca spp., Bemisia tabaci, Diabrotica speciosa, Cerotoma sp, Tetramychus 
urticae e doenças (Uromyces appendiculatus, Colletotrichum lindemuthianum, Phaeoisariopsis griseola) que ocorrem na cultura de feijão na região.

O experimento foi conduzido em regime de irrigação, pelo sistema de pivô central. $\mathrm{O}$ controle da irrigação foi realizado de acordo com a necessidade da cultura (Frizzone et al., 1982).

\subsection{Avaliação agronômica}

Por ocasião do florescimento (50\% das plantas de cada parcela apresentando pelo menos uma flor aberta), estádio fenológico $\mathrm{R}_{6}$, foram avaliadas as seguintes variáveis: (a) massa de matéria seca da parte aérea, avaliada em 12 plantas coletadas ao acaso na parcela. Folhas e ramos e raízes foram lavados com água destilada, e secos em estufa com circulação forçada de ar à temperatura de $60-70^{\circ} \mathrm{C}$, até massa constante; (b) teor de nitrogênio na planta, utilizando-se as doze plantas oriundas da determinação de massa de material seco, que foram moídas em moinho tipo Willey e submetidas a digestão sulfúrica (Sarruge \& Haag, 1974), procedendo-se a destilação em destilador de nitrogênio microkjeldhal; (c) número de nódulos por planta, determinado através da contagem manual de nódulos em seis plantas por tratamento.

Na colheita (após o ponto de maturidade fisiológica das plantas), foram coletadas todas as plantas na área de cada parcela para determinação de: (a) número de vagens por planta; (b) número médio de grãos por vagem; (c) rendimento de grãos, transformandose a massa de grãos obtidos para $\mathrm{kg} \mathrm{ha}^{-1}$ (umidade corrigida para 13\%), (d) massa de 100 grãos, coletados ao acaso em duas amostras de 100 grãos por parcela, (e) massa de matéria seca das raízes, avaliada em doze plantas coletadas ao acaso em cada parcela. As raízes foram lavadas com água destilada e secas em estufa com circulação forçada de ar à temperatura de $60-70^{\circ} \mathrm{C}$, até massa constante, e (f) massa de matéria seca dos nódulos, avaliado em seis plantas por parcela. Os nódulos após a contagem manual foram secos em estufa com circulação forçada de ar a temperatura de $60-70^{\circ} \mathrm{C}$, até massa constante.

O delineamento experimental utilizado, bem como o esquema de análise de variância empregado foi descrito por Gomes (1976), utilizando-se para comparação de médias o teste de Tukey ao nível de $5 \%$ de probabilidade. 
O histórico referente à rotação de culturas executado na área experimental, bem como seu histórico encontra-se na Tabela 3.

Tabela 3. Histórico da área (rotação de culturas sob sistema de semeadura direta).

\begin{tabular}{ccc}
\hline Ano & Inverno & Verão \\
\hline 1993 & Milho & Mucuna cinza \\
1994 & Feijão & Pousio \\
1995 & Nabo & Milho \\
1996 & Milho & Feijão \\
1997 & Aveia & Milho \\
1998 & Pousio & Milho \\
1999 & Milho & Feijão \\
\hline
\end{tabular}

' cultura avaliada

Do resultado obtido na análise foliar (estádio fenológico $R_{6}$ ), o teor de nitrogênio na planta (Tn, g. $\mathrm{kg}^{-1}$ ) e a massa de material seco da parte aérea (MSpa, g. $\mathrm{pl}^{-1}$ ) foram utilizados para o cálculo do índice de utilização do nitrogênio (IUN, g de N por 100 plantas ou \%).

O IUN é a relação entre a massa de matéria seca da parte aérea e teor de nitrogênio na planta, o qual pode ser relacionado com o rendimento de grãos. Para o cálculo do IUN (\%) foi então utilizada a seguinte equação:

$$
I U N=\frac{M S p a \cdot T n}{10}
$$

\subsection{Análise econômica}

O levantamento dos dados, para a elaboração da matriz de exigências dos fatores de produção foi feito nas condições do experimento.

O cálculo do custo total de produção foi baseado na metodologia de custo operacional proposta por Matsunaga et al (1976), contabilizando aqueles custos necessários para a realização de um ciclo da cultura. $\mathrm{O}$ custo operacional de produção é um instrumento que serve ao agricultor para tomar decisões a curto prazo, relativas ao ciclo da cultura atual ou a seguinte, não servindo para avaliar a atividade a longo prazo. 
Para quantificar o custo total, acrescentou-se ao custo operacional, a despesa com depreciação, contribuição a seguridade social rural, encargos financeiros e arrendamento da terra (Martin, 1994).

Os preços dos insumos utilizados referem-se àqueles observados em agosto de 1999. O preço de venda do feijão se refere ao mês de Janeiro de 2000, de acordo com mercado corrente (Brandalizze Consulting, 2000 - Informação pessoal).

O custo operacional (CO) é composto por despesas com mão-de-obra, operações de máquinas e material consumido.

O custo total (CT) é composto pelos seguintes custos: (a) custo operacional (CO); depreciação calculada pelo método linear de máquinas e equipamentos, (c) juros de custeio à taxa de $6 \%$ a.a. sobre a metade do $\mathrm{CO}$, destinado a remunerar o capital circulante; (d) contribuição especial à seguridade social rural (CESSR), que corresponde a 2,2\% da receita bruta; (e) custo com irrigação e (f) remuneração da terra, que corresponde ao valor do arrendamento vigente na região.

A elaboração desses custos permite análises técnicas à médio prazo, com visão global da atividade. Os indicadores de análise utilizados no trabalho foram os seguintes: (a) receita bruta $(\mathrm{RB})$ igual ao produto de rendimento de grãos pelo preço de venda; (b) receita líquida $(\mathrm{RL})$ igual à diferença entre a $\mathrm{RB}$ e o $\mathrm{CT}$, e, (c) índice de lucratividade (IL), igual à proporção da RB, que se constitui em recursos disponíveis, como referência na identificação do desempenho final dos sistemas testados e para remunerar o risco e a capacidade empresarial do produtor.

Dos dados obtidos na pesquisa foi ainda elaborada a matriz de coeficientes técnicos da exploração como referência para quantificar os fatores de produção dos tratamentos testados. 


\section{RESULTADOS E DISCUSSÃO}

\subsection{Avaliação agronômica no florescimento}

\subsubsection{Massa de matéria seca de parte aérea}

Os resultados de massa de matéria seca da parte aérea das plantas, teor de nitrogênio, e número de nódulos encontram-se na Tabela 4.

Tabela 4. Massa de matéria seca da parte aérea (MSpa, $g \cdot \mathrm{pl}^{-1}$ ) do feijoeiro (cv. Pérola), teor de nitrogênio $\left(\mathrm{Tn}, \mathrm{g}^{\mathrm{kg}} \mathrm{kg}^{-1}\right)$ na planta e número de nódulos $(\mathrm{Nn})$ por planta no florescimento (estádio fenológico $\mathrm{R}_{6}$ ) referentes aos nove tratamentos. Piracicaba, SP. 1999.

\begin{tabular}{|c|c|c|c|c|c|c|c|c|c|c|}
\hline \multirow[b]{2}{*}{ Variável } & \multirow[b]{2}{*}{${ }^{1} \mathrm{Un}$} & \multicolumn{9}{|c|}{ Tratamento } \\
\hline & & $\mathrm{T}_{1}^{2}$ & $\mathrm{~T}_{2}$ & $\mathrm{~T}_{3}$ & $\mathrm{~T}_{4}$ & $\mathrm{~T}_{5}$ & $\mathrm{~T}_{6}$ & $\mathrm{~T}_{7}$ & $\mathrm{~T}_{8}$ & $\mathrm{~T}_{9}$ \\
\hline $\mathrm{MSpa}^{* *}$ & g.pl ${ }^{-1}$ & $8,74^{\mathrm{b}}$ & $8,66^{6}$ & $10,55^{b}$ & $13,69^{a}$ & $13,57^{\mathrm{a}}$ & $11,59^{a}$ & $13,68^{a}$ & $10,64^{b}$ & $8,89^{b}$ \\
\hline $\mathrm{Tn}^{*}$ & g. $\mathrm{kg}^{-1}$ & $34,72^{\mathrm{a}}$ & $34,55^{\mathrm{a}}$ & $40,97^{\mathrm{a}}$ & $37,30^{\mathrm{a}}$ & $38,35^{\mathrm{a}}$ & $38,37^{\mathrm{a}}$ & $36,55^{\mathrm{a}}$ & $38,30^{\mathrm{a}}$ & $36,82^{\mathrm{a}}$ \\
\hline $\mathrm{Nn}^{*}$ & - & $74,07^{\mathrm{cd}}$ & $157,70^{\mathrm{a}}$ & $99,58^{\mathrm{bc}}$ & $161,95^{\mathrm{a}}$ & $61,69^{\mathrm{cd}}$ & $164,60^{\mathrm{a}}$ & $73,59^{\mathrm{cd}}$ & $133,9^{\mathrm{ab}}$ & $35,57^{\mathrm{d}}$ \\
\hline
\end{tabular}

Houve diferença estatística ao nível de probabilidade de $10 \%$, entre os tratamentos testados para a produção de massa de matéria seca da parte aérea (Tabela 4). As maiores médias foram obtidas nos tratamentos $T_{4}, T_{5}, T_{6}, T_{7}$ (estatisticamente iguais entre si) diferenciando dos demais tratamentos $\mathrm{T}_{1}, \mathrm{~T}_{2}, \mathrm{~T}_{3}, \mathrm{~T}_{8}, \mathrm{~T}_{9}$ que também foram estatiticamente iguais entre si. Dentre os tratamentos testados sem adubação nitrogenada e sem cobertura (excluindo a testemunha $\mathrm{T}_{1}$ ) as maiores médias foram encontradas nos tratamentos $\mathrm{T}_{4}$ (semente inoculada com Co e Mo) e $\mathrm{T}_{6}$ (semente inoculada com RL, Co e Mo) e a menor média foi encontrada no $T_{2}$ (semente inoculada com RL) (Figura 2). 


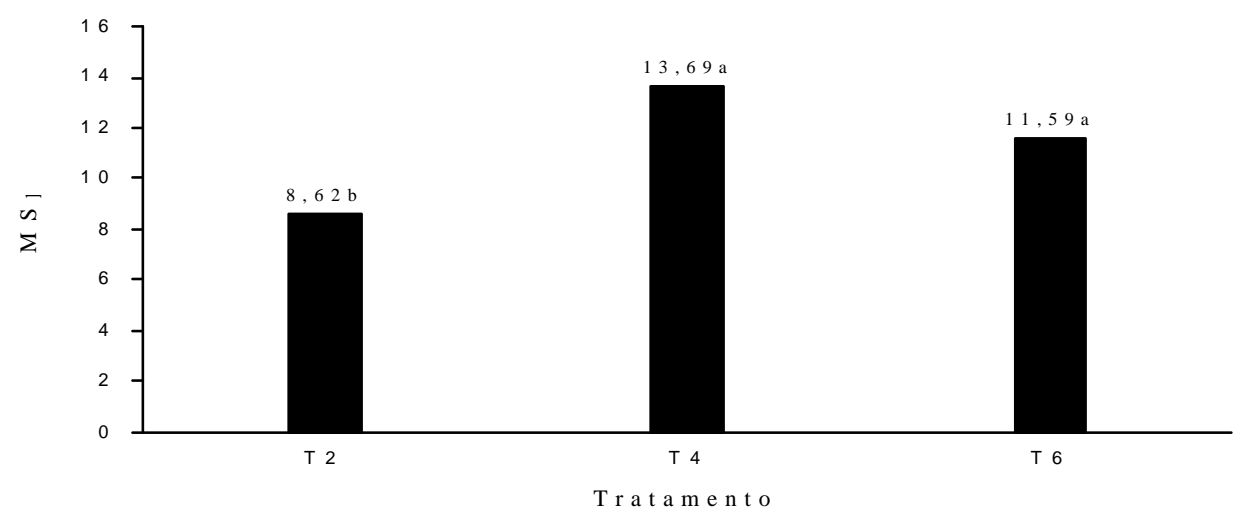

Figura 2 - Massa de matéria da parte aérea (MSpa, g.pl ${ }^{-1}$ ) nos tratamentos sem adubação nitrogenada em cobertura (excluindo a testemunha).

Isso indica que a inoculação da semente com Co e Mo atendeu a demanda da planta por nitrogênio, e proporcionou um desenvolvimento superior aos tratamentos $\mathrm{T}_{8} \mathrm{e}$ $\mathrm{T}_{9}$ que receberam adubação nitrogenada e não receberam RL, Co e Mo (Tabela 4).

Os tratamentos $T_{1}, T_{8}$ e $T_{9}$ (Tabela 2) foram concebidos em função de representar uma significativa parcela de produtores brasileiros que utilizam essa prática para o fornecimento de nitrogênio à cultura do feijão. Nesse caso, a massa de matéria seca da parte aérea no tratamento $T_{9}$, que recebeu adubação nitrogenada na semeadura e em cobertura, foi igual à massa do tratamento $\mathrm{T}_{1}$, que não recebeu nenhum tipo de adubação nitrogenada (Figura 3).

$\mathrm{O}$ feijoeiro no tratamento $\mathrm{T}_{1}$ apresentou desenvolvimento semelhante aos tratamento que receberam adubação nitrogenada $\left(\mathrm{T}_{8}\right.$ e $\left.\mathrm{T}_{9}\right)$ mas que as sementes não foram inoculadas com RL, Co e Mo (Figura 3).

Isso mostra, que o desenvolvimento da planta no tratamento $T_{1}$ foi devido única $\mathrm{e}$ exclusivamente ao fornecimento de $\mathrm{N}$ pelo solo através do sistema de semeadura direta adotado. Nota-se, que os tratamentos que tiveram os melhores resultados para rendimentos de grãos $\left(T_{7}, T_{5}, T_{4}\right.$ e $\left.T_{6}\right)$ também tiveram os melhores resultados para massa de matéria seca da parte aérea. Observa-se nesses tratamentos $\left(T_{7}, T_{5}, T_{4}\right.$ e $\left.T_{6}\right)$ que todos receberam adubação nitrogenada em cobertura, exceto os tratamentos $\mathrm{T}_{4}$ e $\mathrm{T}_{6}$, 
sugerindo que adubação nitrogenada em cobertura pode ser suprimida quando a semente for inoculada com Co e Mo (Figura 4).

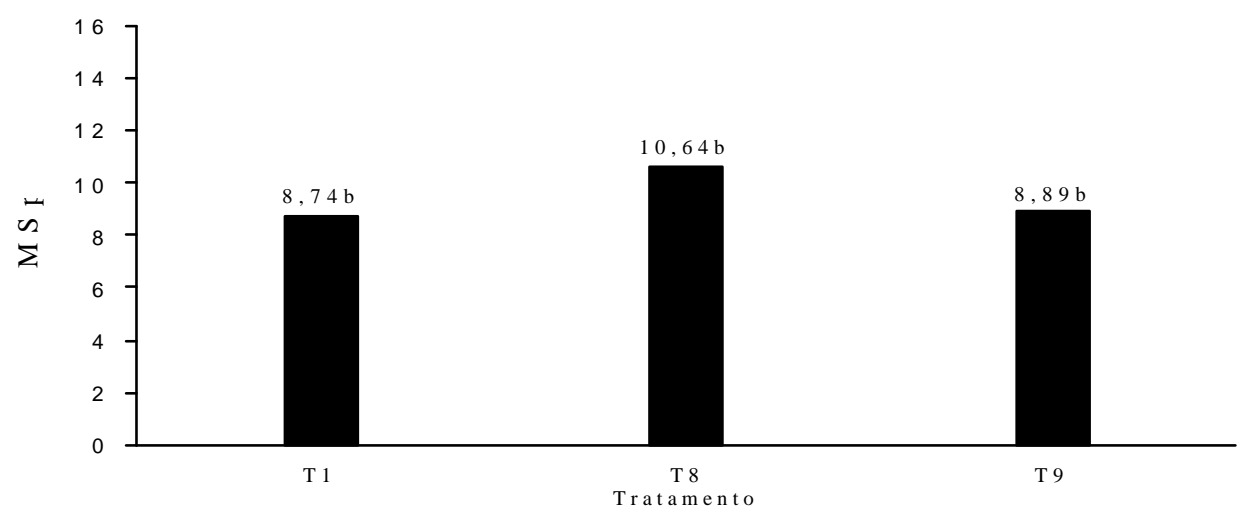

Figura 3 - Massa de matéria seca da parte aérea (MSpa, g. $\mathrm{pl}^{-1}$ ) nos tratamentos em que as sementes não foram inoculadas com RL, Co e Mo na semeadura.

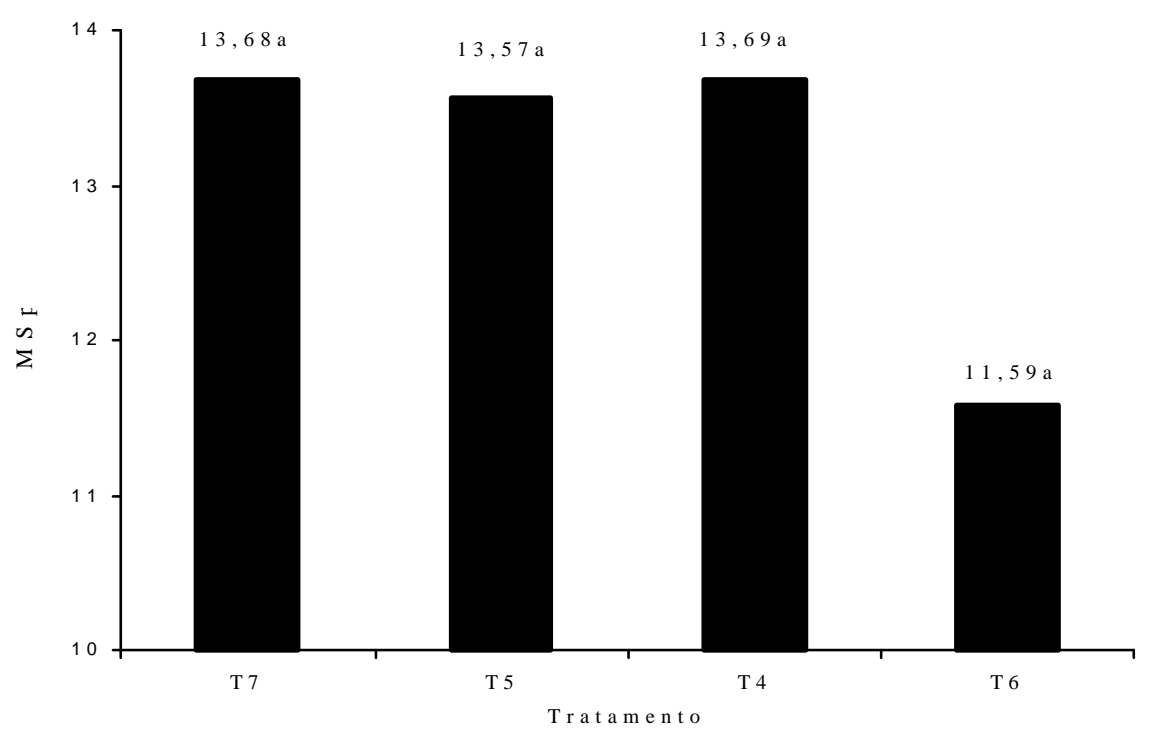

Figura 4 - Massa de matéria seca da parte aérea (MSpa, g.pl ${ }^{-1}$ ) nos tratamentos que apresentaram média superior.

Resultado semelhante foi observado por Amane et al (1994) quando estudaram o efeito da adubação nitrogenada em cobertura na cultura do feijão. Ao aplicar $20 \mathrm{~g} \mathrm{ha}^{-1} \mathrm{de}$ Mo em cobertura aos 25 dias após a emergência, os referidos autores observaram um rendimento superior quando comparado à cobertura realizada com nitrogênio mineral. 
Destaque deve ser dado à forma como foi fornecido o molibdênio. Enquanto Amane et al (1994) forneceram molibdênio via foliar, neste estudo, o fornecimento foi através da inoculação da semente imediatamente antes da semeadura. A inoculação da semente com Co e Mo pode substituir a adubação nitrogenada sem prejuízo do desenvolvimento da cultura.

Nos tratamentos $T_{3}, T_{5}, T_{7}$, que tiveram em comum a adubação nitrogenada em cobertura, as melhores médias para massa de matéria seca da parte aérea foram obtidas nos tratamentos $\mathrm{T}_{5}$ e $\mathrm{T}_{7}$ (Figura 5), destacando-se a inoculação com Co e Mo.

A inoculação da semente com RL, Co e Mo imediatamente antes da semeadura, e adubação nitrogenada em cobertura não foram antagônicos entre si no tocante ao desenvolvimento da parte aérea da planta. Essa conjugação proporcionou satisfatório desenvolvimento da parte aérea da planta e se constitui numa forma alternativa de suprimento de nitrogênio para a cultura de feijão (inoculação da semente com Co e Mo e adubação nitrogenada em cobertura) (Figura 5).

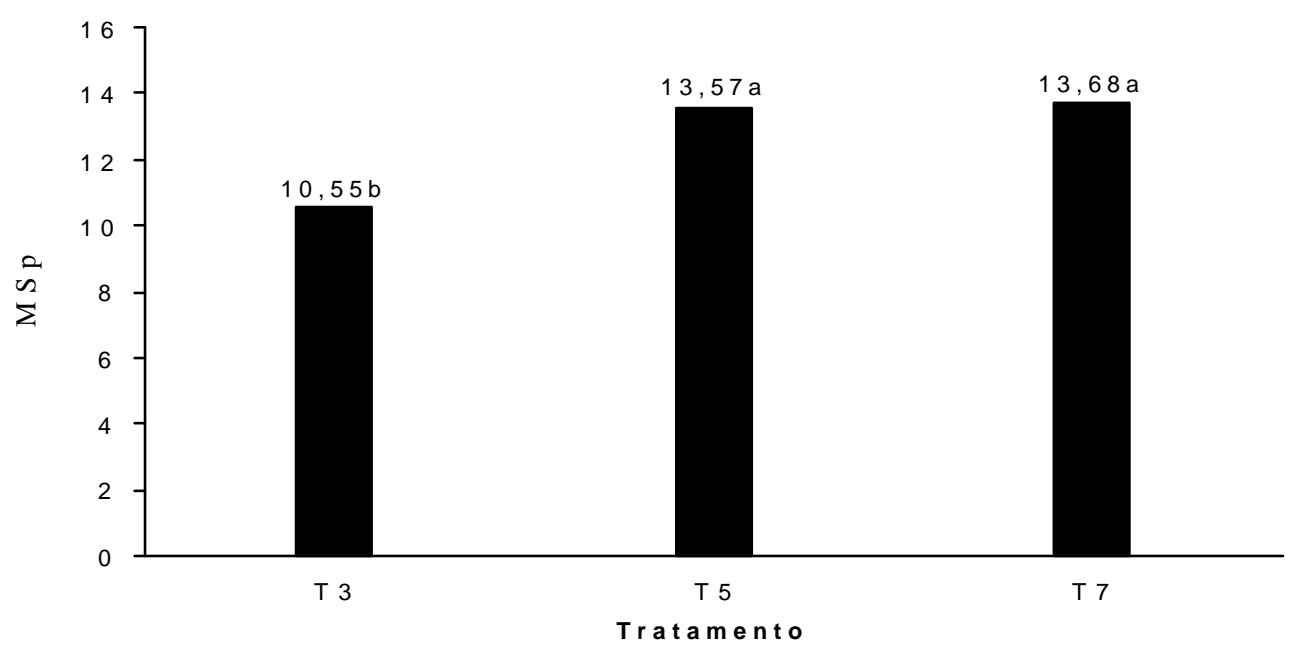

Figura 5 - Massa de matéria seca da parte aérea $\left(M S p a\right.$, g.pl ${ }^{-1}$ ) no tratamentos $\mathrm{T}_{3}, \mathrm{~T}_{5}$ e $\mathrm{T}_{7}$ que tiveram em comum adubação nitrogenada. 


\subsubsection{Teor de nitrogênio na planta}

Com relação ao teor de nitrogênio na planta, não foi observada diferença estatística entre todos os tratamentos, indicando que esse elemento não foi limitante ao crescimento e desenvolvimento da planta.

$\mathrm{O}$ tratamento $\mathrm{T}_{1}$ sem adubação nitrogenada e sem inoculação, apresentou teor de nitrogênio acima do nível crítico de $30 \mathrm{~g} \cdot \mathrm{kg}^{-1}$ (Ambrosano et al, 1996), indicando que o estabelecimento da simbiose com estirpes nativas e a adoção do SSD foram suficientes para atender parte da demanda da planta por nitrogênio, mas não foram suficientemente eficientes para garantir produtividade máxima da variedade cultivada estudada.

Geralmente, as estirpes nativas ou selecionadas de rizóbio são ineficientes e incapazes de suprir as necessidades de nitrogênio, durante todo o ciclo vital da planta (Grahan \& Halliday, 1976; Graham \& Rosas, 1977; Westermann \& Kolar, 1978; Rennie \& Kemp, 1983; Redden et al, 1990; Vargas et al, 1991).

Isso reforça a idéia, de que quando o nível inicial de $\mathrm{N}$ disponível no solo é baixo, o período de absorção de nitrogênio pela planta é aumentado, podendo reduzir tanto o rendimento de grãos, como a nodulação e a fixação de $\mathrm{N}_{2}$ (Eaglesham et al., 1983). George \& Singleton (1992), utilizando ${ }^{15} \mathrm{~N}$, notaram que o feijão foi mais eficiente no acúmulo de $\mathrm{N}$ mineral do que a soja. Nesse mesmo estudo, George \& Singleton (1992) demonstraram que o feijão foi mais "eficiente" em busca do N disponível no solo do que a soja teve biomassa de raiz mais extensa (61\%) e maior quantidade de $\mathrm{N}$ acumulado por unidade de biomassa da raiz do que a soja.

Isso indica que a maior disponibilidade de $\mathrm{N}$ para a planta ocorre através da adoção de práticas culturais que melhoram a qualidade do solo, do que propriamente a melhoria da relação simbiótica entre a planta e o rizóbio.

\subsubsection{Números de nódulos por planta}

Na Figura 6 são apresentados os resultados referentes ao número de nódulos na planta. Cabe salientar que houve diferença estatística entre os tratamentos (Tabela 4). 


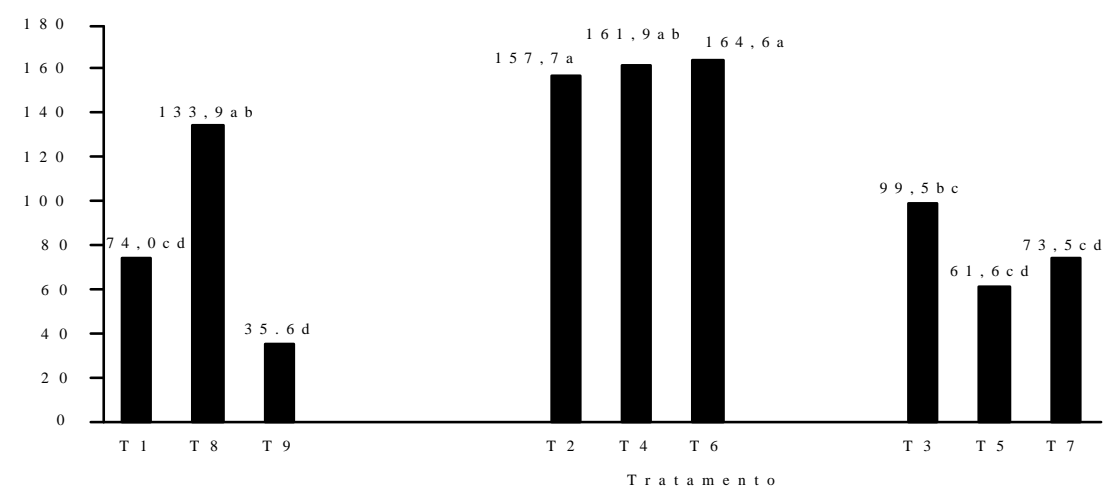

Figura 6 - Número médio de nódulos por planta em todos os tratamentos.

Phia \& Munns (1987), comparando o efeito da inoculação, de estirpes nativas e selecionadas em feijão em casa-de-vegetação, verificaram que nenhuma das variáveis de produção e de fixação biológica de nitrogênio avaliadas foram afetadas negativamente pelas estirpes nativas, indicando que o baixo desempenho dos feijões cultivados no campo não pode ser atribuído ao efeito da competição com as estirpes de rizóbio nativo pelos sítios de nodulação na planta.

Assim, a nodulação encontrada no tratamento $\mathrm{T}_{1}$ pode ser atribuída única $\mathrm{e}$ exclusivamente às estirpes nativas presentes no solo, e serviu como um excelente parâmetro para identificar o efeito da inoculação entre os tratamentos testados.

Considerando que na testemunha tratamento $T_{1}$ houve nodulação o aumento na quantidade de nódulos encontrada nos tratamentos $T_{2}, T_{4}$ e $T_{6}$ pode ser atribuída ao efeito da inoculação com RL, Co e Mo. Nota-se que houve uma redução na nodulação nos demais tratamentos em relação aos tratamentos $\mathrm{T}_{2}, \mathrm{~T}_{4} \mathrm{e} \mathrm{T}_{6}$. Essa redução é explicada pela realização da adubação nitrogenada, e pela sua negativa influência sobre a nodulação. $\mathrm{O}$ tratamento $T_{9}$ que recebeu adubação nitrogenada na semeadura e em cobertura apresentou em média 35,6 nódulos por planta, sendo essa a menor média entre os tratamentos testados. Esses resultados estão de acordo com Mendonça et al. (1998) e Mendes et al. (1998), que também observaram diminuição da nodulação na presença de adubação nitrogenada. 


\subsection{4 Índice de utilização de nitrogênio}

O teor de nitrogênio obtido através da diagnose foliar em todos os tratamentos esteve acima do nível crítico. Isso permite concluir que esse elemento não foi limitante, seja para o desenvolvimento da planta, seja para o rendimento de grãos. Nota-se que os tratamentos que apresentaram os maiores rendimentos, apresentaram também os maiores índices de utilização de nitrogênio, obtidos pelo teor de nitrogênio fixado, presentes na massa de matéria seca da planta no período de florescimento.

A linha de tendência da curva (Figura 7), caso fosse significativa, indicaria que o IUN tem uma correlação positiva com o rendimento de grãos, sugerindo que maiores teores de $\mathrm{N}$ fixado no florescimento pode resultar em maior rendimento. Nota-se na Figura 7 que os tratamentos $\mathrm{T}_{7}, \mathrm{~T}_{5}, \mathrm{~T}_{4}, \mathrm{~T}_{6}$ e $\mathrm{T}_{9}$ tiveram as maiores médias para rendimento de grãos e o IUN, nesses tratamentos, foi em média de 42,3\%.

Se considerarmos que o IUN é o produto entre a massa de matéria seca da parte aérea e o teor de nitrogênio na planta, fica claro que a planta está numa dependência direta da biomassa da parte aérea para ter um alto IUN, o que pode possibilitar um maior rendimento de grãos. Assim, o desenvolvimento inicial da planta nos estádios fenológicos $\left(\mathrm{V}_{0}\right.$ à $\left.\mathrm{R}_{5}\right)$ é de fundamental importância para atingir o estádio fenológico $\mathrm{R}_{6}$ (florescimento) com alta biomassa da parte aérea.

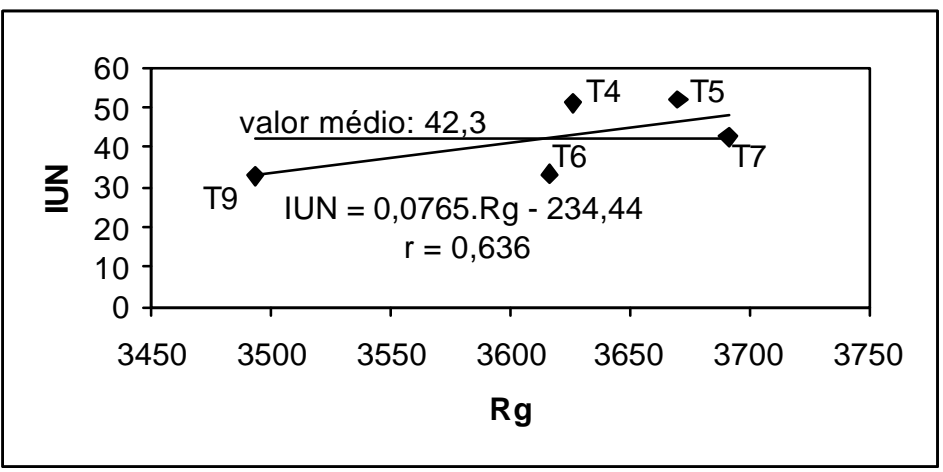

Figura 7 - Índice de utilização de nitrogênio (IUN, \%) nos diferentes tratamentos. 


\subsection{Avaliação Agronômica na colheita}

\subsubsection{Massa de matéria seca de raiz}

$\mathrm{Na}$ Tabela 5 são apresentados os resultados referentes à massa de matéria seca das raízes e nódulos, número de vagens por planta e número de grãos por vagem e rendimento grãos. Cabe salientar que houve diferença estatística entre os tratamentos.

Tabela 5. Massa de matéria seca de raízes (MSr) e de nódulos (MSn), número médio de vagens por planta $(\mathrm{Nv})$ e de grãos por vagem $(\mathrm{Ng})$, massa de 100 grãos $\left(\mathrm{M}_{100}\right)$ e rendimento de grãos ( $\mathrm{Rg}$ ) do feijoeiro, cv. Pérola, inoculado com Rhizobium leguminosrum bv. Phaseoly, Co e Mo nos diferentes tratamentos.

\begin{tabular}{|c|c|c|c|c|c|c|c|c|c|c|}
\hline \multirow[b]{2}{*}{ Variável } & \multirow[b]{2}{*}{${ }^{1} \mathrm{Un}$} & \multicolumn{9}{|c|}{ Tratamento } \\
\hline & & ${ }^{2} \mathrm{~T}_{1}$ & $\mathrm{~T}_{2}$ & $\mathrm{~T}_{3}$ & $\mathrm{~T}_{4}$ & $\mathrm{~T}_{5}$ & $\mathrm{~T}_{6}$ & $\mathrm{~T}_{7}$ & $\mathrm{~T}_{8}$ & $\mathrm{~T}_{9}$ \\
\hline $\mathrm{MSr}$ & ${ }^{3}$ g.pl ${ }^{-1}$ & $1,15^{\mathrm{a}}$ & $1,39^{\mathrm{a}}$ & $1,49^{\mathrm{a}}$ & $1,83^{\mathrm{a}}$ & $1,93^{\mathrm{a}}$ & $1,33^{\mathrm{a}}$ & $2,03^{\mathrm{a}}$ & $1,77^{\mathrm{a}}$ & $1,78^{\mathrm{a}}$ \\
\hline MSn & ${ }^{4} \mathrm{mg} \cdot \mathrm{pl}^{-1}$ & $89,9^{c}$ & $130,7^{\mathrm{ab}}$ & $16,5^{\mathrm{d}}$ & $164,9^{\mathrm{a}}$ & $37,4^{\mathrm{d}}$ & $162,0^{\mathrm{a}}$ & $23,2^{\mathrm{d}}$ & $119,0 \mathrm{bc}$ & $32,1^{\mathrm{d}}$ \\
\hline $\mathrm{Nv}$ & ${ }^{5} \mathrm{vg} \cdot \mathrm{pl}^{-1}$ & $6,8^{\mathrm{cd}}$ & $6,3^{\mathrm{d}}$ & $7,3^{\mathrm{bcd}}$ & $10,8^{\mathrm{a}}$ & $9,2^{\mathrm{abc}}$ & $8,3^{\text {abcd }}$ & $9,5^{\mathrm{ab}}$ & $8,77^{\text {abcd }}$ & $8,0^{\mathrm{bcd}}$ \\
\hline $\mathrm{Ng}$ & ${ }^{6}{\mathrm{gr} . \mathrm{vg}^{-1}}^{-1}$ & $6,1^{\mathrm{a}}$ & $6,2^{\mathrm{a}}$ & $6,0^{\mathrm{a}}$ & $6,3^{\mathrm{a}}$ & $6,4^{\mathrm{a}}$ & $6,0^{\mathrm{a}}$ & $6,6^{\mathrm{a}}$ & $5,7^{\mathrm{a}}$ & $5,7^{\mathrm{a}}$ \\
\hline $\mathrm{M}_{100}$ & $\mathrm{~g}$ & $32,76^{\mathrm{a}}$ & $32,95^{\mathrm{a}}$ & $32,64^{\mathrm{a}}$ & $32,08^{\mathrm{a}}$ & $32,79^{\mathrm{a}}$ & $32,64^{\mathrm{a}}$ & $32,80^{\mathrm{a}}$ & $32,74^{\mathrm{a}}$ & $31,50^{\mathrm{a}}$ \\
\hline $\mathrm{Rg}$ & kg.ha ${ }^{-1}$ & $3062^{\mathrm{ab}}$ & $2928^{\mathrm{b}}$ & $3322^{\mathrm{ab}}$ & $3626^{\mathrm{ab}}$ & $3670^{\mathrm{a}}$ & $3616^{\mathrm{ab}}$ & $3691^{\mathrm{a}}$ & $3193^{\mathrm{ab}}$ & $3493^{a b}$ \\
\hline
\end{tabular}

Os efeitos práticos da inoculação pode garantir aumento no teor de molibdênio na semente e refletir em aumento no rendimento de grãos pela melhor fixação de $\mathrm{N}$ pela planta (Vidor \& Peres, 1988). Como o feijão tem mostrado ser "eficiente" em busca do N disponível no solo (George \& Singleton, 1992) a quantidade de raízes na planta vai depender da variedade cultivada que está sendo utilizada e principalmente das condições do solo. Nos tratamentos onde foram encontrados os melhores rendimentos de grãos $\left(\mathrm{T}_{7}\right.$, $\mathrm{T}_{5}, \mathrm{~T}_{4}, \mathrm{~T}_{6} \mathrm{e} \mathrm{T}_{9}$ ) foram também observadas as melhores médias para massa de matéria seca das raízes (Figura 8). 


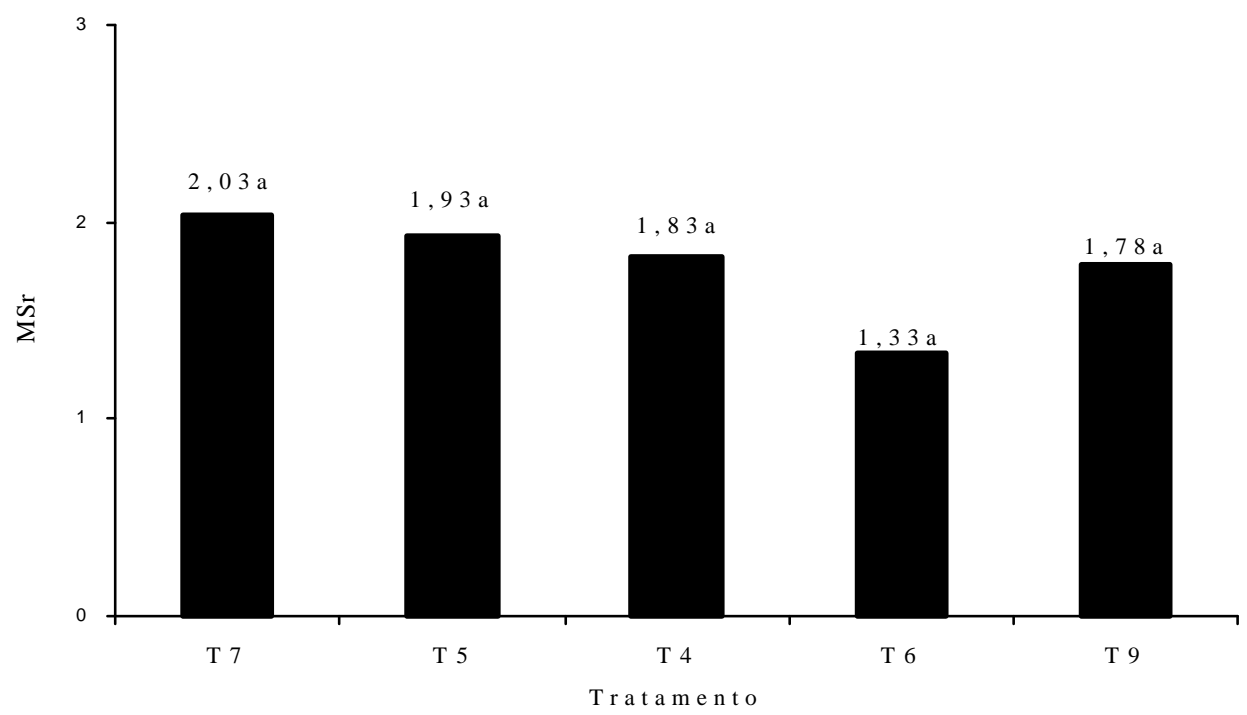

Figura 8 - Massa de matéria seca de raiz $\left(\mathrm{MSr}, \mathrm{g}_{\mathrm{pl}} \mathrm{p}^{-1}\right)$ nos diferentes tratamentos.

Quando a semente foi inoculada com Co e Mo $\left(\mathrm{T}_{4}\right)$ houve um incremento na massa de matéria seca das raízes da ordem 59\% em relação a testemunha $\left(\mathrm{T}_{1}\right)$. Quando a semente foi inoculada com Co e Mo e recebeu adubação nitrogenada em cobertura $\left(T_{5}\right)$ o incremento da massa de matéria seca das raízes foi de $67 \%$ em relação a $T_{1}$.

Quando a semente foi inoculada Co e Mo mais Rhizobium e recebeu adubação nitrogenada em cobertura $\left(T_{7}\right)$ o incremento foi de $76 \%$ em relação a $T_{1}$.

$\mathrm{O}$ destaque deve ser dado à presença do Co e Mo nos estádios iniciais de desenvolvimento da cultura. Entretanto quando o Co e Mo foi conjugado com RL e recebeu adubação nitrogenada em cobertura, obteve-se o máximo desenvolvimento radicular para a variedade cultivada utilizada.

\subsubsection{Massa de matéria seca de nódulos}

Os valores médios para massa de matéria seca de nódulos estão apresentados na Tabela 5. Cabe salientar que houve diferença estatística entre os tratamentos. A massa de matéria seca dos nódulos esta numa relação direta ao número de nódulos na planta, que por sua vez esta numa relação inversa a adubação nitrogenada. Observa-se nos tratamentos $\mathrm{T}_{2}, \mathrm{~T}_{4}$ e $\mathrm{T}_{6}$ os maiores valores $\left(130,7 ; 164,9\right.$ e $\left.162,0 \mathrm{mg} \cdot \mathrm{pl}^{-1}\right)$, que por sua 
vez tiveram maior número de nódulos $(157,70,161,95,164,60)$, que por sua vez não receberam adubação nitrogenada (Figura 9).

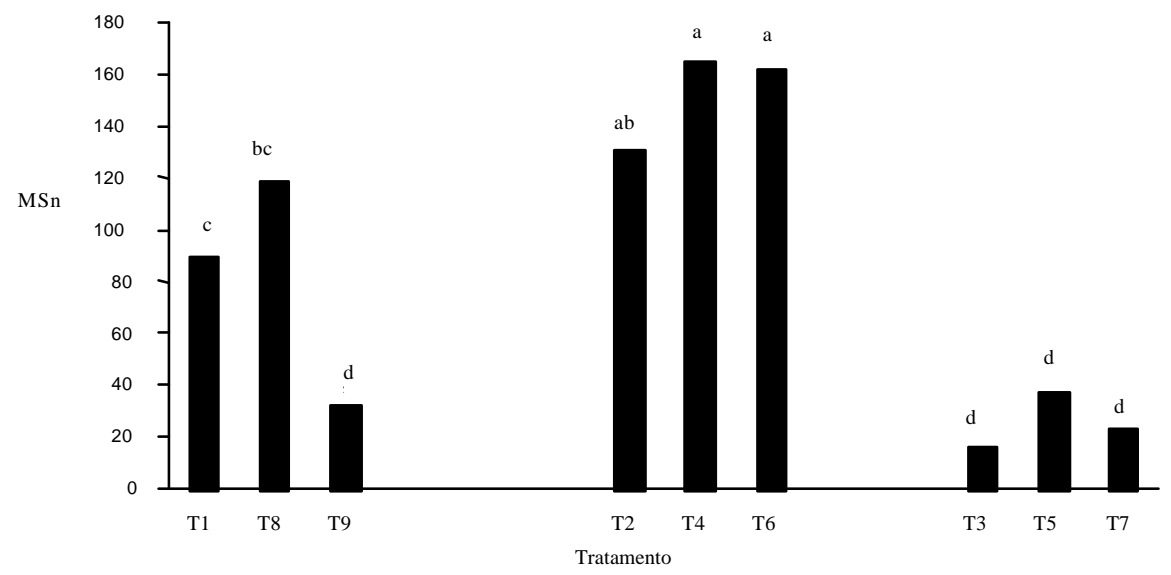

Figura 9 - Massa de matéria seca de nódulos (MSn, mg.pl ${ }^{-1}$ ) nos diferentes tratamentos.

$\mathrm{O}$ número de nódulos não significa necessariamente maior quantidade de $\mathrm{N}$ fixado na planta. A quantidade de nódulos não é diretamente proporcional ao acúmulo de $\mathrm{N}$ na planta, reforçando a idéia de que a relação entre a FBN pelo feijoeiro não é linear.

Hansen et al. (1993) observaram que um mutante supernodulante de feijoeiro apresentou uma massa nodular duas vezes maior e um número de nódulos e seis vezes maior que os parentais. Entretanto, a fixação biológica de nitrogênio foi quase igual sugerindo que a elevada nodulação resulta em formação de nódulos menores, com menor eficiência relativa. Observou-se que, apesar da diferente quantidade de nódulos, todos os tratamentos apresentaram teor de nitrogênio acima do nível crítico de $30 \mathrm{~g} \cdot \mathrm{kg}^{-1}$ (Ambrosano et al, 1996).

Isso reforça a idéia de que a atividade da nitrogenase é um processo flexível que se ajusta à demanda da planta por $\mathrm{N}$, e que a quantidade de $\mathrm{N}_{2}$ fixada esta mais relacionada à demanda da planta por $\mathrm{N}$ do que pela intrínseca capacidade do rizóbio em fixar $\mathrm{N}_{2}$. Assim, se o solo atender a demanda da planta por nitrogênio, esta poderá 
utilizar primeiramente o $\mathrm{N}$ disponível no solo e posteriormente flexibilizara o sistema em busca de $\mathrm{N}$ que poderá vir da simbiose entre a planta e o rizóbio.

\subsubsection{Número de vagens por planta e número de grãos por vagem}

Na Figura 10 são apresentados os resultados referente ao número de vagens por planta e número médio de grãos por vagens. Houve diferença significativa entre os tratamentos no que se refere apenas ao número médio de vagens por planta. $\mathrm{O}$ número de grãos por vagem foi igual para todos os tratamentos (Tabela 5).

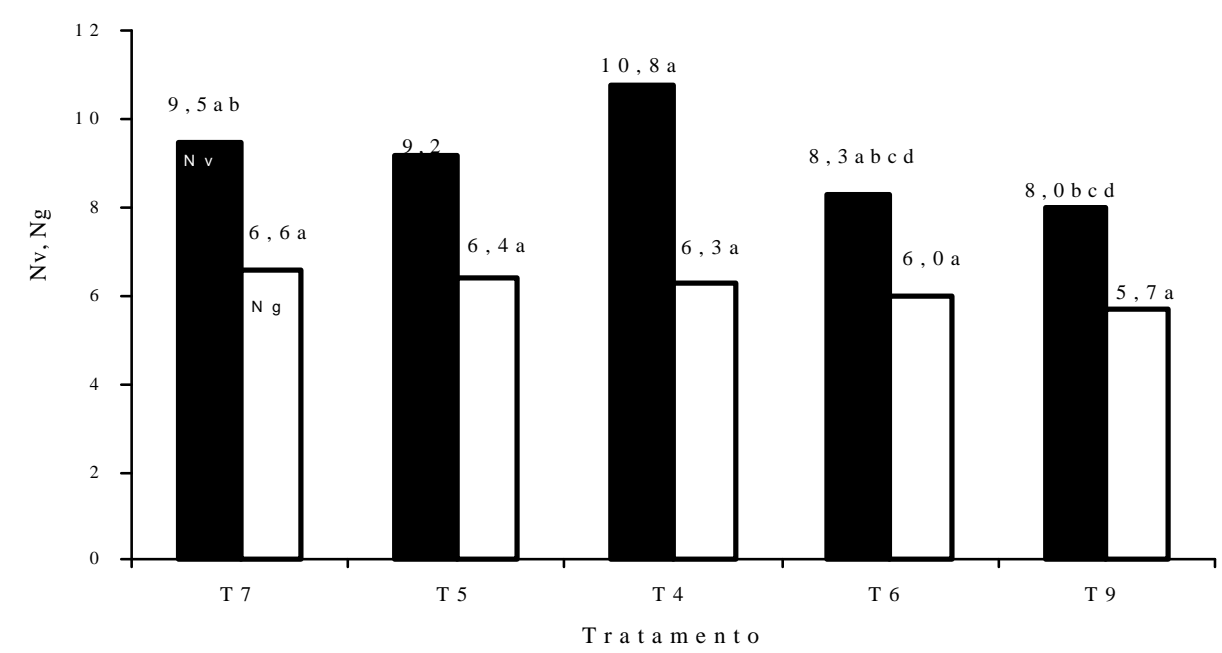

Figura 10 - Número nédio de vagens por planta $(\mathrm{Nv})$ e número médio de grãos por vagem $(\mathrm{Ng})$ nos diferentes tratamentos.

As melhores médias no que se refere ao número de vagens por planta foi observado nos tratamentos $\mathrm{T}_{4}$ (inoculado com Co e Mo), no $\mathrm{T}_{7}$ (semente inoculada com RL, Co e Mo com adubação nitrogenada em cobertura) e $T_{5}$ (semente inoculada com Co e Mo, com adubação nitrogenada em cobertura. Isso sugere, que a inoculação da semente com Rhizobium, mais Co e Mo, disponibilizam nitrogênio nos estádios iniciais de desenvolvimento da planta, pelo estabelecimento da simbiose (com o Rhizobium) e pelo fortalecimento da demanda por Mo para o complexo da nitrogenase, já que em alguns solos o conteúdo total e solúvel de Mo são baixos (Bataglia et al, 1975). 
A adubação nitrogenada pode inibir a nodulação, mas quando foi aplicada em cobertura, teve um efeito interativo e positivo no aumento do rendimento de grãos. Esses resultados estão de acordo com Tsai et al. (1993), que observaram quando o feijoeiro recebeu um balanço adequado de nutrientes não houve inibição, mas sim um efeito sinergístico da adubação nitrogenada sobre a nodulação e fixação de $\mathrm{N}$.

\subsubsection{Massa de 100 sementes e rendimentos de grãos}

Se considerarmos que o número de grãos por vagens e massa de 100 grãos (semente botânica) foi estatisticamente iguais nos diferentes tratamentos, o número de vagens por planta é a variável responsável pela diferença obtida nos diferentes tratamentos entre rendimento de grãos, coincidindo com os tratamentos que tiveram maior biomassa na raiz e na parte aérea (Tabela 4 e Tabela 5).

Houve diferença significativa entre os tratamentos no que refere ao rendimento de grãos. As melhores médias foram obtidas nos tratamentos $\mathrm{T}_{7}, \mathrm{~T}_{5}, \mathrm{~T}_{4}, \mathrm{~T}_{6}$ e $\mathrm{T}_{9}$, respectivamente. Destaca-se nos $\mathrm{T}_{7}, \mathrm{~T}_{5}, \mathrm{~T}_{4}$ e $\mathrm{T}_{6}$ a presença do Co e Mo nos estádios iniciais de desenvolvimento. Os efeitos práticos da inoculação de semente, pode garantir aumento no teor de Mo na semente, e refletir no aumento da produção de grãos pela melhor fixação de $\mathrm{N}$ pela planta.

Quando as sementes foram inoculados Co, Mo e RL, associada à adubação nitrogenada em cobertura, o tratamento $\mathrm{T}$ alcançou a melhor média de rendimento para a variedade cultivada estudada (Figura 11).

As boas condições do solo e as estirpes nativas de rizóbios foram suficientes para suprir parte das necessidades da planta por nitrogênio. Porém, não garantiram produtividade máxima da variedade cultivada utilizada. Fica evidente que disponibilizar nitrogênio dentro SSD assume um papel de alta relevância, principalmente quando essa disponibilização é feita por métodos alternativos, menos danosos ao ambiente e ao Homem, através da inoculação de sementes em substituição aos métodos convencionais. 


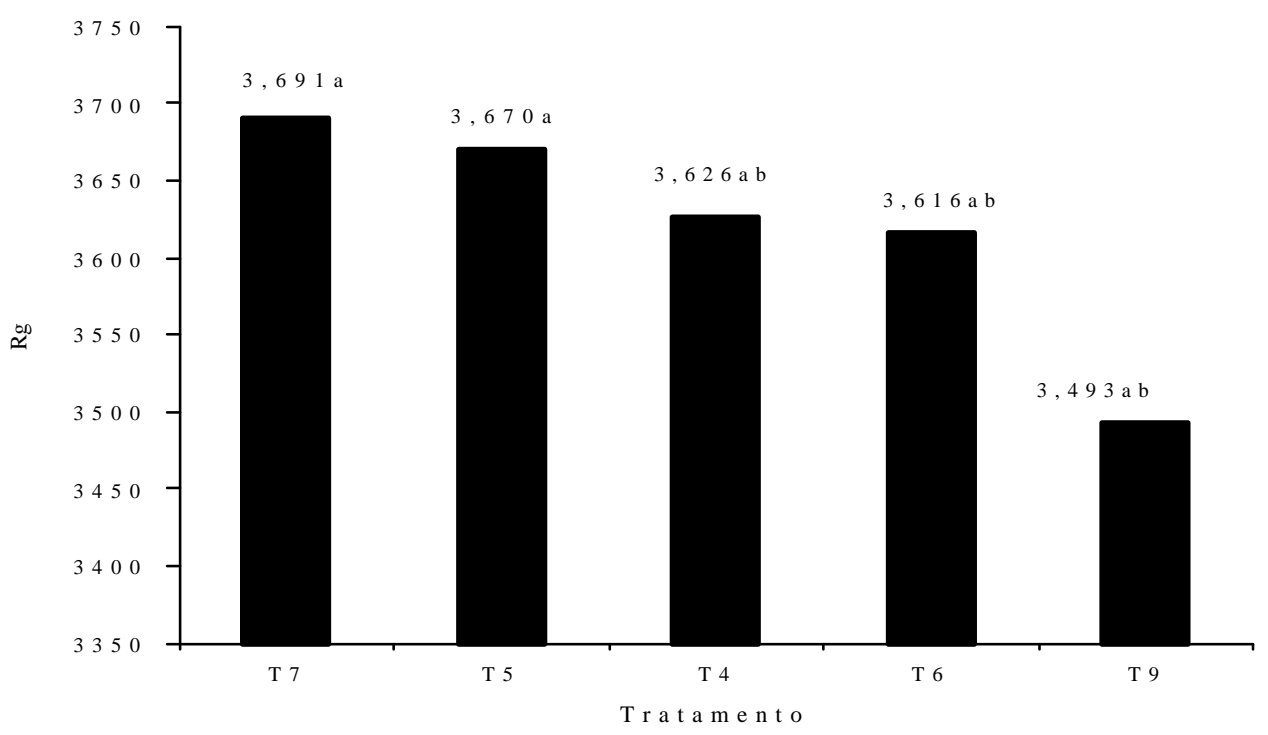

Figura 11 - Rendimento de grãos $\left(\mathrm{Rg}, \mathrm{kg} \cdot \mathrm{ha}^{-1}\right)$ nos diferentes tratamentos.

As três melhores médias observadas para rendimento de grãos $\left(\mathrm{T}_{7}, \mathrm{~T}_{5}\right.$ e $\left.\mathrm{T}_{4}\right)$ tiveram em comum maior biomassa de raiz, maior biomassa da parte aérea, maior número de vagens por planta, maior número de grãos por vagem.

\subsection{Sistema de semeadura direta}

A rotação de culturas (Tabela 3) dentro SSD demonstrou ser eficiente na manutenção da fertilidade do solo. $O$ teor de matéria orgânica presente no solo se manteve praticamente constante no período estudado (1994 a 1999). A análise do solo revelou ainda que a SB e a CTC, tiveram um aumento significativo de 61,90\% e 21,75\%, respectivamente. $\mathrm{O}$ aumento médio do $\mathrm{pH}$ do solo foi de $20 \%$, em 1994 o valor foi de 4,8 mg.dm ${ }^{-3}$, evoluiu em 1999 para 5,8 mg.dm ${ }^{-3}$. Nesse período, o $\mathrm{pH}$ do solo, aumentou de 4,8 para 5,8, $\mathrm{pH}$ esse considerado bom para o desenvolvimento da cultura de feijão (Tabela 1).

Isso indica que a SSD é uma prática eficiente na preservação da matéria orgânica e fertilidade do solo, pois tende a melhorar a composição química do solo. Resultado semelhante também foi encontrado por Mondardo (1978); Derpersch et al (1986); Blevins et al (1997) Sidiras \& Pavan (1994); Thomas (1990); Sá (1997) e Kinsella (1997). 
O solo estando protegido pela palha, apresenta menores temperaturas e amplitude térmica e melhor estrutura, há maior fluxo de oxigênio e de água favorecendo a atividade biológica. Isso pode ser observado no tratamento $T_{1}$ que apesar de não receber nenhum tipo de adubação nitrogenada, apresentou no florescimento teor de nitrogênio na planta de 34,72 g.kg ${ }^{-1}$, acima do nível considerado crítico para a cultura.

Nesse sentido quando a demanda da planta por nitrogênio é maximizada pela adoção do SSD, a disponibilização de nitrogênio dentro do sistema passa assumir um papel de fundamental importância. Dentre outras, quatro são as alternativas viáveis para aumentar a disponibilidade de nitrogênio dentro SSD, (a) inoculação da semente com Rhizobium, (b) inoculação da semente com Co e Mo, (c) utilização de fertilizante mineral nitrogenado, (d) interação entre Rhizobium, Co e Mo e adubação mineral nitrogenada. Essas alternativas foram agrupadas em nove tratamentos, de forma a permitir uma análise mais aprofundada de sua eficácia.

Nas Tabelas 7 a 9 são apresentados os resultados comparativos entre os tratamentos em relação ao índice de rendimento da cultura. Os tratamentos $T_{1}, T_{8}$ e $T_{9}$ representam três formas utilizadas pelos produtores na disponibilização de nitrogênio para a cultura de feijão, com adubação nitrogenada na semeadura e em cobertura ( $T_{8}$ e $\left.\mathrm{T}_{9}\right)$ e sem adubação $\left(\mathrm{T}_{1}\right)$.

Os tratamentos $T_{2}, T_{4}$ e $T_{6}$ disponibilizam nitrogênio para a cultura de feijão através da ativação de mecanismos da Fixação Biológica do Nitrogênio através da inoculação da semente com RL, e Co e Mo.

Os tratamentos $T_{3}, T_{5}$ e $T_{7}$ representa uma forma alternativa na disponibilização de nitrogênio para a cultura de feijão, combinando a inoculação da semente com Rhizobium, Co e Mo e adubação nitrogenada. Esses tratamentos tiveram um índice de rendimento médio superior ao $\mathrm{T}_{1}$ de $10,70 \%\left(\mathrm{~T}_{2}, \mathrm{~T}_{4}\right.$ e $\left.\mathrm{T}_{6}\right)$ e $16,29 \%\left(\mathrm{~T}_{3}, \mathrm{~T}_{5}\right.$ e $\left.\mathrm{T}_{7}\right)$ respectivamente (Tabela 6). 
Tabela 6. Comparação entre os rendimentos (valores absolutos - Rg - e relativos - Rr) referentes à cultura de feijão no tratamento $T_{1}$ com os tratamentos $T_{2}, T_{4}$ e $T_{6}$ e os tratamentos $\mathrm{T}_{3}, \mathrm{~T}_{5}$ e $\mathrm{T}_{7}$. Piracicaba, SP. 1999.

\begin{tabular}{ccccccc}
\hline $\mathrm{T}_{1}$-Rg (kg.ha $\left.{ }^{-1}\right)$ & $\mathrm{Rg}\left(\mathrm{kg} \mathrm{ha}^{-1}\right)$ & Tratamento & $\operatorname{Rr}(\%)$ & $\mathrm{Rg}\left(\mathrm{kg} \cdot \mathrm{ha}^{-1}\right)$ & Tratamento & $\mathrm{Rr}(\%)$ \\
\hline 3062 & 2928 & $\mathrm{~T}_{2}$ & 95,6 & 3322 & $\mathrm{~T}_{3}$ & 108,5 \\
& 3626 & $\mathrm{~T}_{4}$ & 118,4 & 3670 & $\mathrm{~T}_{5}$ & 119,9 \\
& 3616 & $\mathrm{~T}_{6}$ & 118,1 & 3691 & $\mathrm{~T}_{7}$ & 120,5 \\
$\operatorname{Rr}(\%)$ & & - & 110,7 & - & - & 116,3 \\
\hline
\end{tabular}

A adoção do SSD sem incrementar a disponibilidade de nitrogênio para a planta dentro do sistema não proporciona índices elevados de rendimentos de grãos. Com relação ao tratamento $T_{8}$ nota-se que superioridade dos tratamentos $T_{2}, T_{4}$ e $T_{6}$ foi de $6,16 \%$ e dos tratamentos $\mathrm{T}_{3}, \mathrm{~T}_{5}$ e $\mathrm{T}_{7}$ 11,52\%, respectivamente (Tabela 7).

Tabela 7. Comparação entre os rendimentos (valores absolutos - Rg - e relativos - Rr) referentes à cultura de feijão no tratamento $\mathrm{T}_{8}$ com os tratamentos $\mathrm{T}_{2}, \mathrm{~T}_{4}$ e $\mathrm{T}_{6} \mathrm{e}$ os tratamentos $\mathrm{T}_{3}, \mathrm{~T}_{5}$ e $\mathrm{T}_{7}$. Piracicaba, SP. 1999.

\begin{tabular}{ccccccc}
\hline $\mathrm{T}_{8}-\operatorname{Rg}\left(\mathrm{kg} \cdot \mathrm{ha}^{-1}\right)$ & $\mathrm{Rg}\left(\mathrm{kg}^{-h^{-1}}\right)$ & Tratamento & $\operatorname{Rr}(\%)$ & $\operatorname{Rg}\left(\mathrm{kg} \cdot \mathrm{ha}^{-1}\right)$ & Tratamento & $\operatorname{Rr}(\%)$ \\
\hline 3193 & 2928 & $\mathrm{~T}_{2}$ & 91,7 & 3322 & $\mathrm{~T}_{3}$ & 104,0 \\
& 3626 & $\mathrm{~T}_{4}$ & 113,6 & 3670 & $\mathrm{~T}_{5}$ & 114,9 \\
& 3616 & $\mathrm{~T}_{6}$ & 113,2 & 3691 & $\mathrm{~T}_{7}$ & 115,6 \\
$\operatorname{Rr}(\%)$ & - & - & 106,2 & - & - & 111,5 \\
\hline
\end{tabular}

Ao receber adubação nitrogenada em cobertura, o tratamento $T_{8}$ passou a ser mais competitivo que o $\mathrm{T}_{1}$, pois disponibilizou maior quantidade de nitrogênio para planta, e isso acarretou um decréscimo na superioridade dos tratamentos $T_{2}, T_{4}$ e $T_{6}$ e dos tratamentos $\mathrm{T}_{3}, \mathrm{~T}_{5}$ e $\mathrm{T}_{7}$, e aumento na produção de grãos do tratamento $\mathrm{T}_{8}$.

$\mathrm{O}$ tratamento $\mathrm{T}_{9}$ ao receber adubação nitrogenada na semeadura e em cobertura, incrementou a disponibilidade de nitrogênio para planta, e aumentou o rendimento de grãos em relação aos outros tratamentos do seu grupo $\left(\mathrm{T}_{1}\right.$ e $\left.\mathrm{T}_{8}\right)$, e acarretou um índice negativo de rendimento da ordem $2,96 \%$ em relação aos tratamentos $T_{2}, T_{4}$ e $T_{6}$ e a superioridade em relação aos tratamentos $\mathrm{T}_{3}, \mathrm{~T}_{5}$ e $\mathrm{T}_{7}$ foi de apenas de 1,94\% (Tabela 8). 
Tabela 8. Comparação entre os rendimentos (valores absolutos - Rg - e relativos - Rr) referentes à cultura de feijão no tratamento $\mathrm{T}_{9}$ com os tratamentos $\mathrm{T}_{2}, \mathrm{~T}_{4}$ e $\mathrm{T}_{6} \mathrm{e}$ os tratamentos $\mathrm{T}_{3}, \mathrm{~T}_{5}$ e $\mathrm{T}_{7}$. Piracicaba, SP. 1999.

\begin{tabular}{ccccccc}
\hline $\mathrm{T}_{9}-\mathrm{Rg}\left(\mathrm{kg} \cdot \mathrm{ha}^{-1}\right)$ & $\mathrm{Rg}\left({\mathrm{kg} . h{ }^{-1}}^{-1}\right)$ & Tratamento & $\operatorname{Rr}(\%)$ & $\mathrm{Rg}\left({\left.\mathrm{kg} . h a^{-1}\right)}\right.$ & Tratamento & $\operatorname{Rr}(\%)$ \\
\hline 3493 & 2928 & $\mathrm{~T}_{2}$ & 83,8 & 3322 & $\mathrm{~T}_{3}$ & 95,1 \\
& 3626 & $\mathrm{~T}_{4}$ & 103,8 & 3670 & $\mathrm{~T}_{5}$ & 105,1 \\
& 3616 & $\mathrm{~T}_{6}$ & 103,5 & 3691 & $\mathrm{~T}_{7}$ & 105,7 \\
$\operatorname{Rr}(\%)$ & & - & 97,0 & - & - & 101,9 \\
\hline
\end{tabular}

Os tratamentos $\mathrm{T}_{1}, \mathrm{~T}_{8}$ e $\mathrm{T}_{9}$ mostram que a medida que dosagem de $\mathrm{N}$ e sua disponibilidade aumentou, o rendimento de grãos também aumentou (Figura 12). Essa é a razão pela qual os índices de utilização de fertilizantes nitrogenados têm crescido em todo mundo. Estima-se que a fixação industrial de nitrogênio aumentou de 3,5 milhões de t em 1950 para 80 milhões t em 1989 em resposta a necessidade crescente requeridas pelas culturas para manter altos rendimentos. No ano de 2050, com o aumento da população mundial haverá uma demanda mínima de 160 milhões de t de fertilizante industrialmente sintetizado, a mesma quantidade poderia ser sintetizada pelo processo biológico. A quantidade de fertilizante nitrogenado fixado industrialmente requererão no mínimo 270 milhões de toneladas de carvão por volta do ano de 2050. Assim, o ideal seria que a FBN reduza e a longo prazo substitua o fertilizante sintetizado industrialmente.

O feijão responde bem à adubação nitrogenada. Porém, a cultura é conhecida como deficitária na fixação de $\mathrm{N}_{2}$. Embora a adubação nitrogenada seja recomendada para o feijão, alguns autores citam que ela não é economicamente viável, em razão dos seus custos (Silva et al, 1976; CIAT, 1978; Vargas et al., 1991), e dos rendimentos médios estimados. Esta boa resposta do feijão a adubação nitrogenada, entretanto, deve ser considerada.

Os adubos nitrogenados sintéticos, representam a forma assimilada com maior rapidez pelas plantas, mas a um custo elevado. Estima-se que os adubos nitrogenados sintéticos têm em comum os seguintes problemas: (a) em cada tonelada de $\mathrm{NH}_{3}$ sintetizada, gasta-se seis barris de petróleo, (b) a baixa eficiência de sua uilização pelas plantas, raramente ultrapassando $50 \%$, e (c) a lixiviação do $\mathrm{N}$ resulta em acúmulo de 
formas nitrogenadas nas águas de rios e lagos podendo atingir níveis tóxicos para os peixes e ao Homem. Além desses problemas, os resultados revelaram que os tratamentos $\mathrm{T}_{1}, \mathrm{~T}_{8}, \mathrm{~T}_{9}$ não atingiram rendimento máximo da variedade cultivada estudada, quando comparado com os outros sistemas. O rendimento máximo obtido nos diferentes tratamentos está ilustrada na Figura 13.

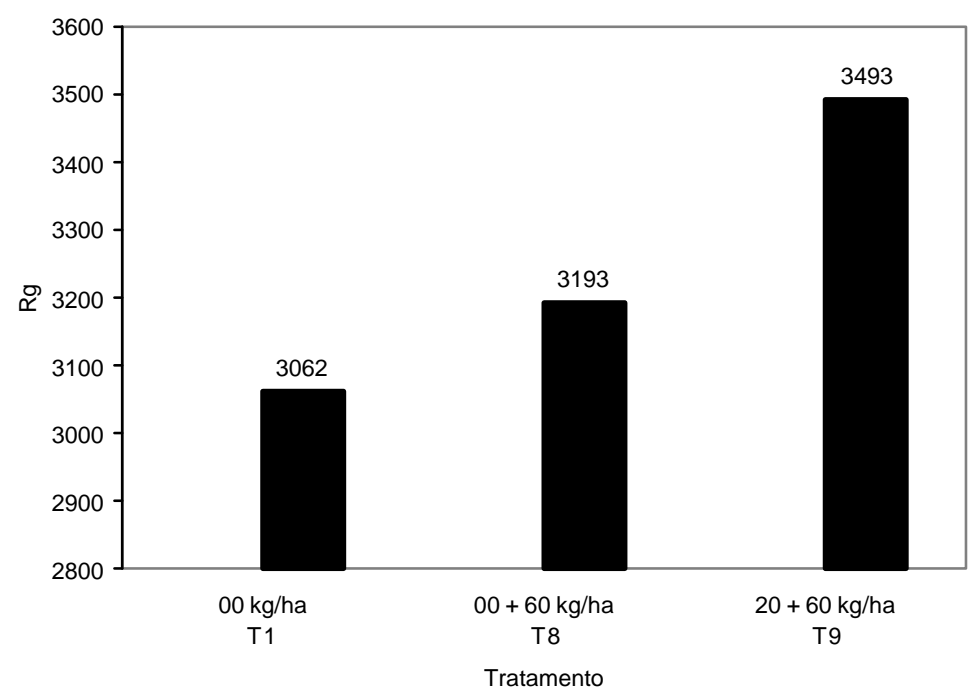

Figura 12 - Rendimento de grãos $\left(\mathrm{Rg}, \mathrm{kg}_{\mathrm{h}} \mathrm{ha}^{-1}\right)$ em função da adubação nitrogenada nos tratamentos $\mathrm{T}_{1}, \mathrm{~T}_{8}$ e $\mathrm{T}_{9}$.

Tomando por base o rendimento médio de grãos referente ao tratamento $\mathrm{T}_{9}$ (3.493 kg.ha ${ }^{-1}$ ), observa-se que os tratamentos $\mathrm{T}_{4}, \quad \mathrm{~T}_{5}, \quad \mathrm{~T}_{6} \quad$ e $\mathrm{T}_{7}$ apresentam estatisticamente iguais, indicando que existe diferentes possibilidades de se obter o mesmo rendimento de forma menos danosa ao ambiente. Como as quantidades de Co e Mo requeridas pelas plantas são pequenas, a sua aplicação via semente, através da inoculação, constitui-se na forma mais prática e eficaz de adubação (Vidor \& Peres, 1988).

O cultivo do solo no SSD por longo período estabilizou a acidez potencial, mantendo o pH do solo em torno de $5,3 \mathrm{mg}^{-\mathrm{dm}^{-3}}$, considerado excelente para o desenvolvimento da cultura do feijoeiro. 
Também foi observado aumento da CTC e sua correlação com o conteúdo de MO e saturação de bases do solo, suportando a afirmação de que o SSD por longo período passa ser importante prática no aumento da fertilidade dos solos.

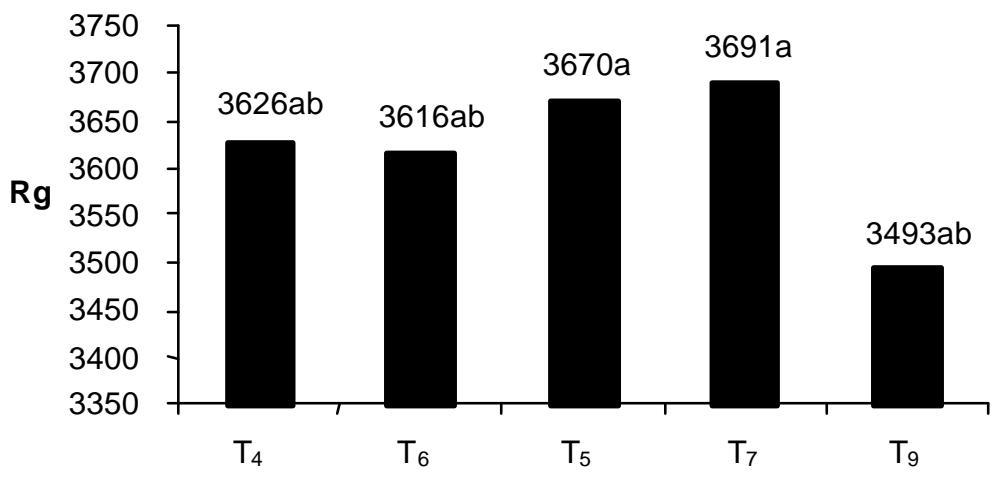

Figura 13 - Rendimento médio de grãos $\left(\mathrm{Rg}, \mathrm{kg}_{\mathrm{g}} \mathrm{ha}^{-1}\right)$ nos tratamentos $\mathrm{T}_{4}, \mathrm{~T}_{5}, \mathrm{~T}_{6}, \mathrm{~T}_{7}$ e $\mathrm{T}_{9}$.

\subsection{Análise econômica}

Na Tabela 9 e na Tabela 10 são apresentados os coeficientes técnicos e o custo total de produção discriminando os índices de lucratividade.

Tabela 9. Coeficientes técnicos (U, unidade.ha ${ }^{-1}$ ) de produção de feijão referentes aos diferentes tratamentos $\left(\mathrm{T}_{1}\right.$ a $\left.\mathrm{T}_{9}\right)$. Piracicaba, SP. Dezembro de 1999.

\begin{tabular}{ccccccccccc}
\hline Especificação & $\mathrm{U}$ & $\mathrm{T}_{1}$ & $\mathrm{~T}_{2}$ & $\mathrm{~T}_{3}$ & $\mathrm{~T}_{4}$ & $\mathrm{~T}_{5}$ & $\mathrm{~T}_{6}$ & $\mathrm{~T}_{7}$ & $\mathrm{~T}_{8}$ & $\mathrm{~T}_{9}$ \\
\hline Operação mecanizada & & & & & & & & & & \\
Conservação do solo & $\mathrm{hm}$ & 2,0 & 2,0 & 2,0 & 2,0 & 2,0 & 2,0 & 2,0 & 2,0 & 2,0 \\
Dessecação & $\mathrm{hm}$ & 2,4 & 2,4 & 2,4 & 2,4 & 2,4 & 2,4 & 2,4 & 2,4 & 2,4 \\
Semeadura direta & $\mathrm{hm}$ & 1,0 & 1,0 & 1,0 & 1,0 & 1,0 & 1,0 & 1,0 & 1,0 & 1,0 \\
Transporte interno & $\mathrm{hm}$ & 1,0 & 1,0 & 1,0 & 1,0 & 1,0 & 1,0 & 1,0 & 1,0 & 1,0 \\
Operação manual & & & & & & & & & & \\
Semeadura & $\mathrm{dh}$ & 1,28 & 1,28 & 1,28 & 1,28 & 1,28 & 1,28 & 1,28 & 1,28 & 1,28 \\
Tratamento de Semente e inoculação & $\mathrm{dh}$ & 1,0 & 1,0 & 1,0 & 1,0 & 1,0 & 1,0 & 1,0 & 1,0 & 1,0 \\
Seme & $\mathrm{dh}$ & 1,2 & 1,2 & 1,2 & 1,2 & 1,2 & 1,2 & 1,2 & 1,2 & 1,2 \\
Transporte interno & $\mathrm{dh}$ & 20 & 20 & 20 & 20 & 20 & 20 & 20 & 20 & 20 \\
Arranquio + Amontoa + Trilha & & & & & & & & & & \\
Insumo & $\mathrm{kg}$ & 50 & 50 & 50 & 50 & 50 & 50 & 50 & 50 & 50 \\
Cloreto de Potássio & $\mathrm{kg}$ & 60 & 60 & 60 & 60 & 60 & 60 & 60 & 60 & 60 \\
Superfosfato Simples & $\mathrm{kg}$ & - & - & 60 & - & 60 & - & 60 & 60 & 80 \\
Nitrato de Amônia & $\mathrm{L}$ & 1,6 & 1,6 & 1,6 & 1,6 & 1,6 & 1,6 & 1,6 & 1,6 & 1,6 \\
Inseticida & $\mathrm{L}$ & 3,25 & 3,25 & 3,25 & 3,25 & 3,25 & 3,25 & 3,25 & 3,25 & 3,25 \\
Herbicida & $\mathrm{L}$ & 2,0 & 2,0 & 2,0 & 2,0 & 2,0 & 2,0 & 2,0 & 2,0 & 2,0 \\
Fungicida & $\mathrm{kg}$ & 60 & 60 & 60 & 60 & 60 & 60 & 60 & 60 & 60 \\
Semente & $\mathrm{g}$ & - & 480 & 480 & - & - & 480 & 480 & - & -
\end{tabular}


Tabela 10. Custos unitário (CU, US\$.unidade ${ }^{-1}$ ) e total $\left(U S \$ \cdot h a^{-1}\right)$ de produção de feijão referentes aos diferentes tratamentos $\left(\mathrm{T}_{1}\right.$ a $\left.\mathrm{T}_{9}\right)$. Piracicaba, SP. Dezembro de 1999.

\begin{tabular}{|c|c|c|c|c|c|c|c|c|c|c|}
\hline Especificação & $\mathrm{CU}$ & $\mathrm{T}_{1}$ & $\mathrm{~T}_{2}$ & $\mathrm{~T}_{3}$ & $\mathrm{~T}_{4}$ & $\mathrm{~T}_{5}$ & $\mathrm{~T}_{6}$ & $\mathrm{~T}_{7}$ & $\mathrm{~T}_{8}$ & $\mathrm{~T}_{9}$ \\
\hline \multicolumn{11}{|l|}{ Operação mecanizada } \\
\hline Conservação do Solo & 10,00 & 20,00 & 20.00 & 20,00 & 20,00 & 20,00 & 20,00 & 20,00 & 20,00 & 20,00 \\
\hline Dessecação & 5,00 & 12,00 & 12,00 & 12,00 & 12,00 & 12,00 & 12,00 & 12,00 & 12,00 & 12,00 \\
\hline Semeadura direta & 5,00 & 5,0 & 5,0 & 5,0 & 5,0 & 5,0 & 5,0 & 5,0 & 5,0 & 5,0 \\
\hline Transporte interno & 3,00 & 3,00 & 3,00 & 3,00 & 3,00 & 3,00 & 3,00 & 3,00 & 3,00 & 3,00 \\
\hline SUBTOTAL 1 & - & 40,00 & 40,00 & 40,00 & 40,00 & 40,00 & 40,00 & 40,00 & 40,00 & 40,00 \\
\hline \multicolumn{11}{|l|}{ Operação manual } \\
\hline Tratamento sementes + inoculação & 1,50 & 1,92 & 1,92 & 1,92 & 1,92 & 1,92 & 1,92 & 1,92 & 1,92 & 1,92 \\
\hline Semeadura & 1,50 & 1,50 & 1,50 & 1,50 & 1,50 & 1,50 & 1,50 & 1,50 & 1,50 & 1,50 \\
\hline Transporte interno & 1,50 & 1,80 & 1,80 & 1,80 & 1,80 & 1,80 & 1,80 & 1,80 & 1,80 & 1,80 \\
\hline Arranquio + amontoa + trilha & 1,50 & 30,00 & 30,00 & 30,00 & 30,00 & 30,00 & 30,00 & 30,00 & 30,00 & 30,00 \\
\hline SUBTOTAL 2 & - & 35,22 & 35,22 & 35,22 & 35,22 & 35,22 & 35,22 & 35,22 & 35,22 & 35,22 \\
\hline \multicolumn{11}{|l|}{ Insumos } \\
\hline Cloreto de Potássio & 0,15 & 7,50 & 7,50 & 7,50 & 7,50 & 7,50 & 7,50 & 7,50 & 7,50 & 7,50 \\
\hline Superfosfato Simples & 0,20 & 12,00 & 12,00 & 12,00 & 12,00 & 12,00 & 12,00 & 12,00 & 12,00 & 12,00 \\
\hline Nitrato de Amônio & 0,25 & - & - & 15,00 & - & 15,00 & - & 15,00 & 15,00 & 20,00 \\
\hline Inseticida & 10,00 & 18,00 & 18,00 & 18,00 & 18,00 & 18,00 & 18,00 & 18,00 & 18,00 & 18,00 \\
\hline Herbicida & 12,00 & 39,00 & 39,00 & 39,00 & 39,00 & 39,00 & 39,00 & 39,00 & 39,00 & 39,00 \\
\hline Fungicida & 11,00 & 22,0 & 22,0 & 22,0 & 22,0 & 22,0 & 22,0 & 22,0 & 22,0 & 22,0 \\
\hline Sementes & 2,50 & 150,00 & 150,00 & 150,00 & 150,00 & 150,00 & 150,00 & 150,00 & 150,00 & 150,00 \\
\hline Rhizobium Phaseoly & 0,025 & - & 12,00 & 12,00 & . & - & 12,00 & 12,00 & 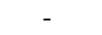 & 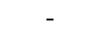 \\
\hline CO-MO98 & 0,04 & & - & - & 5,00 & 5,00 & 5,00 & 5,00 & - & - \\
\hline SUB-TOTAL 3 & - & 248,50 & 260,50 & 275,50 & 253,50 & 268,50 & 265,50 & 280,50 & 263,50 & 268,50 \\
\hline Custo operacional & - & 323,70 & 335,70 & 350,72 & 328,72 & 343,72 & 340,72 & 355,72 & 338,72 & 343,72 \\
\hline Depreciação & - & 15,00 & 15,00 & 15,00 & 15,00 & 15,00 & 15,00 & 15,00 & 15,00 & 15,00 \\
\hline CESSR & - & 39,29 & 37,58 & 42,64 & 46,53 & 47,10 & 46,41 & 47,37 & 40,98 & 44,88 \\
\hline Encargos financeiros & - & 9,71 & 10,07 & 10,52 & 9,86 & 10,31 & 10,22 & 10,67 & 10,16 & 10,31 \\
\hline Irrigação & - & 850,00 & 850,00 & 850,00 & 850,00 & 850,00 & 850,00 & 850,00 & 850,00 & 850,00 \\
\hline Arrendamento da Terra & & 100,00 & 100,00 & 100,00 & 100,00 & 100,00 & 100,00 & 100,00 & 100,00 & 100,00 \\
\hline Custo Total & - & 1337 & 1348 & 1368 & 1349 & 1366 & 1362 & 1378 & 1354 & 1363 \\
\hline
\end{tabular}

A matriz de coeficientes técnicos de produção (Tabela 9) mostra as exigências físicas dos fatores de produção. Observa-se que o $\mathrm{CO}$ varia de acordo com os tratamentos utilizado, porém não se altera com a produção obtida. A maior variação é encontrada no CT (Tabela 10), pois nele está embutido os custos, a CESSR, que varia com receita obtida, que por sua vez varia com a produção obtida.

Os dados apresentados na Tabela 10 mostram que o CO têm valores diferenciados, devido à variação na forma de disponibilizar nitrogênio para a planta, já que o custo com mão-de-obra, operação de máquinas, adubação potássica e adubação fosfatada não variam em função da produção obtida. A produção sazonal e o mercado restrito, com safra e entressafra bem definidas, acaba influindo na variação de preços. A 
Figura 14 ilustra o comportamento dos preços recebido pelo produtor, onde se observa a sazonalidade dos mesmos.

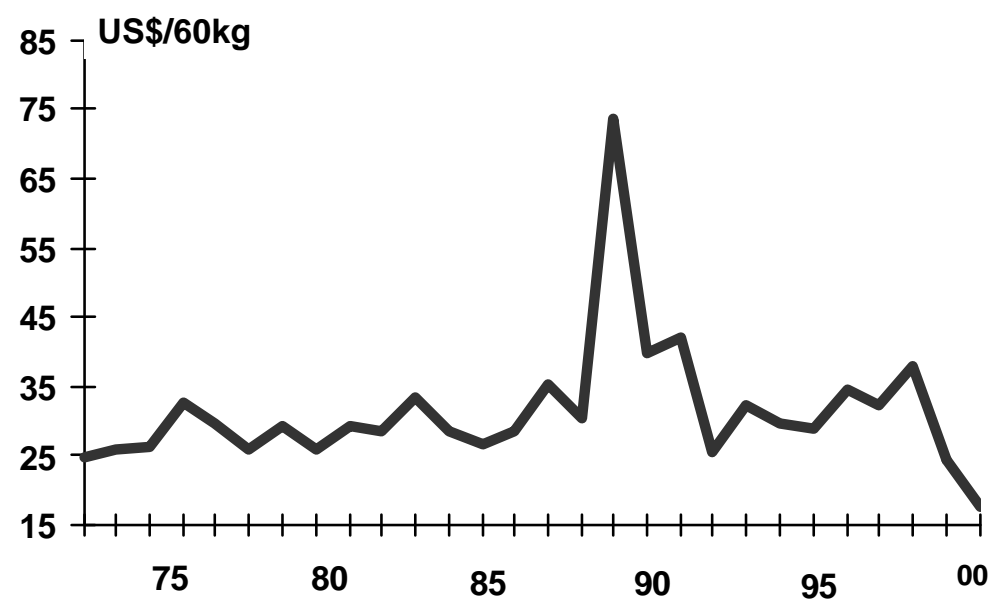

Figura 14 - Variação temporal de preço do saco de feijão (Brandalizze Consulting, 2000 - Informação pessoal).

A inoculação de sementes com o intuito de disponibilizar nitrogênio dentro do SSD foi o fator que mais influenciou nos tratamentos e no rendimento de grãos.

Considerando que para um mesmo conjunto de coeficientes técnicos, porém com diferentes maneiras de disponibilizar nitrogênio para a cultura, acarretou grande variação no rendimento de grãos e nos austos. Os índices de lucratividade dos tratamentos estão ilustrados na Tabela 11.

Nota-se que o aumento no rendimento, tem-se um aumento na receita líquida e que a eficiência no processo de produção é recompensada no resultado econômico da atividade.

Analisando-se a receita líquida da atividade nos diferentes sistemas, observa-se que o tratamento $T_{1}$, sem adubação nitrogenada e sem inoculação, a produção foi de $3062 \mathrm{~kg} \cdot \mathrm{ha}^{-1}$ e o IL foi de $24,67 \%$, só superando o tratamento $\mathrm{T}_{2}$, que teve $20,61 \%$ de lucratividade.

Isso indica que somente o SSD, sem incrementar a disponibilidade de nitrogênio para a cultura, não foi suficiente para manter alto rendimento e lucratividade. 
Assim como também, a inoculação da semente somente com RL não foi capaz de apresentar alto rendimento e lucratividade, devido a extrema competição com as estirpes nativas presentes na área. Considerando ser esta a menor produção para o conjunto de fatores de produção utilizado, é portanto, inviável produzir em patamares tão baixos. A relação entre o IL e os melhores rendimentos não é linear.

Tabela 11. Rendimento de grãos $\left(\mathrm{Rg}, \mathrm{kg} \mathrm{ha}^{-1}\right)$, preço $\left(\mathrm{Pr}, \mathrm{US} \$ . \mathrm{kg}^{-1}\right)$, receita bruta $(\mathrm{RB}$, US\$.ha ${ }^{-1}$ ), custo total (CT, US\$.ha ${ }^{-1}$ ), receita líquida (RL, US\$.ha $\left.{ }^{-1}\right)$, índice de lucratividade (IL, \%), da cultura de feijão conduzidos em todos os tratamentos. Piracicaba, SP. Dezembro de 1999.

\begin{tabular}{ccccccc}
\hline Rg & Tratamento & $\operatorname{Pr}^{1}$ & RB & CT & RL & IL \\
\hline 3.062 & $\mathrm{~T}_{1}$ & 0,58 & 1.775 & 1.337 & 438 & $24,67(8)$ \\
2.928 & $\mathrm{~T}_{2}$ & 0,58 & 1.698 & 1.348 & 350 & $20,61(9)$ \\
3.322 & $\mathrm{~T}_{3}$ & 0,58 & 1.926 & 1.368 & 558 & $28,97(6)$ \\
3.626 & $\mathrm{~T}_{4}$ & 0,58 & 2.103 & 1.349 & 754 & $35,85(1)$ \\
3.670 & $\mathrm{~T}_{5}$ & 0,58 & 2.128 & 1.366 & 762 & $35,80(2)$ \\
3.616 & $\mathrm{~T}_{6}$ & 0,58 & 2.097 & 1.362 & 735 & $35,05(4)$ \\
3.691 & $\mathrm{~T}_{7}$ & 0,58 & 2.140 & 1.378 & 762 & $35,60(3)$ \\
3.193 & $\mathrm{~T}_{8}$ & 0,58 & 1.851 & 1.354 & 497 & $26,85(7)$ \\
3.493 & $\mathrm{~T}_{9}$ & 0,58 & 2.025 & 1.363 & 662 & $32,69(5)$ \\
\hline
\end{tabular}

${ }^{1}$ Cotação do dólar R $\$ 1,94 / \mathrm{US} \$ 1.00$

Maior rendimento não significa maior IL. Isso explica-se, devido cada tratamento usar diferente produto na inoculação da semente, o que acarreta um maior ou menor custo. Os melhores rendimentos foram encontrados nos tratamentos $\mathrm{T}_{7}, \mathrm{~T}_{5}, \mathrm{~T}_{4}, \mathrm{~T}_{6} \mathrm{e} \mathrm{T}_{9}$ em ordem decrescente, respectivamente.

Os índices de lucratividade porém estão na seguinte ordem $\mathrm{T}_{4}(35,85 \%), \mathrm{T}_{5}$ $(35,80 \%), \mathrm{T}_{7}(35,60 \%), \mathrm{T}_{6}(35,05 \%)$ e $\mathrm{T}_{9}(32,69 \%)$. Destaca-se que nos tratamentos $\mathrm{T}_{4}$ (semente inoculada com Co e Mo) e $\mathrm{T}_{6}(\mathrm{Co}$, Mo Rhizobium) a produção foi praticamente a mesma, indicando uma estabilidade do sistema. $\mathrm{O}$ tratamento $\mathrm{T}_{5}$ (semente inoculada com Co e Mo, e adubação nitrogenada em cobertura) produziu $3.670 \mathrm{~kg} \cdot \mathrm{ha}^{-1}$.

Entretanto quando a semente foi noculada com Co e Mo, Rhizobium e recebeu adubação nitrogenada em cobertura $\left(\mathrm{T}_{7}\right)$, houve incremento no rendimento de grãos da

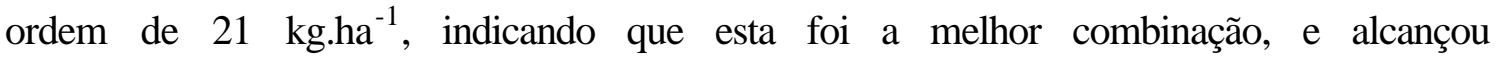


produtividade máxima para a variedade cultivada estudada. A boa produção encontrada no SC ( $\left.\mathrm{T}_{9}\right)$ é justificada pela aplicação de nitrogênio mineral na semeadura e em cobertura, com boa resposta do feijão a adubação nitrogenada. Entretanto sua adoção não se justificaria, pelo IL apresentado, e pela possibilidade de se alcançar produção superior com métodos alternativos de adubação. O custo de produção mostra também que o comportamento dos preços pode influenciar na receita final, assim o preço de US\$ $0,58 . \mathrm{kg}^{-1}$, utilizado como parâmetro de comercialização, estava vigente na época (Molina, 1971). Pode-se então, a partir daí, em função do preço e da produção esperada, fazer portanto, uma análise antes de se iniciar a atividade.

A lucratividade para $\mathrm{T}_{4}(35,85 \%), \mathrm{T}_{5}(35,80 \%), \mathrm{T}_{7}(35,60 \%)$ e $\mathrm{T}_{6}(35,05 \%)$, em nível de produtor é bastante satisfatória, permitindo investir na atividade. Nas condições em que foi desenvolvido o presente trabalho, a produção de grãos de feijão comum (Phaseolus vulgaris L.), irrigado e conduzido SSD, revelou melhores índices de lucratividade quando as sementes foram inoculadas com Co e Mo ( $\left.\mathrm{T}_{4}\right)$, Co e Mo mais adubação nitrogenada em cobertura $\left(\mathrm{T}_{5}\right)$, Co e Mo, Rhizobium leguminosarum bv. phaseoly e adubação nitrogenada em cobertura $\left(\mathrm{T}_{7}\right)$, Co, Mo e Rhizobium leguminosarum bv. phaseoly ( $\left.\mathrm{T}_{6}\right)$, cujo IL foi de 35,85\%, 35,80\%, 35,60\% e 35,05\%, respectivamente.

A utilização da matriz de coeficientes técnicos, a análise do custo de produção e da receita, e o índice de rendimento são ferramentas que possibilitam a realização de uma criteriosa análise técnica e econômica antes de investir na atividade. 


\section{CONCLUSÕES}

Pela evidência dos resultados alcançados, conclui-se que: (a) a inoculação de sementes imediatamente antes da semeadura com Co, Mo (116 g.ha $\left.{ }^{-1}\right)$ e Rhizobium leguminosarum bv. Phaseoly (400 g por $50 \mathrm{~kg}$ de sementes), e adubação nitrogenada em cobertura $\left(60 \mathrm{~kg} \cdot \mathrm{ha}^{-1}\right.$ de $\left.\mathrm{N}\right)$, alcançou a melhor produtividade para a variedade cultivada estudada (3.691 kg.ha ${ }^{-1}$ ), e se constitui numa alternativa no sentido de disponibilizar nitrogênio para a cultura de feijão comum (Phaseolus vulgaris L.) dentro do sistema de semeadura direta; (b) a adubação nitrogenada na semeadura inibiu a nodulação com rizóbios (nativos e/ou inoculados), e quando aplicado em cobertura aumentou a produtividade; (c) o sistema de semeadura direta foi ficiente na manutenção do teor de matéria orgânica no solo, mas não foi para suprir totalmente a demanda da planta por nitrogênio, evidenciando a necessidade de adotar métodos alternativos para incrementar a disponibilidade de nitrogênio, a qual pode ser através da inoculação conjugada da semente com Co, Mo e rizóbio, específico para a cultura de feijão; (d) dentre os sistemas testados, a inoculação de sementes com Co, Mo e Rhizobium leguminosarum bv. phaseoly imediatamente antes da semeadura pode possibilitar a não utilização de nitrogênio em cobertura; (e) a quantidade total de nitrogênio fixada na planta está mais relacionada à dependência de sua demanda por $\mathrm{N}$ do que à capacidade do rizóbio em fixar nitrogênio; e (f) a prática da inoculação da semente com Co, Mo e rizóbio, quando comparada à aplicação de $\mathrm{N}$ na semeadura e em cobertura, propicia aumento na produtividade de grãos e na lucratividade; além de possibilitar não poluir o ambiente. 


\section{REFERÊNCIAS BIBLIOGRÁFICAS}

ADAMS, J.F.; BURMESTER, C.H.; MITCHELL, C.C. Long term fertility treatments: molybdenum availability. Fertilizer Research, v.21, p.167-170, 1990.

ADAMS, M.W.; WIERMSA, J.V.; SALAZAR, J. Differences in starch accumulation among dry bean cultivars. Crop Science, v.18, p.155-157, 1978.

ALVAREZ, R.; DÍAZ, R.A.; BARBERO, N.; SANTANATOGLIA, O.J.; BLOTTA, L. Soil organic carbon, microbial biomass and $\mathrm{CO}_{2}-\mathrm{C}$ production from three tillage systems. Soil and Tillage Research, v.33, p.17-28, 1995.

AMANE, M.V.I.; VIEIRA, C.; CARDOSO, A.A.; ARAÚJO, G.A. Resposta de cultivares de feijão (Phaseolus vulgaris L.) às adubações nitrogenadas e molibdicas. Revista Ceres, v.41, n.234, p.202-216, 1994.

AMBROSANO, E.J.; TANAKA, R.T.; MASCARENHAS, H.A.A.; RAIJ. B. van; QUAGGIO, J.A.; CANTARELlA, H. Leguminosas e oleaginosas. In: RAIJ, B. van; CANTARELLA, H.; QUAGGIO, J.A.; FURLANI A.M.C. (Ed.) Recomendações de adubação e calagem para o Estado de São Paulo. 2.ed. Campinas: Instituto Agronômico; Fundação IAC, 1996. p.187-199.

BATAGLIA, O.C.; FURLANI, P.R.; VALADARES, J.M.A.S. O molibdênio em solos do Estado de São Paulo. In: CONGRESSO BRASILEIRO DE CIÊNCIA DO SOLO, 15., Campinas, 1975. Anais. Campinas: Sociedade Brasileira de Ciência do Solo, 1975. p.107-117.

BECK, D.P.; WERY, J.; SAXENA, M.C.; AYADI, A. Dinitrogen fixation; nitrogen balance in cool-season food legumes. Agronomy Journal, v.83, p.334-341, 1991.

BECKER, M.; LADHA, J.K.; ALI, M. Green manure technology -- potential, usage; limitations - a case study for lowland rice. Plant and Soil, v.174, p.181- 194, 1995. 
BERGER, P.G.; VIEIRA, C.; ARAÚJO, G.A.A. de. Efeitos de doses e épocas de aplicação do molibdênio sobre a cultura de feijão. Pesquisa Agropecuária Brasileira, v.31, n.7, p.473-480, 1996.

BEVERLY, R.B.; JARRELL, W.M. Cowpea responses to $\mathrm{N}$ form, rate and timing of application. Agronomy Journal, v.76, p.663-668, 1984.

BLEVINS, R. L.; THOMAS, G.W.; CORNELLIUS, P.L. Influence of no-tillage; nitrogen fertilization on certain soil properties after 5 years of continuous corn. Agronomy Journal, v.69, p.383-386, 1977.

BLISS, F.A. Breeding common bean for improved biological nitrogen fixation. Plant and Soil, v.152, p.71-79, 1993.

BLISS, F.A.; HARDARSON, G. Enhancement of biological nitrogen fixation of common bean in Latin America. Dordrecht: Kluwer Academic, 1993. 160 p.

BLISS, F.A.; MILLER JUNIOR., J.C. Selecting; breeding grain legumes for enhanced nitrogen fixation. In: SUMMERFIELD, R.J. (Ed.) World crops: cool season food legumes. London: Kluwer Academic, 1988. p.1001- 1012.

BOCK, B.R.; HERBERT, G.W. Fertilizer nitrogen management. In:. FOLLETI R.F, KEENEY D.R., CRUSE R.M (Ed.) Managing nitrogen for groundwater quality; farm profitability. Madison: Soil Science Society of America, 1991. p.139-164.

BODDEY, R.M.; SA, J.C.; DE, M., BRUNO, J.; ALVES, R.; URQUIAGA, S. The contribution of biological nitrogen fixation for sustainable agricultural systems in the tropics. Soil Biology and Biochemistry, v.29, p.787- 799, 1997.

BREMER, E.; VAN KESSEL, C.; NELSON, L.; RENNIE, R.J.; RENNIE, D.A. Selection of Rhizobium leguminsosarum strains for lentil under growth room: field conditions. Plant and Soil, v.121, p.47- 56, 1990.

BROCKWELL, J.; BOTTOMLEY, P.J. Recent advances in inoculant technology: prospects for the future. Soil Biology and Biochemistry, v.27, p.683-697, 1995.

BROCKWELL, J.; BOTTOMLEY, P.J.; THIES, J.E. Manipulation or rhizobia microflora for improving legume productivity soil fertility: a critical assessment. Plant and Soil, v.174, p.143- 180, 1995. 
BROCKWELL, J.; DIATLOFF, A.; ROUGHLEY, R.J.; DATE, R.A. Selection of Rhizobium for inoculants. In: VINCENT, J.M. (Ed.). Nitrogen fixation in legumes. New York: Academic Press, 1982. p.173-189.

BURMESTER, C.H.; ADAMS, J.F.; ODOM, J.W. Response of soybean to liming; molibdenum on Utisols in Northern Alabama. Soil Science Society of America Journal, v.52, p.1391-1394, 1988.

CARTER, J.M.; TIEMAN, J.S.; GIBSON, A.H. Competitiveness; persistence of strains of rhizobia for fababean in acid; alkaline soils. Soil Biology and Biochemistry, v.27, p.617- 623, 1995.

CENTRO INTERNACIONAL DE AGRICULTURA TROPICAL. Annual report of the bean production program. Cali, 1978. 75p.

CENTRO INTERNACIONAL DE AGRICULTURA TROPICAL. Sistemas de produccion de frijol. Cali, 1975. 64p.

CENTRO INTERNACIONAL DE AGRICULTURA TROPICAL. Sistemas de produccion de frijol. Cali, 1976. 91p.

CHEN, Z:; MACKENZIE, A.F.; FABNOUS, M.A. Soybean nodulation; grain yield as influences by $\mathrm{N}$-fertilizer rate, plant population density; cultivar in southern Quebec. Canadian Journal of Plant Science, v.72, p.1049- 1056, 1992.

DE MOOY, C.J.; PESEK, J.; SPALDON, E. Mineral nutrition. In: CALDWELL, B.E., (Ed.) Soybeans: improvement, production and uses. Madison: American Society of Agronomy, 1973. p. 267-334.

DERPERSCH, R.; SIDIRAS, N.; ROTH, C. H. Results of studies made from 1977 to 1984 to control erosion by cover crops; no-tillage techniques in Paraná, Brazil. Soil Tillage Research, v.8, p.253-263, 1986.

DIAZ-ROMEU, R.; BALERDI, F.; FASSENBER, H.W. Contenido de matéria orgânica y nitrogênio en suelos de América Central. Turrialba, v.20, p.185-192, 1970.

DÖBEREINER, J.; DUQUE, F.F. Contribuição da pesquisa em fixação biológica do nitrogênio para o desenvolvimento do Brasil. In: CURSO SOBRE FIXAÇÃO BIOLÓGICA DO NITROGÊNIO, 3., Rio de Janeiro: 23p. (Mimeografado), 1980 
DURAND, J.L., SHEEHY, J.E., MINCHIN, F.R. Nitrogenase activity, photosynthesis, nodule water potential in soybean plants experiencing water deprivation. Journal of Experimental Botany, v.38, p.311-321, 1987.

EAGLESHAM, A.R.J.; HASSOUNA, S.; SEEGERS, R. Fertilizer-N effects on $\mathrm{N}_{2}$ fixation by cowpea; soybean. Agronomy Journal, v.75, p.61- 66, 1983.

ENDO, R.M. Efeito de inoculação, de nitrogênio mineral e fornecimento de micronutrientes, sobre a cultura do feijoeiro (Phaseolus vulgaris L.) de inverno, cultivar Carioca-80. Jaboticabal, 1986. 48p. Dissertação (Mestrado) - Faculdade de Ciências Agrárias e Veterinárias, Universidade Estadual Paulista "Júlio de Mesquita Filho."

FANCELLI, A.L.; DOURADO NETO, D. Feijão irrigado: estratégicas básicas de manejo. Piracicaba: Agropecuária,1999. p.108-125: Manejo da fertilidade do solo na cultura de feijão irrigado.

FAO QUARTERLY BULLETIN OF STATISTICS. Rome, v.5, 121p. 1992.

FERREIRA, A.N; ARF, O.; CARVALHO, M.A.C.; ARAÚJO, R.; SÁ, M.E.; BUZETTI, S. Estirpes de Rhizobium tropici na inoculação do feijoeiro. Scientia Agricola, v.57, n.3, p.507-512, 2000.

FERREIRA, M.C.; ANDRADE, D.S.; CHUEIRE, L.M.; TAKEMURA, S.M.; HUNGRIA, M. Tillage method; crop rotation effects on the population sizes, diversity of bradyrhizobia nodulating soybean. Soil Biology and Biochemistry, v.32, p. 627-637, 1999.

FRED, E.B., BALDWIN, I.L., MCCOY, E. Root nodule bacteria and leguminous plants. Wisconsin: University of Wisconsin, 1932.343p.

FREIRE, J.R.J.; KOLLING, J. Alguns tópicos sobre o manejo para a maximização do $\mathrm{N}_{2}$ pela simbiose Rhizobium-leguminosas. In: REUNIÃO LATINO AMERICANA DE Rhizobium, 12.,Campinas, 1986. Anais. Campinas: Instituto Agronômico, 1986. p.461-481. 
FRIZZONE, J.A.; CASSIANO SOBRINHO, F.; SÁ, M.E.; BUZETTI, S. Efeito da irrigação e da adubação fosfatada sobre a produção de feijão Phaseolus vulgaris L.). In: REUNIÃO NACIONAL DE PESQUISA DE FEIJÃO, 1., Goiânia, 1982. Anais. Goiânia: EMBRAPA, CNPAF, 1982. p.169-172.

GENTRY, H.S. Origin of the common bean (Phaseolus vulgaris L.). Economic Botany, v.22, p.55-69, 1969.

GEORGE, T.; SINGLETON, P.W. Nitrogen assimilation traits; dinitrogen fixation in soybean and common bean. Agronomy Journal, v.84, p.1020- 1028, 1992.

GEPTS, P; KMIECIK, K.; PEREIRA, P.A.A.; BLISS, F.A. Dissemination pathways of common bean (P. vulgaris L. ) deduced form phaseolin electrophoretic variability I. The Americas. Economic Botany, v.42, p.73-85, 1988.

GOMES, F.P. Curso de estatística experimental. Piracicaba: ESALQ, 1976. 430p.

GRAHAM, P.H. Some problems of nodulation; symbiotic nitrogen fixation in Phaseolus vulgaris L.: a review. Field Crops Research, v.4, p.93- 112, 1981.

GRAHAM, P.H.; HALLIDAY, J. Inoculation; nitrogen fixation in the gender Phaseolus. In: REUNIAO LATINO-AMERICANA DE Rhizobium, 8., Cali, 1976. Anais. Cali: CIAT, 1976. p.313-337.

GRAHAM, P.H.; ROSAS, J.C. Growth and development of indeterminate bush and climbing cultivars of Phaseolus vulgaris L. inoculated with Rhizobium. Journal of Agricultural Science, v.88, p.503-508, 1977.

GRAHAM, P.H.; TEMPLE, S.R. Selection for improved nitrogen fixation in Glycine $\max$ (L.) Merr.; Phaseolus vulgaris L. Plant and Soil, v.82, p.315- 327, 1984.

GURLEY, W.H.; GIDDENS, S. Factors affecting uptake, yield response; carryover molybdenum in soybean seed. Agronomy Journal, v.61, p.7-9, 1969.

HALL, A.; CLARK, N. Coping with change, complexity; diversity in agriculture -- the case of rhizobial inoculants in Thailand. World Development, v.23, p.1601-1614, 1995. 
HANSEN, A.P.; YONEYAMA, T.; KOUCHI, H.; MARTIN, P. Respiration; nitrogen fixation of hydroponically cultured Phaseolus vulgaris L., cv. OAC Rico; supernodulating mutant. I. Growth, mineral composition and effect of sink removal. Plant and soil, v.189, p.538-545, 1993.

HARDARSON, G.; ZAPATA, F.; DANSO, K.S.A. Effect of plant genotype; nitrogen fertilizer on symbiotic nitrogen fixation by soybean cultivars. Plant and Soil, v.82, p.397-405, 1984.

HERRIDGE, D.F.; BROCKWELL, J. Contributions of fixed nitrogen; soil nitrate to the nitrogen economy of irrigated soybean. Soil Biology and Biochemistry, v.20, p.711-717, 1988.

HERRIDGE, D.F.; ROSE, I.A. Heritability; repeatability of enhanced $\mathrm{N}_{2}$ fixation in early; late inbreeding generations of soybean. Crop Science, v.34, p.360-367, 1994.

HOBBS, S.L.A.; MAHON, J.D. Effects of pea (Pisum sativum) genotypes; Rhizobium leguminosarum strains on $\mathrm{N}_{2}\left(\mathrm{C}_{2} \mathrm{H}_{2}\right)$ fixation; growth. Canadian Journal of Botany, v.60, p.2594-2600, 1982.

HODGSON, J.F. Micronutrientes in soils. Advances in Agronomy, v.15, p.119-154, 1963.

HUGHES, R.M.; HERRIDGE, D.F. Effect of tillage on yield, nodulation; nitrogen fixation of soybean in far north-coastal New South Wales. Australian Journal of Experimental Agriculture, v.29, p.671-677, 1989.

HUNGRIA, M., VARGAS, M. A. T. Environmental factors affecting $\mathrm{N}_{2}$ fixation in grain legumes in the tropics, with an emphasis on Brazil. Field Crops Research, v.65, p.151-164, 1999.

HUNGRIA, M.; RUSCHEL, A.P. Atividade da nitrogenase e evolução do hidrogênio pelos nódulos de Phaseolus vulgaris L. Fertilizer Research, v.11, p.269-274, 1987.

IMSANDE, J. Agronomic characteristics that identify high yield, high protein soybean genotypes. Agronomy Journal, v.84, p.409-414, 1992.

IMSANDE, J. Rapid dinitrogen fixation during soybean pod fill enhances net photosynthetic output; seed yield: a new perspective. Agronomy Journal, v.81, p.549-556, 1989. 
IMSANDE, J.; EDWARDS, D.G. Decreased rates of nitrate uptake during pod fill by cowpea, green gram; soybean. Agronomy Journal, v.80, p.789- 793, 1988.

INSTITUTO BRASILEIRO DE GEOGRAFIA E ESTATISTICA. Levantamento Sistemático da Produção Agrícola: pesquisa mensal de previsão e acompanhamento das safras agrícolas no ano civil. Rio de Janeiro: Fundação Instituto Brasileiro de Geografia e Estatística, 1997. 70p.

JENSEN, E.S. Seasonal patterns of growth and nitrogen fixation in field-grown pea. Plant and Soil, 101, p.29- 37, 1987.

JORDAN, D.C. Family III. Rhizobiaceae Conn, 1938, 32AL. In: KRIEG, N.R.; HOLT, J.G. (Ed.). Bergej's manual of systematic bacteriology. London: Williane and Williana, 1984.,v.1. p.234-256.

KAPLAN, L. Archeology; domestication in American Phaseolus (Bean). Economic Botany, v.19, p.358-368, 1965.

KEMPER, B.; DERPERSCH, R. Results of studies made in; to control erosion by covers crops; no-till tillage techniques in Paraná, Brazil. Soil and Tillage Research, p.253$267,1981$.

KINSELLA, J. Improving soil, water; air quality with no-tillage. In: CONGRESSO NACIONAL DE AAPRESID, 5., Mar del Plata, 1997. Annals. AAPRESID,1997. p.91-93.

LAFOND, G.P.; LOEPPKY, H.; DERKSEN, D.A. The effects of tillage systems; crop rotations on soil water conservation, seeding establishment; crop yield. Canadian Journal of Plant Science, v.72, p.103- 105, 1992.

LANTMANN, A.F.; CAMPO, RJ.; SFREDO, G.J.; BORKERT, C.M. Micronutrientes para a cultura da soja no Estado do Paraná: zinco e molibdênio. Londrina: EMBRAPA Soja, 1985. 8p. (Comunicado Técnico).

LAWN, R. J.; BRUN, W. A. Symbiotic nitrogen fixation in soybeans. I. Effect of photosynthetic source sink manipulations. Crop Science, v.14, p.11-16, 1974.

LEEPER, G. W. Six trace elements in soils. Melbourne: Melbourne University, 1970. p.53-59. 
LIPS, S.A.; MARSHALL, J.G.; SLOANE, L.W.; MELVILLE, D.R.; RABB, J.L. Molybdenum investigation with soybeans in Louisiana. Louisiana: Louisiana State University, 1973. 39p. (Bulletin 670).

MAIER, R.J.; TRIPLETT, E.W. Toward more productive, efficient and competitive nitrogen-fixing symbiotic bacteria. Plant Science, v.15, p.191- 234, 1996.

MALAVOLTA, E. Nutrição e adubação. In: SIMPÓSIO BRASILEIRO DO FEIJÃO, 1., Viçosa, 1972. Anais. Viçosa: UFV, 1972. p.211-242.

MALAVOLTA, E.; LIMA FILHO, O.F. Nutrição e adubação do feijoeiro. In FANCELLI, A.L.; DOURADO NETO, D. (Ed.) Tecnologia da produção de feijão irrigado. Piracicaba: ESALQ, 1997. p.22-51.

MALAVOLTA, E.; VITTI, G.C.; OLIVEIRA, S.A. Metodologia para análise de elementos em material vegetal. In: Avaliação do estado nutricional das plantas: princípios e aplicações. Piracicaba: POTAFOS, 1989. p.135-189.

MARTIN, N.B. Custos: sistema de custo de produção agrícola. Informações Econômicas, v.24, n.9, p.98-122, 1994.

MATSUNAGA, M.; BEELMANS, P.F.; TOLEDO, P.E.N.; DULLEY, R.D.; OKAWA, H; PEDROSO, I.A. Metodologia de custo de produção utilizada pelo IEA. Agricultura em São Paulo, v.23, n.1, p.123-139. 1976.

MATUS, A.; DERKSEN, D.A.; WALLEY, F.L.; LOEPPKY, H.A.; VAN KESSEL, C. The influence of tillage and crop rotation on nitrogen fixation in lentil and pea. Canadian Journal of Plant Science, v.77, p.197- 200, 1997.

MCCOWN, R.L. Being realistic about no tillage, legume farming for the Australian semi-arid tropics. Australian Journal of Experimental Agriculture, v.36, p.1069- 1080, 1996. 
MENDES, L.C.; VARGAS, M.A.T.; HUNGRIA, M. Adubação nitrogenada e inoculação do feijoeiro em solo dos cerrados. In: REUNIÃO BRASILEIRA DE FERTILIDADE DO SOLO E NUTRIÇÃO DE PLANTAS, 23; REUNIÃO BRASILEIRA SOBRE MICORRIZAS, 7; SIMPÓSIO BRASILEIRO DE MICROBIOLOGIA DO SOLO, 5.; REUNIÃO BRASILEIRA DE BIOLOGIA DO SOLO, 2., Caxambu, 1998. Resumos. Lavras: Universidade Federal de Lavras, 1998. p.202.

MENDONÇA, L.F.; MARQUES, E.M.G.; ARAÚJO, R.S. Resposta do feijoeiro a cinco estirpes e rizóbio e à adubação nitrogenada no estado do Espírito Santo. In: REUNIÃO BRASILEIRA DE FERTILIDADE DO SOLO E NUTRIÇÃO DE PLANTAS, 23.; REUNIÃO BRASILEIRA SOBRE MICORRIZAS, 7.; SIMPÓSIO BRASILEIRO DE MICROBIOLOGIA DO SOLO, 5.; REUNIÃO BRASILEIRA DE BIOLOGIA DO SOLO, 2., Caxambu, 1998. Resumos. Lavras: Universidade Federal de Lavras, 1998. p.200.

MENGEL, K. Symbiotic dinitrogen fixation: its dependence on plant nutrition and its ecophysiological impact. Bodenk, v.157, p.233- 241, 1994.

MOLINA FILHO, J. Amostragem por área para estudos sócio-econômico. Piracicaba: ESALQ, 1971. 23p. (Séries Estudos, 11).

MONDARDO, A. Resultados de pesquisa. In: ENCONTRO NACIONAL DE PESQUISA SOBRE CONSERVAÇÃO DO SOLO, Passo Fundo, 1978. Anais. Passo Fundo: EMPRAPA Trigo, 1978. p.249-252.

MORRISON, S.L.; BAIRD, L.M. Relationship of plant development to nodulation um determinate; indeterminate beans. Horticultural Science, v.112, p.510-513, 1987.

MYTTON, L.R. Developing a breeding strategy to exploit quantitative variation in symbiotic nitrogen fixation. Plant and Soil, v.82, p.329-335, 1984.

NUTMAN, P.S. Genetics of symbosis and nitrogen fixation in legumes. Proceedings Royal Society, v.127, p.417-437, 1969.

NUTMAN, P.S. Hereditary host factors affecting nodulation and nitrogen fixation. In: GIBSON, A.H.; NORTON, W.E. (Ed.). Current perspectives in nitrogen fixation. Camberra: Australian Academy of Science, 1981. p.194-204. 
PACOVSKY, R.S.; BAYNE, H.G.; BETHLENFALVAY, G.L. Symbiotic interactions between strains of Rhizobium phaseoly and cultivars of Phaseolus vulgaris L. Crop Science, v.24, p.101-105, 1984.

PARKER, M.B.; HARRIS, H.B. Yield and leaf nitrogen of nodulating soybeans as affected by nitrogen and molybdenum. Agronomy Journal, v.69, p.551-554, 1977.

PAVAN, M.A.; BINGHAM, F.T.; PRATT, P.F. Chemical and mineralogical characteristics of selected acid soils of the State of Paraná, Brazil. Turrialba, v.35, p.131-139, 1985.

PEOPLES, M.B.; CRASWELL, E.T. Biological nitrogen fixation: Investments, expectations and actual contributions to agriculture. Plant and Soil, v.141, p.13-39, 1992.

PEOPLES, M.B.; HERRIDGE, D.F. Nitrogen fixation by legumes in tropical and subtropical agriculture. Advances in Agronomy, v.44, p.155-223, 1990.

PEOPLES, M.B.; HERRIDGE, D.F.; LADHA, J.K. Biological nitrogen fixation: An efficient source of nitrogen for sustainable agricultural production. Plant and Soil, v.174, p.3-28, 1995a.

PEOPLES, M.B.; LADHA, J.K.; HERRIDGE, D.F. Enhancing legume $\mathrm{N}_{2}$ fixation through plant and soil management. Plant and Soil, v.174, p.83-101, 1995b.

PEREIRA, P.A.A. Evidências de domesticação e disseminação do feijoeiro comum e conseqüências para o melhoramento genético da espécie. Pesquisa Agropecuária Brasileira, v.25, p.19-23, 1990.

PEREIRA, P.A.A.; BLISS, F.A. Nitrogen fixation; plant growth of common bean (Phaseolus vulgaris L.) at different levels of phosphorus availability. Plant and Soil, v.104, p.79-84, 1987.

PIHA, M.I.; MUNNS, D.N. Nitrogen fixation potential of beans (Phaseolus vulgaris L.) compared with other grain legumes under controlled conditions. Plant and Soil, v.98, p.169-182, 1987. 
POLIDORO, J.C.; TEIXEIRA, P.C.; DEUS, M.A.T.; URQUIAGA, S.; ALVES, B.J.R. Avaliação da nutrição molíbdica e suas interações com o fósforo e nitrogênio no crescimento de plantas de feijoeiro (Phaseolus vulgaris L.) inoculadas com Rhizobium. In: FERTBIO 98, Caxambu, 1998. Anais. Caxambu, 1998. v.1, p.741.

POWLSON, D.S.; JENKINSON, D.S. A comparison of organic matter, biomass, adenosine triphosfate; minerazable nitrogen contents of plowed and direct drilled soils. Journal of Agricultural Sciences, v.97, p.713-721, 1981.

RAVURI, V.; HUME, D.J. Soybean stover nitrogen affected by dinitrogen fixation and cultivar. Agronomy Journal, v.85, p.328- 333, 1993.

REDDEN, R.J.; DIATLOFF, A.; USHER, T. Field screening accessions of Phaseolus vulgaris for capacity to nodulate over a range of environments. Australian Journal of Experimental Agriculture, v.30, p.265-270, 1990.

RENNIE, R.J.; KEMP, G.A. $\mathrm{N}_{2}$-fixation in field beans quantified by ${ }^{15} \mathrm{~N}$ dilution. I. Effect of strains of Rhizobium phaseoly. Agronomy Journal, v.75, p.640-644, 1983.

RENNIE, R.J.; RENNIE, D.A.; SIRIPAIBOOL, C.; CHAIWANAKUPT, P.; BOONKERD, N. $\mathrm{N}_{2}$ fixation in Thai soybeans: effect of tillage and inoculation on ${ }^{15} \mathrm{~N}$-determined $\mathrm{N}_{2}$ fixation in recommended cultivars and advanced breeding lines. Plant and Soil, v.112, p.183-193, 1988.

ROGER, P.A. Biological $\mathrm{N}_{2}$ fixation and its management in wetland rice cultivation. Fertilizer Research, v.42, p.261-276, 1995.

ROSAS, J.C.; CASTRO, J.A.; ROBLETO, E.A.; HANDELSMAN, J. A method for screening Phaseolus vulgaris L. germplasm for preferential nodulation with a selected Rhizobium etli strain. Plant and Soil, v.203, p.71- 78, 1998.

RUSCHEL, A.P.; VOSE, R.B.; MATSUI, E.; VICTORIA, R.L.; SAITO, S.M.T. Field evaluation of $\mathrm{N}_{2}$ fixation and $\mathrm{N}$ utilization by Phaseolus bean varieties determined by ${ }^{15} \mathrm{~N}$ isotope dilution. Plant and Soil, v.65, p.367-407, 1982. 
SÁ, J.C.M. Semeadura direta em campos nativos. In: PEIXOTO, R.T. dos G.; AHRENS, D.C.; SAMAHA, M.J. (Ed.) Plantio direto: o caminho para uma agricultura sustentável. Ponta Grossa: Instituto Agronômico do Paraná, 1997. p.5365.

SAITO, S.M.T.; MARTINS, E.C.S.; FREITAS, J.R.; ROSTON, A.J. Levantamento da presença de micorriza e Rhizobium phaseoly naturalmente estabelecidos em áreas com feijoeiro. In: REUNIÃO NACIONAL DO FEIJÃO, 1., Goiânia: 1982. Trabalhos. Goiânia, 1982. p.320-322.

SARRUGE, J.R.; HAAG, H.P. Análises químicas em plantas. Piracicaba: ESALQ; Departamento de Química, 1974. 56p.

SATALEY, T.E.; EDWARDS, W.M.; SCOTT, C.L.; OWENS, L.B. Soil microbial biomass and organic component alterations in a no-tillage chronosequence. Soil Science Society of America Journal, v.52, p.998-1005, 1988.

SEDBERRY JUNIOR., J.E.; DHARMADUTRA, T.S.; BRUPBACKER, R.H.; PHILLIPS, S.A.; MARSHALL, J.G.; SLOANE, L.W.; MELVILLE, D.R.; RABB, J.L. Molybdenum investigation with soybeans in Louisiana. Louisiana: Louisiana State University, 1973. 39p. (Bulletin 670).

SEMU, E.; HUME, D.J. Effects of inoculation; fertilizer $\mathrm{N}$ levels on $\mathrm{N}_{2}$ fixation and yields of soybeans in Ontario. Canadian Journal of Plant Science, v.59, p.1129-1137, 1979.

SERRAJ, R.; VADEZ, V.; PURCELL, L.C.; SINCLAIR, T.R. Recent advances in the physiology of drougth stress effects on symbiotic $\mathrm{N}_{2}$ fixation in soybean. In: MARTINEZ, E.; HERNÁNDEZ, G. (Ed.) Highlights of nitrogen fixation research. New York: Kluwer Academic , 1999. p.49-55.

SHUBERT, K.R. Products of biological nitrogen fixation in higher plants: synthesis, transport and metabolism. Annual Review of Plant Physiology, v.37, p.539-574, 1986. 
SIDIRAS, N.; HENKLAIN, J.C.; DERPERSCH, R. Comparison of three different tillage systems with respect to aggregate stability, the soil and water conservation and the yields of soybean and wheat on oxisol. Journal of Agronomy and Crop Science, v.151, p.137-148, 1982.

SIDIRAS, N.; PAVAN, M.A. Influência do sistema de manejo do solo no nível de fertilidade. Revista Brasileira de Ciência do Solo, v.18, p.541-547, 1994.

SILVA, S.L.B.F.; SILVA, J.L.;TEIXEIRA, T.D Análise de produtividade marginal dos insumos na cultura de feijão na região de Viçosa, Zona da Mata, Minas Gerais, em 1968-1969. Revista Ceres, v.23, p.83-98, 1976.

SINCLAIR, T.R.; DE WIT, C.T. Analysis of the carbon; nitrogen limitations to soybean yield. Agronomy Journal, v.69, p.274- 278, 1976.

SINGLETON, P.W.; BOHLOOL, B.B.; NAKAO, P.L. Legume response to rhizobial inoculation in the tropics: myths and realities. Soil Science Society of America, v.29, p.135- 155, 1992.

SINGLETON, P.W.; BOONKERD, N.; HOLLYER, J.R. The biological and economical implications of nitrogen fertilizer use in legume production. In: PORTCH, S. (Ed.), International Symposium on Fertilizer and Agricultural Development. Phosphate Institute of Canada, 1999.1v.

SINGLETON, P.W.; TAVARES, J.W. Inoculation responses of legumes in relation to the number and effectiveness of indigenous Rhizobium populations. Applied Environmental Microbiology, v.51, p.1013-1018, 1986.

SMIL, R. Some unorthodox perspectives of agricultural biodiversity: the case for legume cultivation. Agricultural Ecosystems and Environment, v.62, p.135-144, 1997.

SORWLI, F.K.; MYTTON, L.R. Nitrogen limitations to field bean productivity: a comparison of combined nitrogen applications with Rhizobium inoculation. Plant and Soil, v.94, p.267-275, 1986.

SPRENT, J.I. Water deficits and nitrogen-fixing root nodules. In: KOZLOWSKI, T.T. (Ed.). Water deficits and plant growth. New York: Academic Press, 1976. p.291315. 
STAPlES, R. C.; TOENNIESSEN, G. R. Plant disease control. New York: Wiley, 1981. p.221-234.

STARLING, M.E.; WOOD, C.W.; WEAVER, D.B. Starter nitrogen and growth habit effects on late-planted soybean. Agronomy Journal, v.90, p.658- 662, 1998.

STEVENSON, F.C.; VAN KESSEL, C. Nitrogen contribution of pea residue in a hummock terrain. Soil Science Society of America Journal, v.61, p.494-503, 1997.

STOUT, P.R.; MEAGHER,W.R.; PEARSON, G.A.; JOHNSON, C.M. Molybdenum nutrition of crop plants. I. The influence of phosphate and sulfate on the absorption of molybdenum from soils and solution cultures. Plant and Soil, v.3, p.51-87, 1951.

STREETER, J.G.; SMITH, R.S. Introduction of rhizobia into soils: problems, achievement and prospects for the future. In: SUBBA RAO, N.S., DOMMERGUES, Y.R. (Ed.) Microbial interactions in agriculture and forestry. Oxford: IBH, 1998. p.45- 64.

TEIXEIRA, S.M.; ROCHA, L.S. de A. Análise sócio-econômica da produção. In: ZIMMERMANN, M.J. O. Fatores que afetam a produtividade. Piracicaba: Associação Brasileira para Pesquisa da Potassa e do Fosfato, 1988. p.32-56.

THIES, J.E.; SINGLETON, P.W.; BOHLOOL, B.B. Influence of size of indigenous rhizobial populations on establishment and symbiotic performance of introduced rhizobia on field-grown legumes. Applied and Environmental Microbiology, v.57, p.19-28, 1991.

THOMAS, G.T. Labranza zero, resultados en Estados Unidos de la America y observaciones en campos argentinos. Rosario: AAPRESID, 1990. 16p.

TRIPLETT, E.W.; SADOWSKY, M.J. Genetics of competition for modulation of legumes. Annual Review of Microbiology, v.46, p.399- 428, 1992.

TSAI, S.M.; BONETTI, R.; ABDALA, S.M.; ROSSETTO, R. Minimizing the effect of mineral nitrogen on biological nitrogen fixation in common bean by increasing nutrient levels. Plant and Soil, v.152, p.131-138, 1993.

UNKOVICH, M.J., PATE, J.S.; SANFORD, P. Nitrogen fixation by annual legumes in Australian Mediterranean agriculture. Australian Journal of Agricultural Research, v.48, p.267-293, 1997. 
VAN KESSEL, C. Seasonal accumulation and partitioning of nitrogen by lentil. Plant and Soil, v.164, p.69-76, 1994.

VAN KESSEL, C.; HARTLEY, C. Agricultural management of grain legumes: has it led to an increase in nitrogen fixation? Field Crop Research, v.65, p.165-181, 2000 .

VANCE, C.P. Legume symbiotic nitrogen fixation: agronomic aspects. In: SPAINK, H.P. (Ed.). The rhizobiaceae. Dordrecht: Kluwer Academic, 1998. p.509- 530.

VARGAS, A.A.T.; SILVEIRA, J.S.M.; ATHAYDE, J.T.; ATHAYDE, A.; PACOVAB, E.V. Comparação entre genótipos de feijão quanto a capacidade nodulante e produtividade com inoculação com rizóbios e/ou adubação de N-mineral. Fertilizer Research, v.15, p.267-272, 1991.

VIDOR, C.; PERES, J.R. Nutrição de plantas com molibdênio e cobalto. In: SIMPÓSIO SOBRE ENXOFRE E MICRONUTRIENTES NA AGRICULTURA BRASILEIRA, Londrina, 1988. Anais. Londrina: EMBRAPA; IAPAR; SBCS, 1988. p.179-203.

VIEIRA, R.F. Comparação dos gêneros Vigna e Phaseolus com o feijão comum (Phaseolus vulgaris L.). Viçosa, 1989. 213p. Tese (Doutorado) - Universidade Federal de Viçosa.

VLEK, P.L.G.; DIAKITE, M.Y.; MUELLER, H. The role of Azolla in curbing ammonia volatilization from flooded rice systems. Fertilizer Research, v.42, p.165-174, 1995.

VLEK, P.L.G.; KUHNE, R.F.; DENICH, M. Nutrient resources for crop production in the tropics. Philosophical Transactions Royal Society of London. B, v.352, p.975-984, 1997.

WALSH, K. B. Physiology of the legume nodule and its response to stress. Soil Biology and Biochemistry, v.27, p.637-655, 1995.

WANI, S.P.; RUPELA, O.P.; LEE, K.K. Sustainable agriculture in a semi-arid tropics through biological nitrogen fixation in grain legumes. Plant and Soil, v.174, p.29- 49, 1995. 
WEAVER, R.W.; FREDERICK, L.R. Effect of inoculum rate on competitive nodulation of Glycine max (L.) Merrill. II. Feld studies. Agronomy Journal, v.58, p.233-236, 1974.

WEBER, C.R. Nodulating; non nodulating soybean isolines. II. Response to applied nitrogen and modified soil condition. Agronomy Journal, v.58, p.46-49, 1966.

WESTERMANN, D.T.; KOLAR, J.J. Simbolic $\mathrm{N}_{2}\left(\mathrm{C}_{2} \mathrm{H}_{2}\right)$ fixation in beans. Crop Science, v.18, p.986-990, 1978.

WHEATLEY, D.M.; MACLEOD, D.A.; JESSOP, R.S. Influence of tillage treatments on $\mathrm{N}_{2}$ fixation of soybean. Soil Biology and Biochemistry, v.27, p.571- 574, 1995.

YINBO, G., PEOPLES, M.B.; REKASEM, B. The effect of $\mathrm{N}$ fertilizer strategy on № fixation, growth, growth; yield of vegetable soybean. Field Crops Research, v.51, p.221-229, 1997.

YING, J., HERRIDGE, D.F., PEOPLES, M.B.; RERKASEM, B. Effect of $\mathrm{N}$ fertilization on $\mathrm{N}_{2}$ fixation and $\mathrm{N}$ balances of soybean grown after lowland rice. Plant and Soil, v.147, p.235-242, 1992.

ZAPATA, F.; DANSO, S.K.A.; HARDARSON, G.; FRIED, M. Nitrogen fixation and translocation in field-grown fababean. Agronomy Journal, v.79, p.505- 509, 1987. 